University of Redlands

\title{
A Web-Based Index of Historical Valuation Maps for the Erie Railroad
}

\author{
A Major Individual Project submitted in partial satisfaction of the requirements \\ for the degree of Master of Science in Geographic Information Systems \\ by \\ Matthew Flewelling \\ Ruijin Ma, Ph.D., Committee Chair \\ Mark Kumler, Ph.D.
}

December 2014 
A Web-Based Index of Historical Valuation Maps for the Erie Railroad

Copyright (C) 2014

by

Matthew Flewelling 
The report of Matthew Flewelling is approved.

Mark Kumler, Ph.D.

Ruijin Ma, Ph.D., Committee Chair

December 2014 


\section{Acknowledgements}

First and foremost I would like to thank my family and friends, without whose help, support and constant encouragement, none of this would have been possible.

I would also like to thank the faculty at the University of Redlands for all their efforts. To my advisor Dr. Ruijin Ma and to Dr. Douglas Flewelling, thank you for encouraging me to do my best work, and the occasional pointy stick to keep me on track. And thank you Mark Kumler for your advisement as part of my comity. To Nathan Strout, thank you for introducing me to the wondrous would of programming and for all your support and finding where I had missed a semicolon. Also, I would like to thank the University of Redlands for its contributions to my education and future through the Inland Empire Research Fellowship.

Lastly, I would like to thank Dr. Scott Randolph for his cooperation, patience and enthusiasm through the completion of this project.

A very special thanks to all of the friends I made in Cohorts 24, 25, 25.5 and 26, for not just helping me throughout the program but also helping to keep me sane. 



\begin{abstract}
A Web-Based Index of Historical Valuation Maps for the Erie Railroad

by

Matthew Flewelling
\end{abstract}

The purpose of this project was to develop a web based index of historical railroad valuation maps for the Erie Lackawanna Historical Society (ELHS). The ELHS was in possession of a complete collection of over 3600 scanned 1918 railroad valuation map for the Erie Railroad, however these scanned maps lacked spatial reference. The first step in making these maps usable in modern GIS was to georeference them using Esri's ArcGIS. Once the maps were georeferenced, they were organized into a geodatabase, along with additional supporting layers, as well as geotagged historical photos relating to the railroads. In order to make these maps and data available to a wider audience, an interactive web application was developed using HTML, CSS, and Esri's ArcGIS API for JavaScript, which allows users to view the georeferenced maps as a fully mosaicked map layer, or access the original maps and photographs individually or in bulk. 



\section{Table of Contents}

Chapter 1 - Introduction ................................................................................................ 1

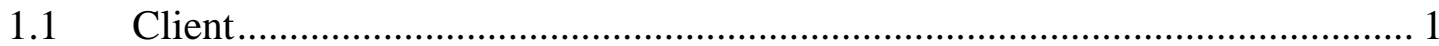

$1.2 \quad$ Problem Statement ................................................................................ 1

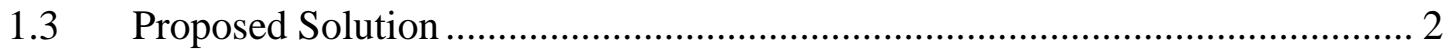

1.3.1 Goals and Objectives ............................................................................. 2

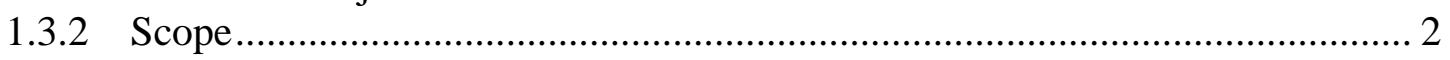

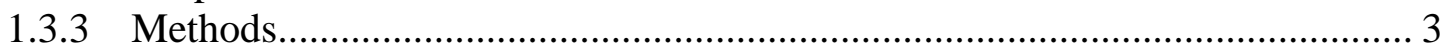

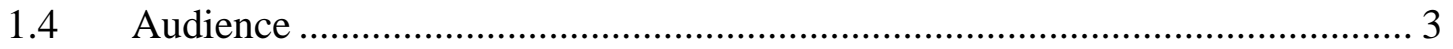

1.5 Overview of the Rest of this Report ........................................................... 3

Chapter 2 - Background and Literature Review ............................................................. 5

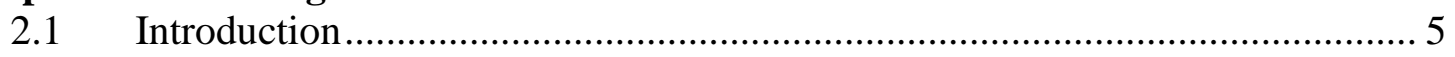

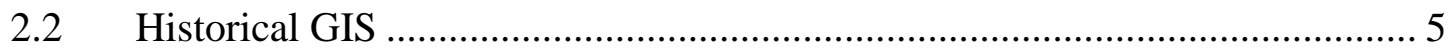

2.3 Valuation Map Background ....................................................................... 7

2.3.1 The Rise of the Rail Barons ....................................................................... 7

2.3.2 The Interstate Commerce Commission and the Valuation Act ........................ 9

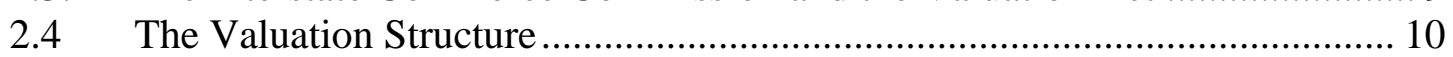

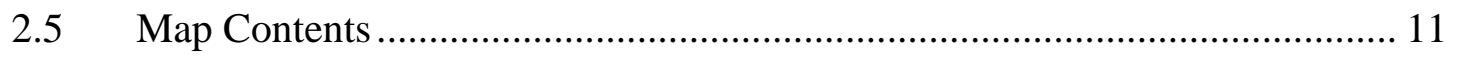

2.5.1 Textual Records ............................................................................. 12

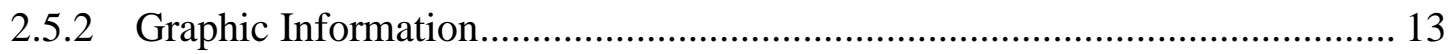

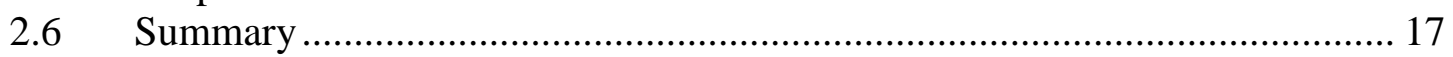

Chapter 3 - Systems Analysis and Design.................................................................... 19

$3.1 \quad$ Problem Statement ........................................................................... 19

$3.2 \quad$ Requirements Analysis ……………………………………………….... 19

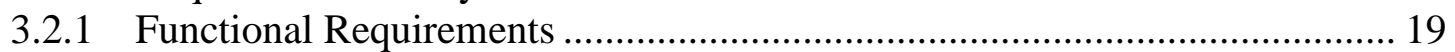

3.2.2 Non-Functional Requirements .............................................................. 20

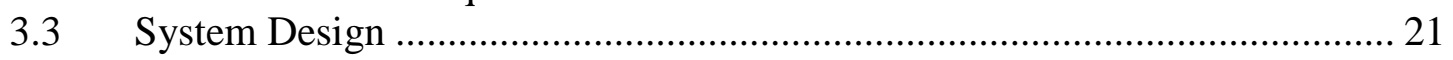

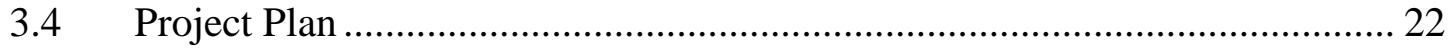

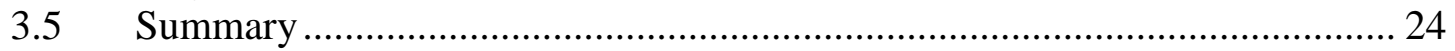

Chapter 4 - Database Design................................................................................................ 25

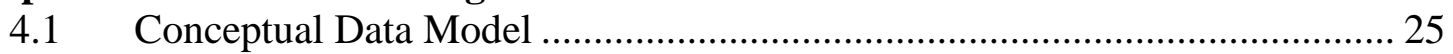

$4.2 \quad$ Logical Data Model ............................................................................... 26

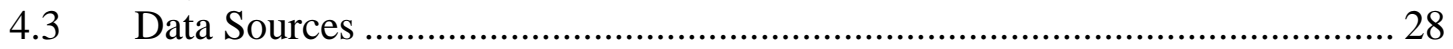

4.4 Data Scrubbing, Loading, and Creation..................................................... 28

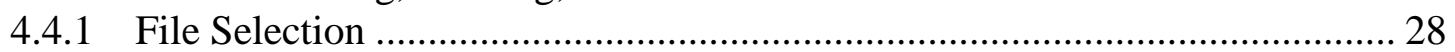

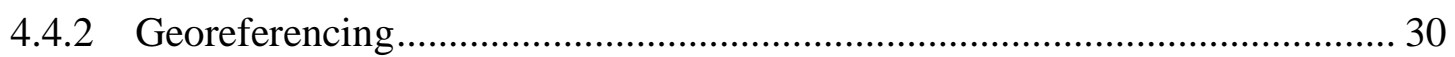

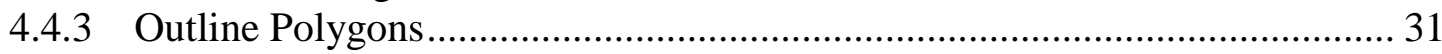

4.4.4 Archival Materials .............................................................................. 32

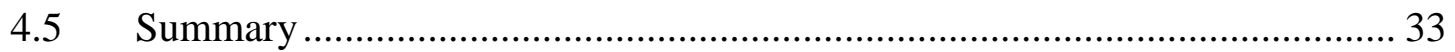

Chapter 5 - Database Preparation ........................................................................................ 35

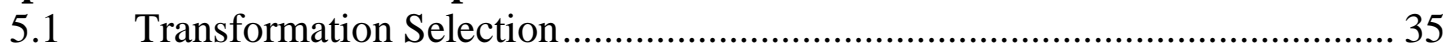

5.2 Control Point Selection ............................................................................. 37

5.3 Preparing Data for Sharing ...................................................................... 42 


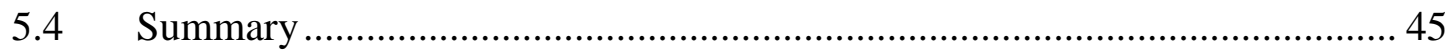

Chapter 6 - Web Application Development ......................................................................... 47

$6.1 \quad$ Service Publication .................................................................................. 47

6.2 Web Application Development................................................................... 48

6.2.1 The Map Viewer and Layer Controls ........................................................... 49

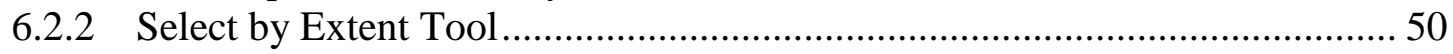

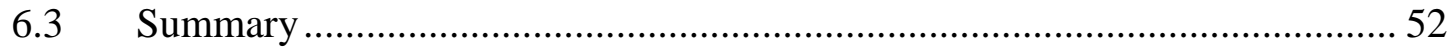

Chapter 7 - Results and Analysis..............................................................................53

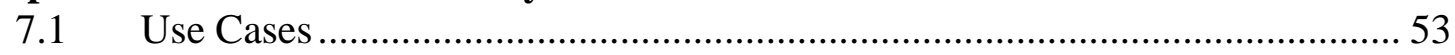

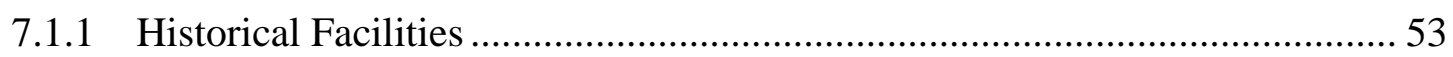

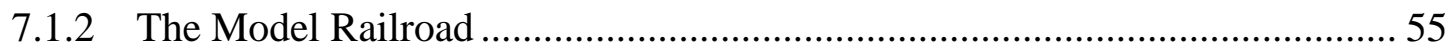

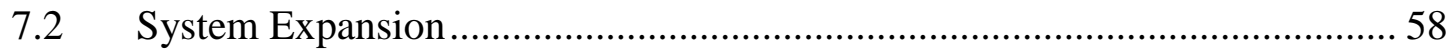

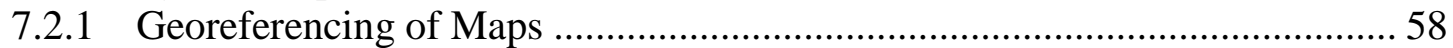

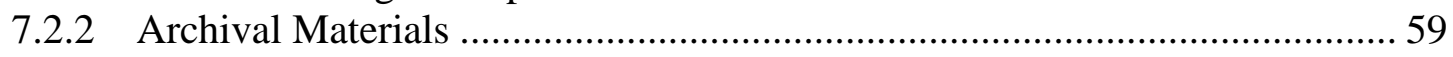

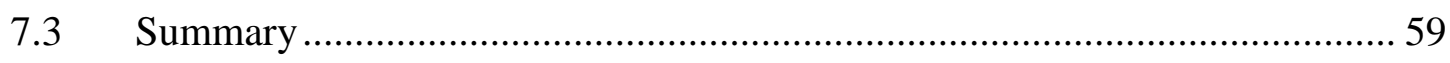

Chapter 8 - Conclusions and Future Work ...................................................................... 61

Works Cited ........................................................................................................................... 63

Appendix A. Erie Lackawanna Historical Map Index Web

Application Script................................................................................................. 65 


\section{Table of Figures}

Figure 2-1. Old Maps Online historic map web application.

Figure 2-2 . Close up of the New York, New Haven Hartford Railroad Valuation Map Index. Individual maps are represented by rectangular outline polygons. 7

Figure 2-3. Political cartoon depicting Cornelius Vanderbilt's attempts to gain control of the Erie Railroad..

Figure 2-4. Erie Railroad System map as of 1914.

Figure 2-5. Close up of valuation section map covering valuation sections $15,15 a$ and $15 b$

Figure 2-6. Example of a valuation map from the 1918 Erie Railroad Valuation (map number V15.NY.ST02).

Figure 2-7. Reference for valuation map V15.NY.015 .................................. 12

Figure 2-8. Example of corresponding Land (left) and Track (right) map labeling.....

Figure 2-9. (a) Centerline of rail for the valuation subject rail road

(b) Neighboring rail owned by a different railroad.

Figure 2-10. (a) Railroad underpass (b) Railroad overpass (c) Railroad crossing street at grade.

Figure 2-11. A comparison of how streets were depicted in valuation maps (left) and how they appear in modern imagery (right). 15

Figure 2-12. An example of a milepost marking (a). and an example of a survey station marking (b). 16

Figure 2-13. Example of a surveyor's chain. Reproduction by David Manthey (Titchenal, 2014).

Figure 2-14. Close-up of a match mark from valuation map V15.NY.008.....

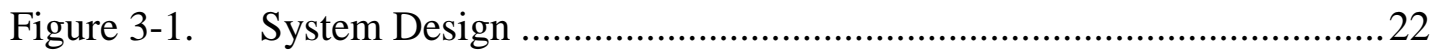

Figure 4-1. Conceptual Data Model .........................................................25

Figure 4-2. $\quad$ Logical Data Model .................................................................. 27

Figure 4-3. Close-up of Buffalo, NY area valuation section map ......................29 
Figure 4-4. Close-up of individual valuation map 2.15.NY.15 as represented in valuation section map.......................................................... 30

Figure 4-5. Close-up of valuation map reference notation .............................. 31

Figure 5-1. High feature-detail valuation map ................................................. 35

Figure 5-2. Low feature-detail valuation map............................................. 36

Figure 5-3. Affine transformation processes................................................ 37

Figure 5-4. The same intersection as illustrated on the valuation map(a), imagery(b), and World Street $\operatorname{Map}(\mathrm{c})$.......................................... 38

Figure 5-5. The left (a) is a roundhouse as it was depicted on the original 1918 Erie Railroad Valuation map, the right (b) is what remains of the same round house as it appears in modern imagery.............. 39

Figure 5-6. Example of a milepost symbol .............................................. 40

Figure 5-7. Close-up of a match mark from valuation map V15.NY.008 .......... 40

Figure 5-8. Illustration of transparent valuation map layer overlaying

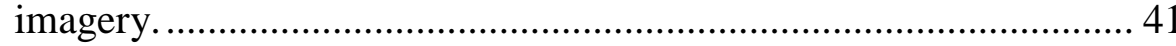

Figure 5-9. Create Mosaic Dataset tool............................................................ 42

Figure 5-10. Add Rasters to Mosaic Dataset tool ............................................. 43

Figure 5-11. Minimum bounding box outlines in red .................................... 44

Figure 5-12. Manually digitized outline polygons …...................................... 44

Figure 5-13. Valuation Map reference notation ............................................... 45

Figure 6-1. Overview of ELHMI web application ...................................... 48

Figure 6-2. Select by Extent tool............................................................. 50

Figure 6-3. Maps and Materials lists ........................................................ 51

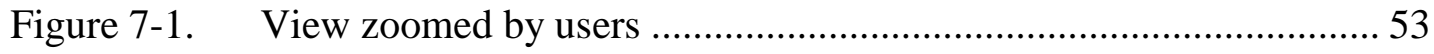

Figure 7-2. Close up of Roundhouse ...................................................... 54

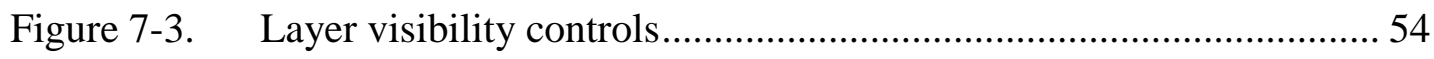

Figure 7-4. Close-up of American Agricultural Chemical Co.......................... 55 


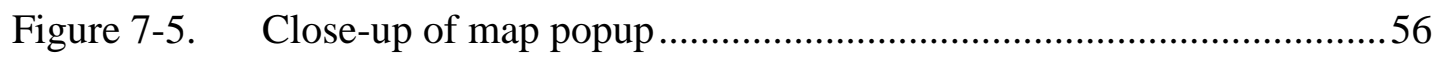

Figure 7-6. Close up of archival materials popup...........................................57

Figure 7-7. Close up of "Select by Extent" and Map and Material lists ..............58 



\section{List of Tables}

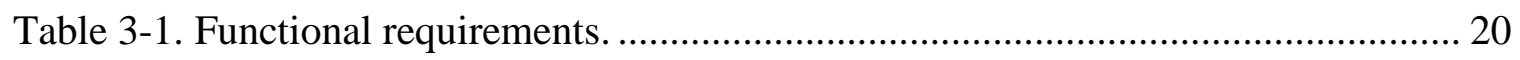

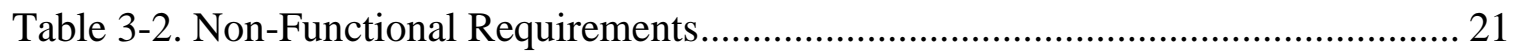

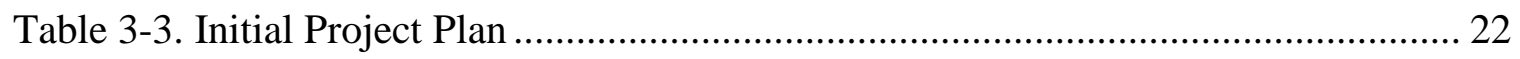

Table 4-1. Outlines Feature layer attributes ........................................................... 32

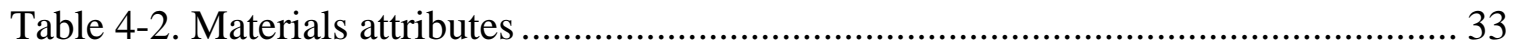





\section{Chapter 1 - Introduction}

At the turn of the $20^{\text {th }}$ century, amidst growing anti-trust concerns in regards to the railroads in America, the Interstate Commerce Act established a regulatory body, the Interstate Commerce Commission (ICC) (Dempsey, 2012). Within the ICC, the Bureau of Valuation required all railroad companies to provide accurate appraisals of all lines and properties owned, in order to determine fair shipping rates. As a product of this, all railroads had to keep accurate valuation maps of all properties, documents that were maintained and updated up until the 1970's. This record, going back nearly a hundred years, represents a wealth of historic data, and this project explores how these maps can be used in modern GIS applications.

\subsection{Client}

Dr. Scott Randolph is the curator of the Erie Lackawanna Historical Society (ELHS), a historical society dedicated to the preservation and dissemination of information about the Erie, Erie Lackawanna, and Delaware, Lackawanna \& Western Railroads. Dr. Randolph manages the historical society's archives of documents and materials. In 2000, the ELHS began work on scanning its complete set of 36001918 railroad valuation maps, covering the entire properties of the Erie railroad. In 2003 they completed scanning the collection and made the images available for purchase, in 2013, distributed by DVD or digital download. Originally, the maps were scanned as TIFF images and had not been georeferenced. Dr. Randolph approached the project team with these maps in the interest of exploring the value that could be added to these maps by making them usable in a GIS.

\subsection{Problem Statement}

The key problem the ELHS faced with the scanned maps was that they were only digitized to the level of having been scanned to TIFF format. This meant that they had no spatial reference, and therefore could not be implemented in a GIS. With over 3600 individual maps, each covering roughly one mile, it was very difficult to locate individual maps, and next to impossible to view multiple maps in relation to each other.

Additionally, without a spatial reference, the maps could not be placed in a spatial context within a GIS, preventing the information within the maps from being used in spatial analysis. This required the maps to be georeferenced, and since the original maps did not contain any identifiable projection data, this meant that the georeferencing would need to be done manually.

In addition to the valuation maps, the EHLS archives contain a large amount of historical materials, such as photographs, documents, journal articles and time tables, much of which has been donated from the personal collections of members. Many of these materials have spatial context, such as photographs of specific structures, or journal articles referring to specific locations along the lines. The ELHS was interested in exploring the possibilities of taking advantage of this fact to relate these materials to the valuation maps, to broaden their historical context. 
In addition to getting these maps and images referenced in a spatial coordinate system, the ELHS wanted to explore what applications these materials could have. In the past the maps had been used for a number of purposes such as commercial, legal and historical reference. In keeping with the ELHS's goals, it was decided that the aim of this project was to increase interest and exposure for the collection and for the ELHS, primarily in the interest of taking the final product to potential investors to secure grants.

\subsection{Proposed Solution}

After discusions with the client, it was decided that the final form of the product should take the form of a web application. The application would make use of the georeferenced valuation maps as a graphic layer that would display the individual maps as a unified whole, placed appropriately in space. On top of these maps, there would then be a functional layer that included individual icons representing archival materials that had been spatially referenced to specific point locations. These icons could be clicked by users, at which point a popup would present users with a thumbnail and a link to the specific document, along with metadata about the document. Additionally each map will have a footprint polygon attributed to it that will be clickable by users, much like the icons, that would allow users to access the individual scanned maps.

\subsubsection{Goals and Objectives}

The goal of this project was to develop a proof of concept that illustrates a modern use for the ELHS's collection of valuation maps. By georeferencing the maps, they could be implemented in a GIS and converted into a form that could be displayed and distributed to a wider audience through the world wide web. It was important to make the interface as simple and intuitive as possible in order to further ensure reaching as wide an audience as possible.

\subsubsection{Scope}

It was unfeasible, for the scope of this project and the time allotted, to include the full collection of over 3600 individual valuation maps. The project team and the client agreed upon a representative sample of the collection, which would include all maps covering the greater Buffalo, New York area. This area was chosen because the the two railroads that would later be combined to form the Erie Lackawanna Railroad - the Erie and the Delaware, Lackawanna \& Western - had rails present at the time of the valuation maps' drafting. This fact was important because there are ELHS members whose interests are specific to the individual railroads, and to insure the highest level of buy in within the ELHS, it was important to make sure that all parties' interests were represented. Fifteen scanned maps were selected.

The project team was responsible for georeferencing all maps within the sample and organizing them into a database that would serve as the base for the web application. The team was also responsible for developing the web application that would display the maps, display archival materials as individual icons that could be clicked by users and presented in the form of popups. The web application and data would be hosted on the 
project team's servers during the development, however it was the responsibility of the client to manage the hosting of the web application after the project was completed. Lastly, along with the final database and web application, the project team was also responsible for delivering instructions that could be used to expand the database and web application to include the rest of the valuation maps collection.

\subsubsection{Methods}

A number of methods were used for the different stages in the project. In order to georeference and organize the scanned valuation maps, Esri's ArcGIS was used. Since no accurate and complete aerial imagery was available from the time of the valuation maps' drafting, a combination of modern street map and aerial imagery layers were used to select ground control points for the use of georeferencing. After each image was georeferenced, a separate auxiliary XML file was created containing all of the rectification and spatial reference data for that particular image. Once all the maps had been georeferenced, all files were loaded into a single raster mosaic to be published to a server. An additional feature layer was created that contained footprint polygons and was published as a feature service with the purpose of allowing users to select individual valuation map files. The web application was developed making use of the ArcGIS API for JavaScript.

\subsection{Audience}

The intended audience of this paper includes anyone interested in web GIS application development with a basic understanding of JavaScript and GIS. Additionally, those interested in the use of GIS for the conveying of historical maps and materials in a spatial context should find this relevant.

\subsection{Overview of the Rest of this Report}

The remainder of this report is comprised of six chapters. Chapter 2 is an overview of case studies on the uses of historical maps in modern GIS applications. System design and project planning for the project are covered in Chapter 3, and Chapter 4 discusses logical and conceptual database models for the project, as well as data integration methods. Chapter 5 will discuss the process of georeferencing the valuation maps while Chapter 6 will discuss the JavaScript web application development. Testing of the application and deployment will be addressed in chapter 7 . The project summary, conclusions and future work are presented in Chapter 8. 



\section{Chapter 2 -Background and Literature Review}

\subsection{Introduction}

This chapter examines previous work done in the field of historical GIS and the history and origin of the Interstate Commerce Commission (ICC) valuation maps. Section 2.2 describes historical GIS and provides examples of previous work. Additionally, it looks at the incorporation of web GIS into telling the story of history. Section 2.3 provides a brief history of America's railroads predating the time in which the valuation maps were created, and looks at the political and economic climate that led to the creation of the ICC. Section 2.4 describes the structure and process of railroad valuation. Section 2.5 goes into detail about the contents of the valuation maps.

\subsection{Historical GIS}

Historical GIS is a field of study that explores past events through the lens of GIS technology and spatial context (Chauvin, 2008). By consolidating vast amounts of data which can vary in temporal and spatial reference into a visual medium, the information can be quickly conveyed to, and understood by, the human mind (Owens, 2007). Without historical maps, historical GIS would not be possible. These maps can contain information about vegetation, geomorphology, and manmade features that may have changed since the time the maps were created, and offer historians a view into past geographies (Rumsey, D., \& Williams, M., 2002)

Despite the wealth of data contained in historical maps, these data can be difficult to access with modern GIS technology, as they often do not contain metadata on the spatial context. In the event that these metadata are not available, the data require georeferencing, which is the process of transforming data layers to align to a known coordinate system. Once a historical map has been georeferenced, historians can compare it to other historic and modern data to draw conclusions (Locke, 2011).

Historical GIS is a relatively young field of study. Through much of the history of academia, historians and geographers have typically operated quite separately. However since the mid-1990s there has been a dramatic increase in interest in the benefits that GIS can offer to the historical community, so much so that historical GIS has risen as a field unto itself (Gregory and Ell, 2007). In the introduction of her 2002 book, Past Time Past Place: GIS for History, Ann Kelly Knowles stated that "[h]istorical GIS has ... become a meeting ground for historians, geographers, geographic information scientists, and others who previously had little contact" (pg. xii).

The World Wide Web and web GIS have also proven useful to historians for sharing information and story-telling. Old Maps Online (2014) is a collaborative project developed by the Great Britain Historical GIS Project based at The University of Portsmouth and Klokan Technologies GmbH in Switzerland, with map collections contributed from 20 institutions around the world. The site offers a web application (Figure 2-1) comprised of a main map view with a user definable extent. To the right of the main map viewer is a list of all of the historic maps that intersect the defined extent, with the option of narrowing the results by year. 


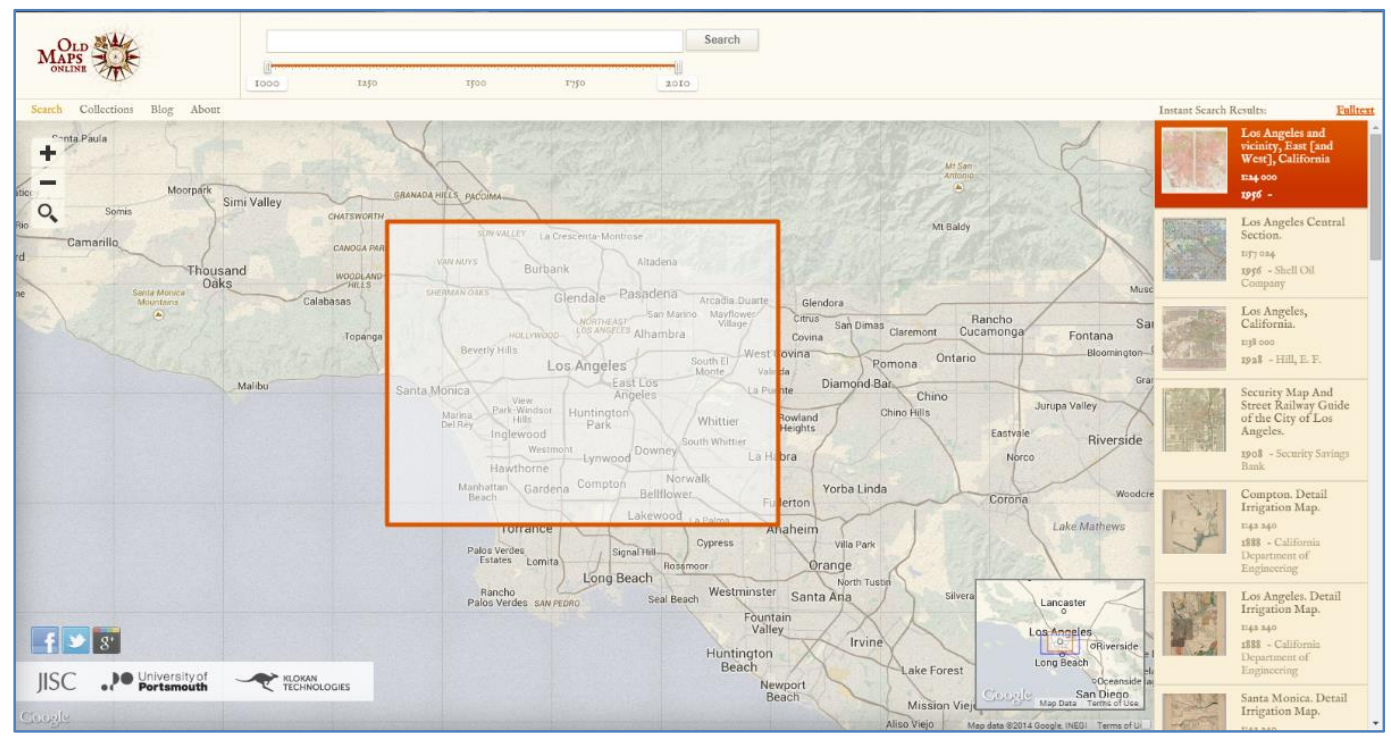

Figure 2-1. Old Maps Online historic map web application.

Another example of web GIS being used to share historic maps comes from the University of Connecticut (2011) with their New York, New Haven Hartford Railroad Valuation Map Index (Figure 2-2). The project started with a collection of physical ICC valuation maps from 1915, and included scanning the maps, georeferencing the scans, organization of the maps into a GIS, and the publishing of the collection to the web (Chauvin, 2008). The map index gives users the ability to visualize the true scale and shape of the network of maps, as well as access to the individual maps.

Jean Marie Locke's work for the A.K. Smiley and Armacost Libraries also made use of web GIS in order to index the libraries' collections of historic maps and images. 


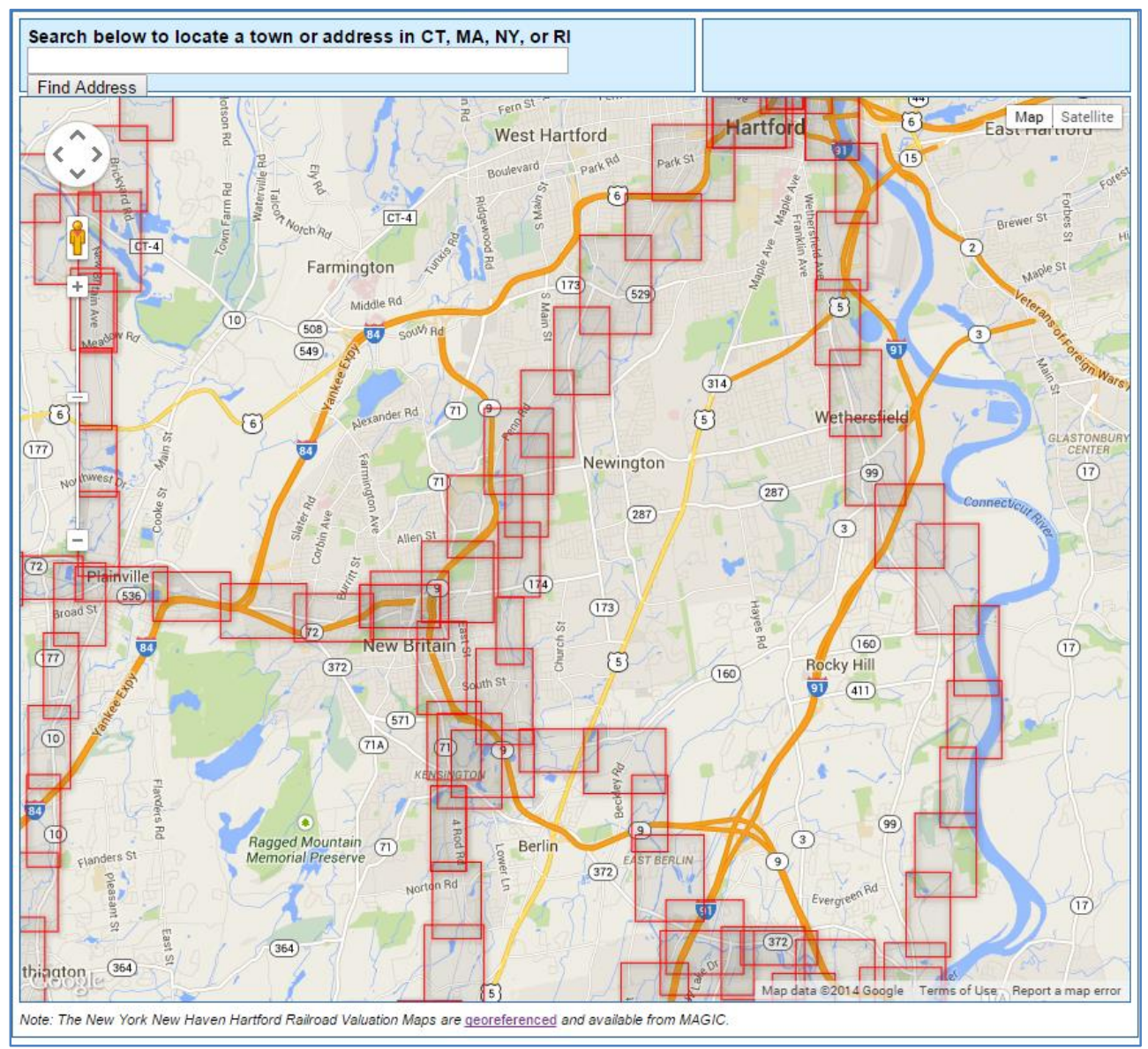

Figure 2-2 . Close up of the New York, New Haven Hartford Railroad Valuation Map Index. Individual maps are represented by rectangular outline polygons.

\subsection{Valuation Map Background}

In 2013, the Erie Lackawanna Historical Society completed its 13-year project of scanning its collection of more than 3,600 1918 Interstate Commerce Commission (ICC) railroad valuation maps for the Erie Railroad. These scans were the primary data in the Erie Lackwanna Historical Map Index (ELHMI). To truly understand the value of this collection, it is important to understand where these maps came from, why they were created, and what they contain.

\subsubsection{The Rise of the Rail Barons}

Starting in 1857, Cornelius Vanderbilt, the richest man in America in the mid-19 ${ }^{\text {th }}$ century, began buying up smaller railroads running between New York and Chicago, and by 1868 had consolidated them into the New York Central Railroad. Others followed his lead and began consolidating railroads of their own to compete with Vanderbilt in transporting freight and passengers between New York and Chicago (Dempsey, 2012). Among these competing railroads was the Erie Railroad. As more of the track in America 
was being bought up and held by an ever smaller number of individuals, competition for traffic grew more intense. This led to rate wars in competitive markets, in turn reducing profits, which led to highly discriminatory pricing. This meant that shippers, such as local farmers in areas served by only one railroad, were charged significantly higher rates than those customers in areas where multiple railroads or access to other forms of transportation were competing for business (Dempsey, 2012). Additionally, the larger shippers were often given special pricing, as well as large rebates, while smaller shippers were given higher rates. This all happened in a time before the antitrust regulation that came about in the 1910s. When the railroad companies were not trying to undercut each other, they would periodically take part in "price fixing and pooling agreements, whereby carriers in competitive markets would agree to raise prices and pool revenue and freight, whereupon rates soared" (Dempsey, 2012, pg. 1156).

The power and money accrued by these rail barons allowed them to extend their power beyond just the world of business. It was not uncommon for them to bribe politicians and officials in order to avoid regulation. The practices of the rail barons did not escape the public eye, as McNamara (2014) points out in his description of what was known as the "Erie War", which took place from 1867 to 1868. The Erie War was one of the better publicized examples of the aggressive competition between railroad owners at the time. Vanderbilt was attempting to gain control of the Erie Railroad in order to corner control of rail access between New York and Chicago, and to give him more control over the national rail system, primarily through the tactic of purchasing as much stock as possible in the company. The owners of the Erie Railroad, Daniel Drew, Jay Gould, and Jim Filk Jr., found out about this plan and secretly had thousands of Erie shares printed, watering down the stock (Ackerman, 2012). Upon discovering this, Vanderbilt used his influence to find a judge who would hold the Erie owners in contempt, forcing them to flee to New Jersey to avoid arrest. Gould then returned to Albany with a "suitcase full of cash" (Ackerman, 2012, para. 13) in order to buy influence in the statehouse. The senators, in turn, played Vanderbilt and Gould against each other until the money ran out. Eventually the Erie bill was passed in 1868, legitimizing the secretly issued stock and leaving Vanderbilt and the Erie owners in a stalemate. Gould, Drew, and Filk retained ownership, but had to purchase back the stocks sold to Vanderbilt (Dempsey, 2012). 


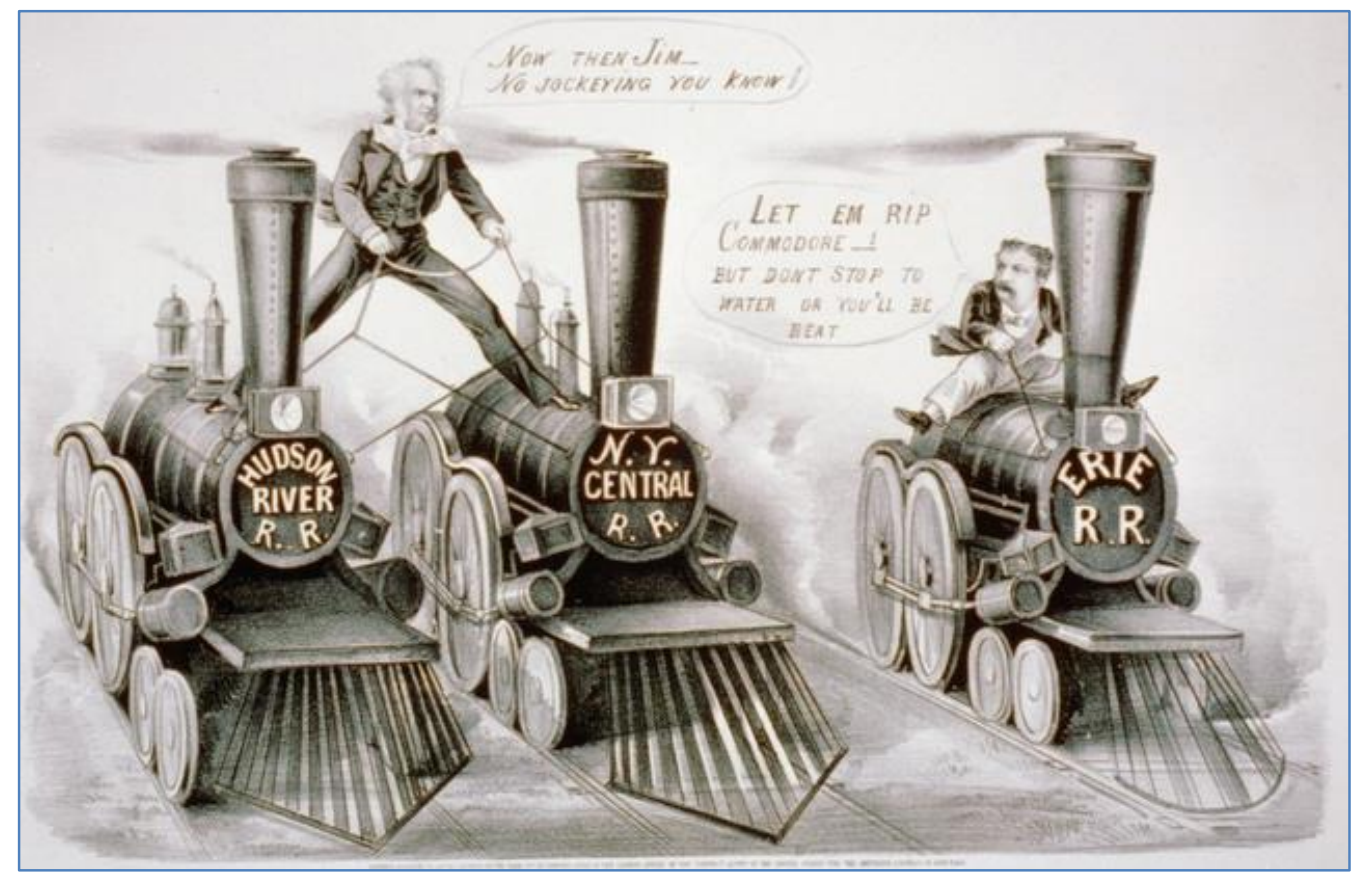

Figure 2-3. Political cartoon depicting Cornelius Vanderbilt's attempts to gain control of the Erie Railroad (source: McNamara, 2014)

\subsubsection{The Interstate Commerce Commission and the Valuation Act}

It is important to note that these rail barons were not doing anything technically illegal, because there were not any laws or regulations against such practices. However, as the $19^{\text {th }}$ century drew to a close, this was about to change. The first attempts at regulating the railroads came from the state level. As the railroad companies continued to grow and expand over state boarders, the individual states could not regulate interstate commerce. This period saw the Panic of 1873, an economic crisis lasting until 1979, in which the business practices of the railroads played no small part. This led to an intensifying of the competition and rate wars among the railroad companies and saw the railroads cutting wages and laying off employees (Dempsey, 2012), which led to a number of violent labor strikes. Against this back-drop, Congress passed the Interstate Commerce Act (ICA) in 1887, which created the Interstate Commerce Commission (ICC). The ICC was instated to act as a regulatory and oversight body for all interstate commerce, chiefly the railroads. Dempsey (2012) describes the provisions of the ICA as follows:

"The [Interstate Commerce] Act granted the ICC the authority to regulate the interstate rates charged by railroads, thereby ensuring that the rates would be just and reasonable. Under the Act, rail carriers could no longer discriminate in rates or services between persons, localities, or traffic. Furthermore, they could no longer charge a higher rate for a shorter distance that was included within a longer haul over the same line in the same direction. Nor could the rail carriers pool freight or revenue. Most importantly, railroads were required to make their rates public, file them with the newly formed Commission, and adhere to the published tariffs." (pg. 1161) 
This was the first time in American history that the federal government placed regulation on an industry as a whole. In its early years the ICC saw minimal success, as it did not have the power to truly enforce its regulations (PBS, 2014). The Hepburn Act of 1906 and the Mann-Elkins Act of 1910 gave the ICC the power it needed to set rates and enforce regulations, and in 1913 the Valuation Act created the Bureau of Valuation. The role of the Bureau of Valuation was to oversee the valuation of all property held by each railroad, and to determine fair and reasonable rates based on that information (Sakolski, 1915). The valuation process was conducted from 1914 to 1921 and the railroads were required to submit valuation records to the Bureau. One of the central documents generated for these records were valuation maps.

\subsection{The Valuation Structure}

During the valuation process each railroad had to produce a set of maps coving the entirety of its holdings. In the case of the Erie Railroad, this extended from New York City, to Buffalo, New York and to Chicago, Illinois (Figure 2-4) with over 2,300 miles of track, as well as a ferry line running from Buffalo, New York to Detroit, Michigan.

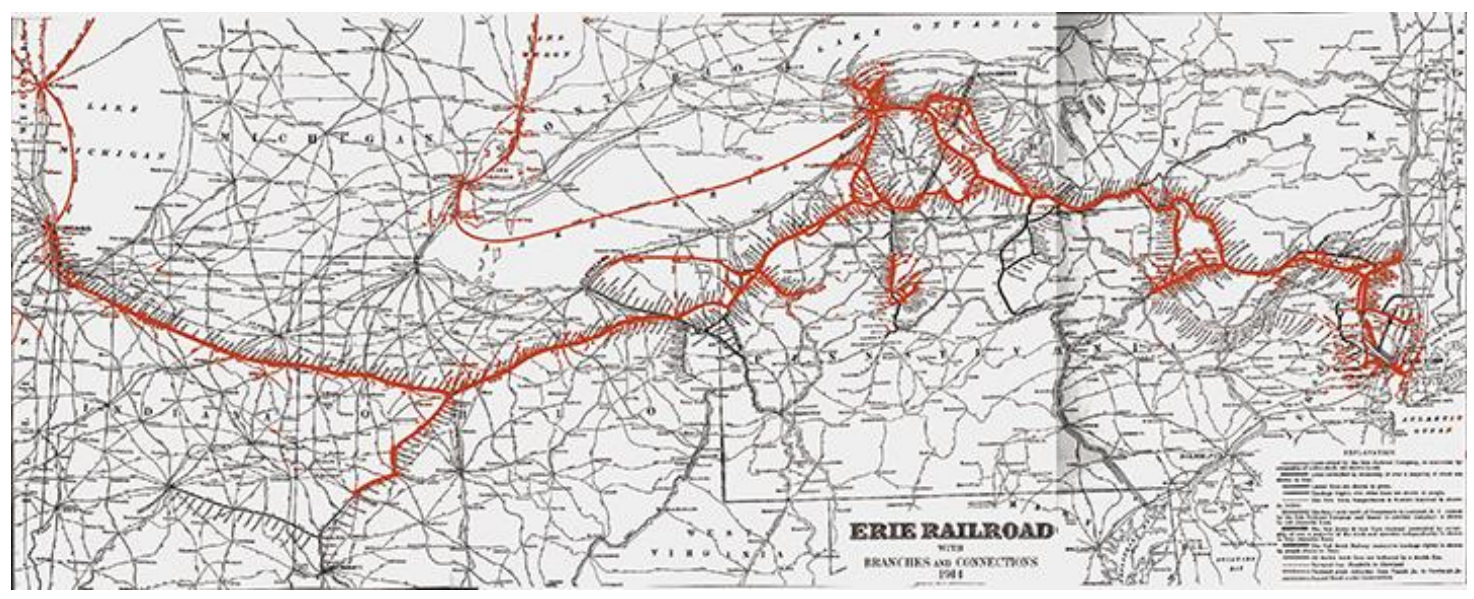

Figure 2-4. Erie Railroad System map as of 1914. Adapted from erierailroad.org (2014)

The valuations were first split up by state, then each state was broken into valuation sections (Figure 2-5). Each of these valuation sections had a series of maps, each covering a half mile, one mile, or two miles of track. In the 1918 valuation of the Erie Railroad, the full valuation included over 3,600 individual map sheets. Each waxed canvas map sheet (Figure 2-6) was roughly twenty-four by fifty-four inches (Pfeiffer, 1997). 


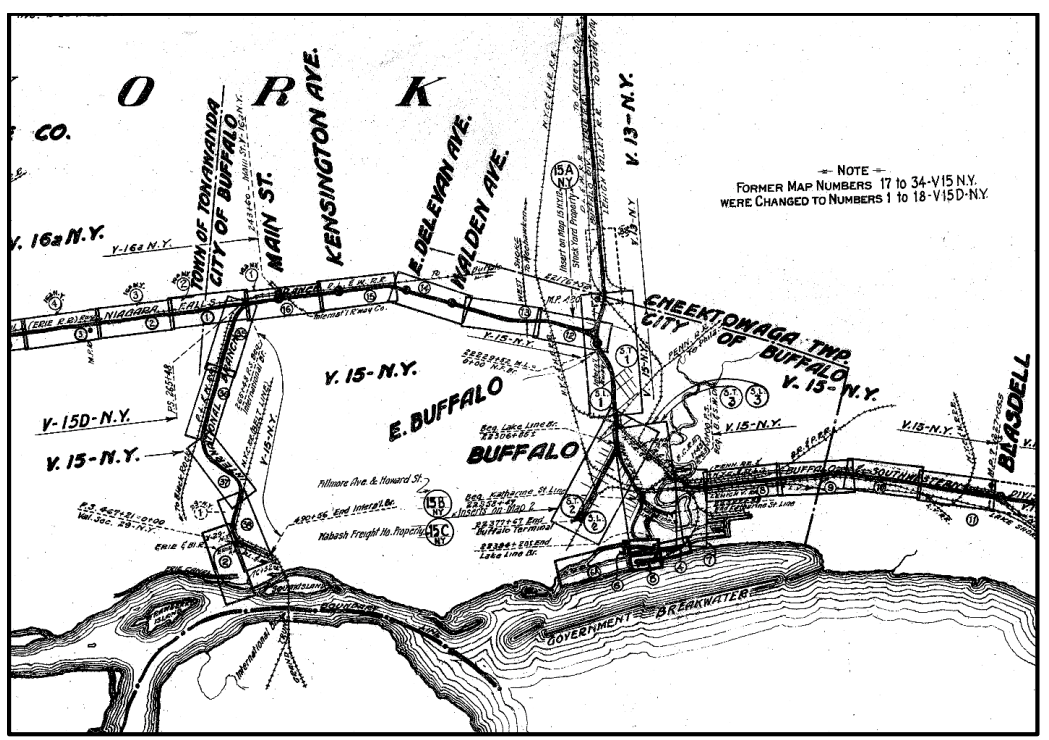

Figure 2-5. Close up of valuation section map covering valuation sections 15, 15a and $15 b$

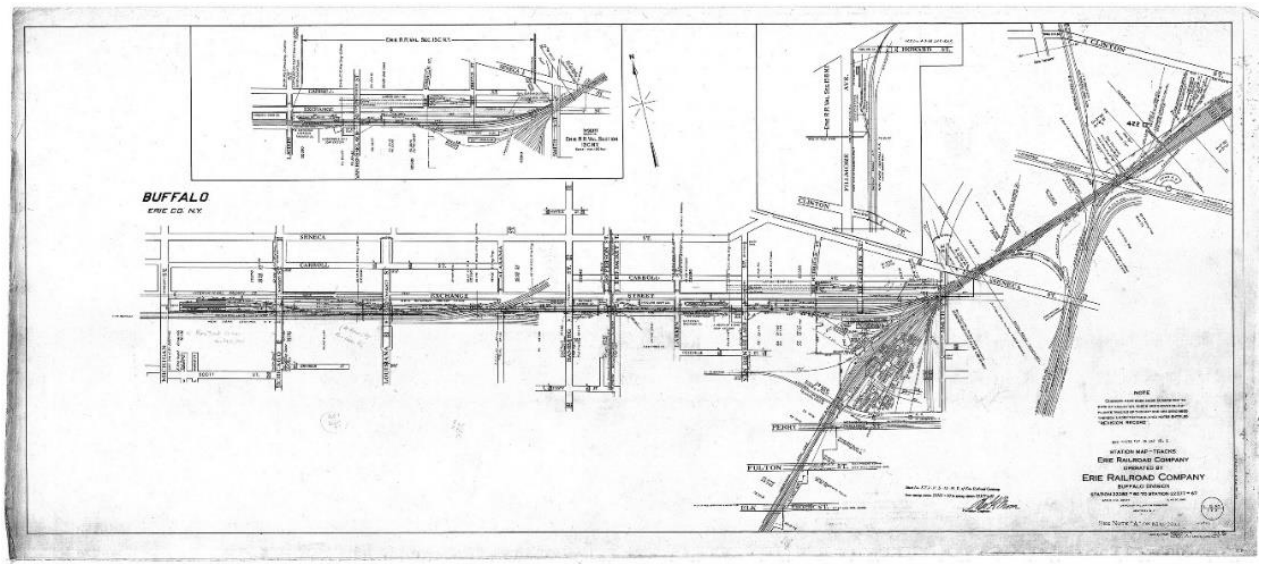

Figure 2-6. Example of a valuation map from the 1918 Erie Railroad Valuation (map number V15.NY.ST02)

\subsection{Map Contents}

The maps contained graphical features, such as railroad tracks, rights of way, land parcels and structures owned by the railroads, as well as textual records of land ownership schedules and revisions to the maps. These maps also included information about surrounding features that were not owned by the railroad, such as streets, bridges, and structures or rails owned by other railroads. 


\subsubsection{Textual Records}

Of the textual records found in the maps, the valuation reference information at the bottom left of each map (Figure 2-7) was of the most relevance to historians, as it contained the metadata of how the individual map relates to the full collection. Found in these references is information on: type of map; owning railroad company; operating railroad company; railroad division; railroad branch; start and end survey station covered by the map; map scale; reference date; valuation reporting official, as well as any additional notes about the map. Also included is a circular indexing badge denoting the valuation section and sheet number. Each map has its own unique valuation number; however in areas of high complexity, such as stations, there could be two versions of the same map, one for lands, the other for tracks (Figure 2-8). In these cases the numbers were prefixed with "ST" for track maps and "SL" for land maps.

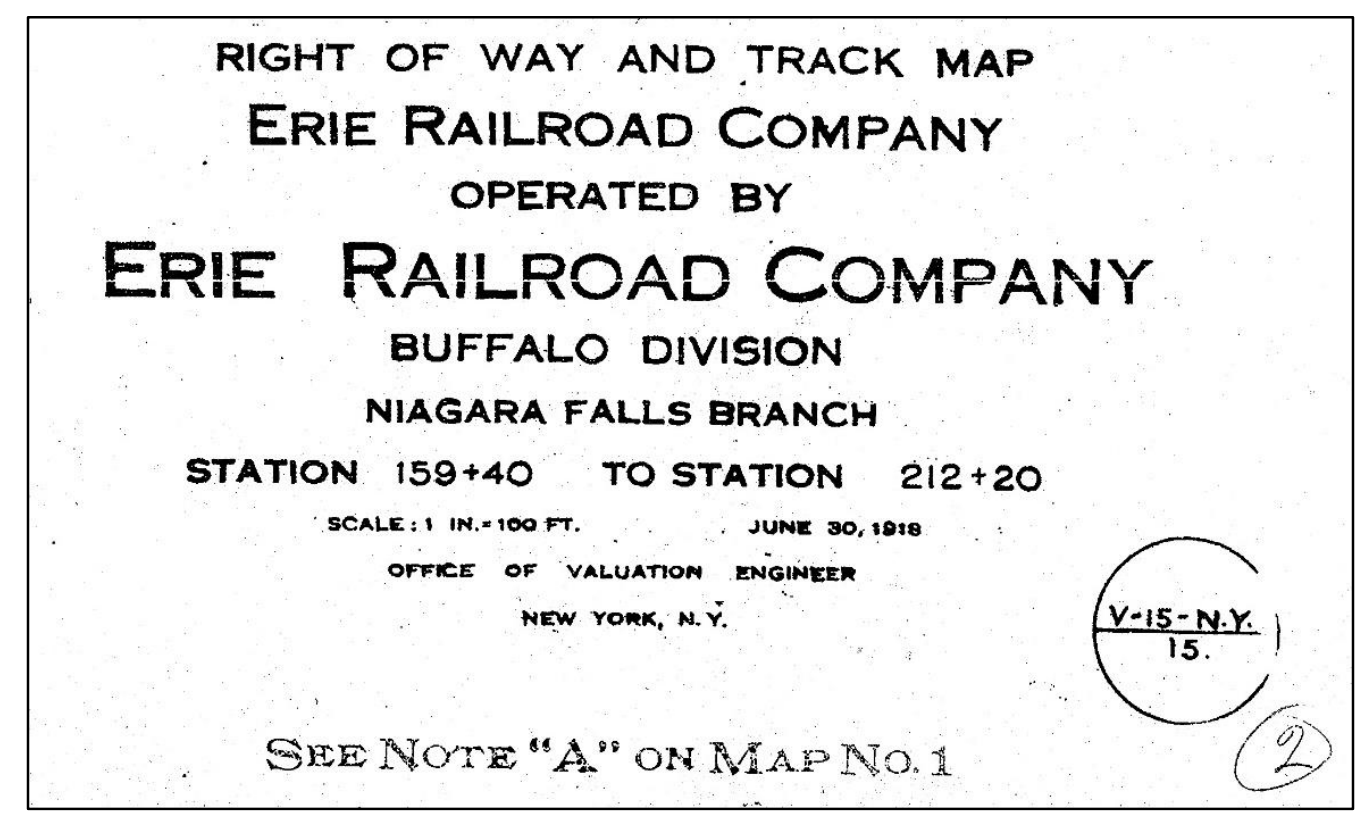

Figure 2-7. Reference for valuation map V15.NY.015 


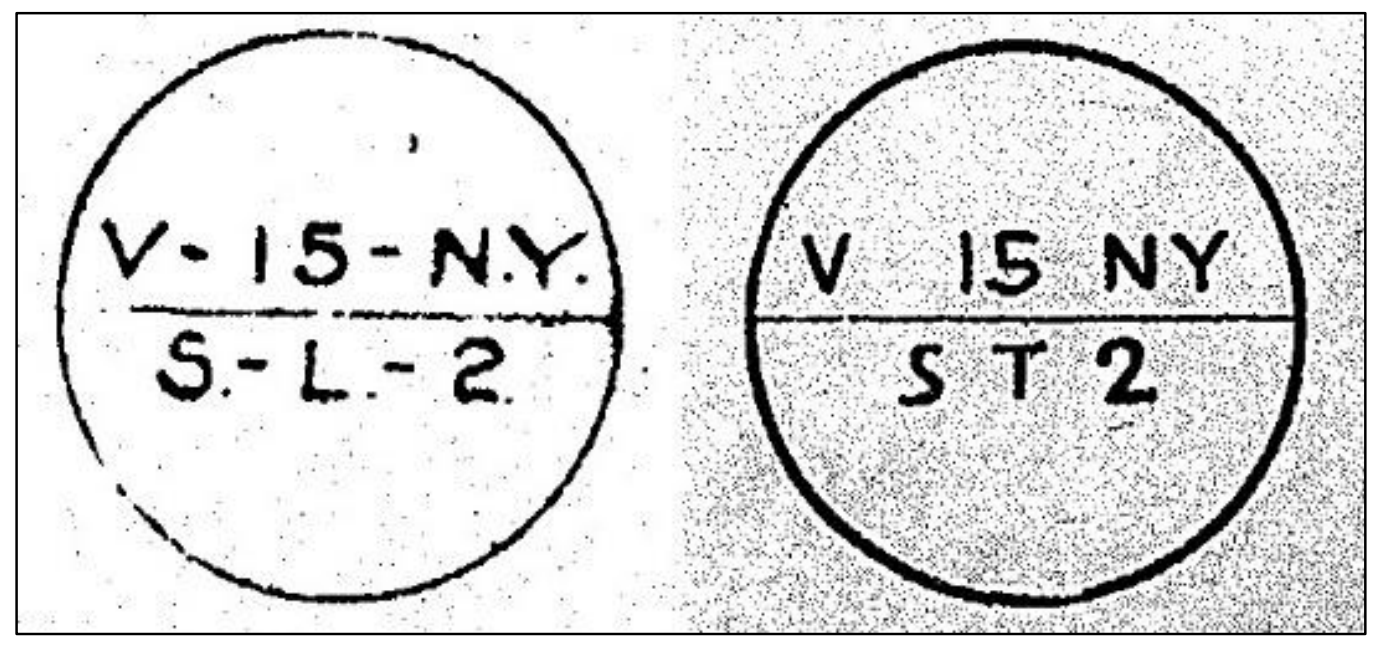

Figure 2-8. Example of corresponding Land (left) and Track (right) map labeling

Also of interest to historians, the maps often included revision records that kept track of any changes made to maps over time, and land ownership schedules that contained information on how each right of way and parcel came into the ownership of the railroad.

\subsubsection{Graphic Information}

Of the information stored in the valuation maps, the graphic information is of the most importance to historians. The key features within the maps can be divided into four main classes: rails, streets, structures and survey markings.

The primary features within the valuation maps are the railroad tracks. Rails that were the property of the owner railroad are symbolized by simple lines following the centerline of the track (Figure 2-9a), while neighboring tracks owned by other railroads are symbolized by lines with tick marks (b) (American Railway Engineering Association, 1915). In the event that tracks were covered by a tunnel, underpass, or structure, the track line symbol changed to a dashed line. There are other markings that relate to the rails' interaction with surrounding features (Figure 2-10), such as underpasses (a), overpasses (b), and street crossings (c). Since the creation of the valuation maps, much of the track has been removed, but in many places the landscape still shows the evidence of their presence. 


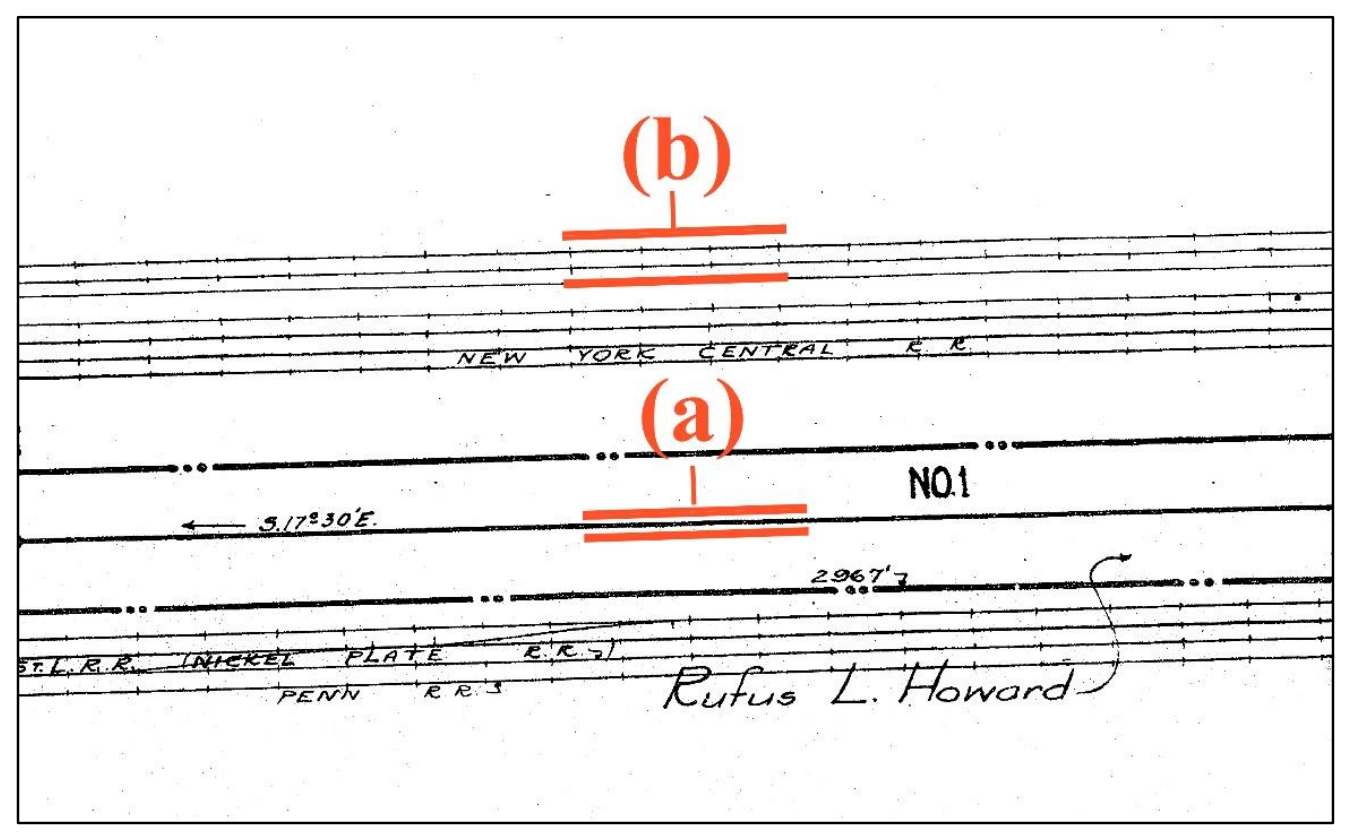

Figure 2-9. (a) Centerline of rail for the valuation subject rail road (b) Neighboring rail owned by a different railroad.

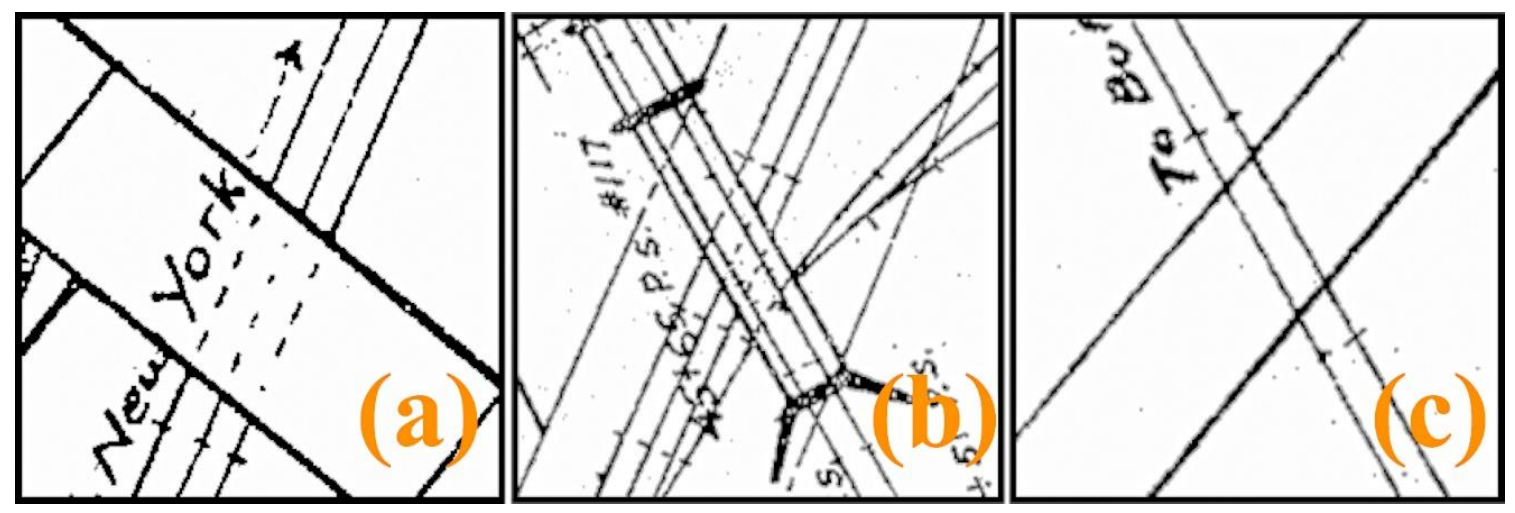

Figure 2-10. (a) Railroad underpass (b) Railroad overpass (c) Railroad crossing street at grade

Many of the maps also included details about the streets surrounding the rails. These are particularly important to historians, as these add context and reference. Even though the rails may not exist today, much of the surrounding road network is in place as it was when the maps were created. In the maps, the streets are symbolized by two parallel lines (Figure 2-11), at a width to scale with their real world width at the time of survey. The streets were labeled with their names, within the lines of the street. 


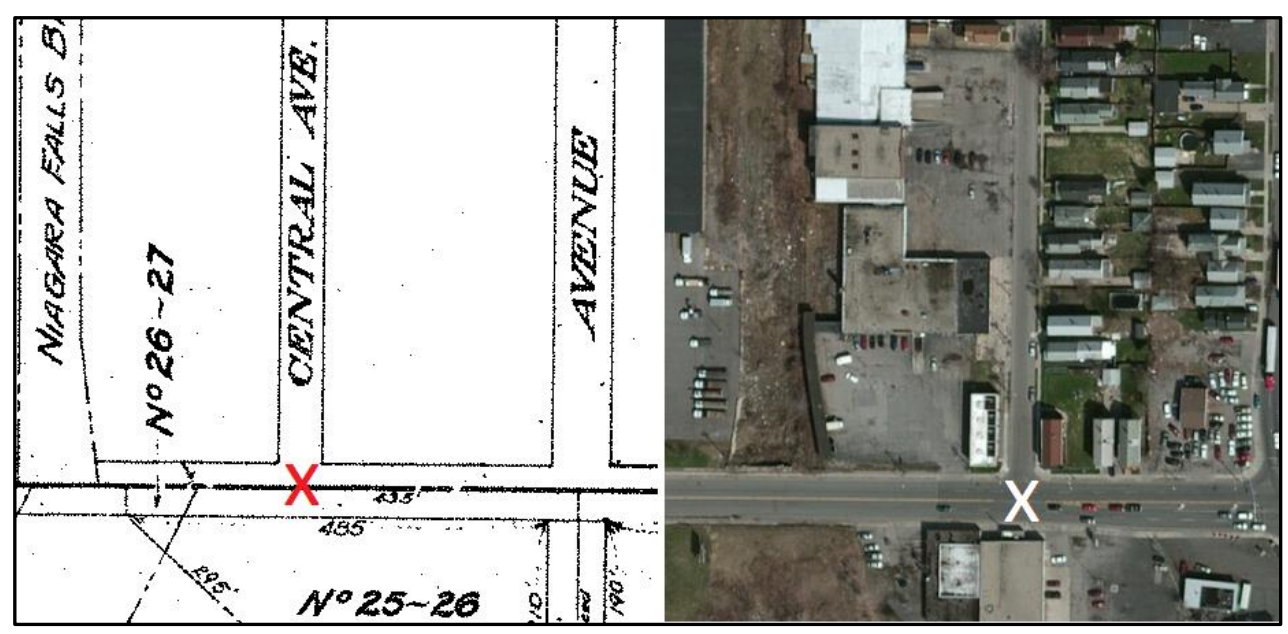

Figure 2-11. A comparison of how streets were depicted in valuation maps (left) and how they appear in modern imagery (right).

The structures contained within the maps are another feature that is of great interest to historians. These included buildings, such as engine houses, workshops, train stations, and coal chutes as well as other structures such as bridges, overpasses and abutments (American Railway Engineering Association, 1915). Much like the rails, the majority of these structures are either gone or significantly changed. These maps allow historians a view of the industrial landscape as it was at the time the maps were created, and by comparing later edits and updates to the maps, historians are able to see in more detail how it has changed over time.

The last class of features, the survey markings (Figure 2-12), offers historians reference and measurement information. These included milepost markings (a), as well as survey station markings. The survey stations were marked (b) along the lines of the track and were measured at intervals of ten "chains." Chains were a measurement tool used by surveyors (Figure 2-13), with one chain equaling 66 feet (Titchenal, 2014). The other survey marking of importance was the match mark (Figure 2-14). These were straight line marks within the maps that showed how to match up the map to the next in the series. Each map would have a matching set of marks, each labeled with the station measurement number. These gave maps a relation reference to each other. 


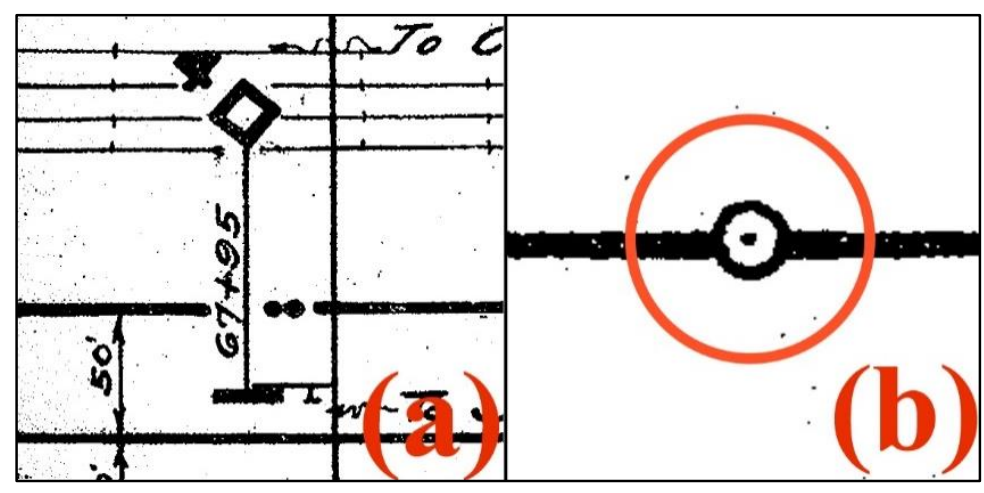

Figure 2-12. An example of a milepost marking (a). and an example of a survey station marking (b).

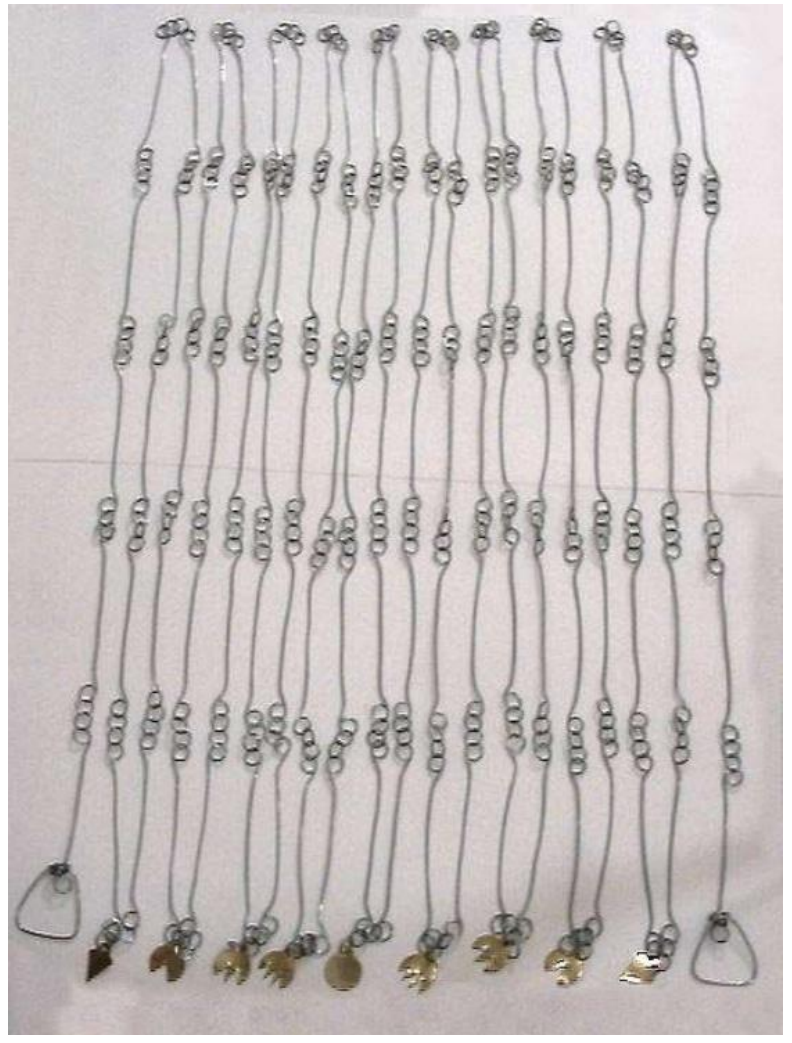

Figure 2-13. Example of a surveyor's chain. Reproduction by David Manthey (Titchenal, 2014) 


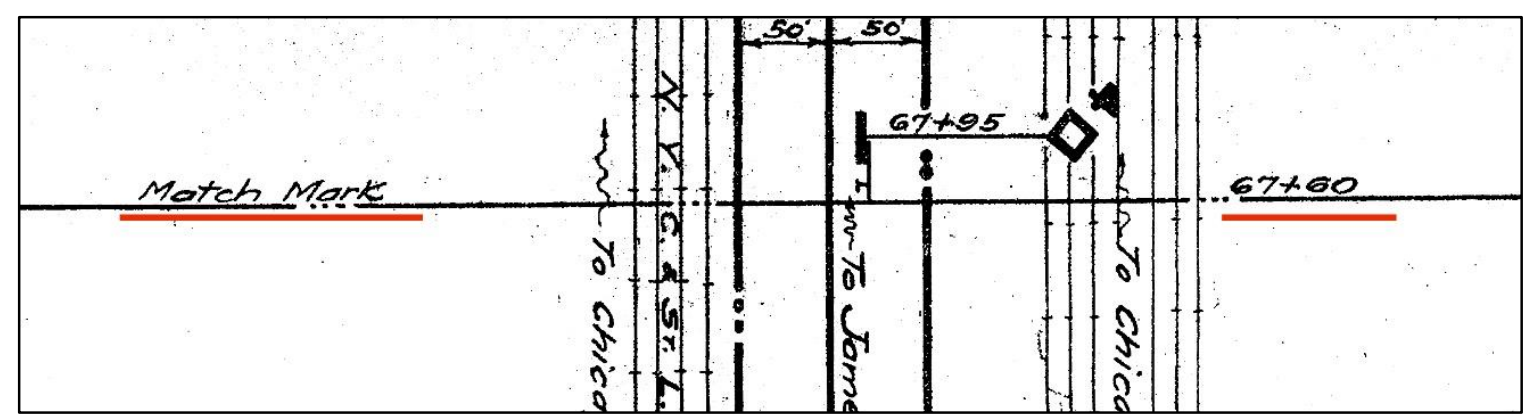

Figure 2-14. Close-up of a match mark from valuation map V15.NY.008

\subsection{Summary}

This chapter looked at some of the previous work that has been done in the field of historical GIS, and outlined influences for the work that was done during this project. Also discussed was the history behind the ICC valuation maps, which were the primary data within the project. In addition to the history, this chapter illustrated the contents of these maps, and later chapters will describe how these maps were utilized for this project. 


\section{Chapter 3 - Systems Analysis and Design}

This chapter describes the design and requirements of the Erie Lackawanna Historic Map Index (ELHMI). Included in this chapter are the functional and nonfunctional requirements, the system design, and the project plan that were implemented in the development of a prototype of the ELHMI.

\subsection{Problem Statement}

The Erie Lackawanna Historical Society (ELHS) possesses a collection of over 3,600 physical 1918 railroad valuation maps for the Erie Railroad. In 2000 they completed work on scanning these maps into a digital format; however, these scans had no spatial reference, making it impossible to implement them into a GIS for analysis and visualization. The ELHS approached the project team to develop methods for making these maps accessible in a GIS and to explore modern applications for the collection.

\subsection{Requirements Analysis}

When Scott Randolph, the head curator for the ELHS, initially approached the project team, he was interested in seeing how modern GIS technologies could be applied to their collection of historic valuation maps. Through conversations with the client, it was agreed that the project would deliver a prototype for an interactive map index web application. The project team decided on the following functional and non-functional requirements for the completion of this project.

\subsubsection{Functional Requirements}

Working from discussions with the client, the project team developed a number of functionalities that would be required in the project deliverables. Table 3-1 outlines the functional requirements for the project. 
Table 3-1. Functional requirements.

\begin{tabular}{|c|c|}
\hline Requirement & Description \\
\hline $\begin{array}{l}\text { Query individual valuation } \\
\text { maps }\end{array}$ & $\begin{array}{l}\text { Allows web application users to select } \\
\text { individual maps }\end{array}$ \\
\hline \multicolumn{2}{|l|}{$\begin{array}{l}\text { Display valuation maps on top } \\
\text { of a georeferenced basemap }\end{array}$} \\
\hline Select basemap & $\begin{array}{l}\text { Allows web application users to select from a } \\
\text { list of different basemaps, including imagery, } \\
\text { topographic and street maps }\end{array}$ \\
\hline Query archival materials & $\begin{array}{l}\text { Allows web application users to select } \\
\text { individual archival materials to view source } \\
\text { image and description in pop-up }\end{array}$ \\
\hline $\begin{array}{l}\text { Query maps and materials } \\
\text { within a defined extent }\end{array}$ & $\begin{array}{l}\text { Allows web application users to select all } \\
\text { maps and archival materials within either map } \\
\text { extent or specified extent to be listed in } \\
\text { sidebar menu }\end{array}$ \\
\hline Choose what layers to display & $\begin{array}{l}\text { Allows web application users to define which } \\
\text { layer(s) is displayed in the map viewer }\end{array}$ \\
\hline Overview map(s) of interest & $\begin{array}{l}\text { Users will be presented with an information } \\
\text { window(s) including the attributes of the } \\
\text { selected valuation map(s) as well as a } \\
\text { thumbnail of the original valuation map image }\end{array}$ \\
\hline $\begin{array}{l}\text { Visualize original valuation } \\
\text { map file }\end{array}$ & $\begin{array}{l}\text { The thumbnail image will link to a full-sized } \\
\text { view of the original nongeoreferenced } \\
\text { valuation map file }\end{array}$ \\
\hline
\end{tabular}

The web application had to present the collection of georeferenced valuation maps in such a way that users would be able to interact with each map and access the metadata, as well as view the full-size image in its non-georeferenced form. In addition to selecting maps and archival materials individually, users also needed to be able to define an extent within which all maps and archival materials are queried and presented in list format.

\subsubsection{Non-Functional Requirements}

The non-functional requirements are those that define how the system will work. The project for the ELHS had non-functional requirements for both the georeferencing of the valuation maps and development of the database, as well as the development and hosting of the elements of the web application. These requirements are outlined in Table 3-2. 
Table 3-2 Non-Functional Requirements

\begin{tabular}{|l|l|}
\hline Requirement & $\begin{array}{l}\text { Description } \\
\text { Used for georeferencing of valuation maps, } \\
\text { editing of feature and raster mosaic datasets }\end{array}$ \\
\hline ArcServer 10.2 and ArcSDE & $\begin{array}{l}\text { Used for hosting and management of feature } \\
\text { and image services within enterprise database }\end{array}$ \\
\hline Web Server & $\begin{array}{l}\text { Used for hosting web page and related } \\
\text { materials }\end{array}$ \\
\hline $\begin{array}{l}\text { ArcGIS JavaScript API 3.10 } \\
\text { and Dojo Toolkit }\end{array}$ & $\begin{array}{l}\text { Used for script development of web } \\
\text { application in HTML format }\end{array}$ \\
\hline $\begin{array}{l}\text { Mozilla Firefox, Google } \\
\text { Chrome, Microsoft Internet } \\
\text { Explorer and Apple Safari } \\
\text { Browsers }\end{array}$ & $\begin{array}{l}\text { Supported browsers used to access web } \\
\text { application }\end{array}$ \\
\hline
\end{tabular}

ArcMap was used for the georeferencing of the valuation maps, as well as organizing the individual rasters into a raster mosaic dataset. It was also used for the creation and editing of the map outline polygon and the archival materials point feature layers. The web application itself was scripted using JavaScript, Esri's ArcGIS JavaScript API 3.10, and the Dojo Toolkit, and was hosted on the webserver along with the graphics and materials used within the web application. Finally, the web application needed to be accessible in all major web browsers as listed in Table 3-2.

\subsection{System Design}

After consulting with the client, the project team developed a system design, based in an ArcGIS environment, which supports two major functionalities (Figure 3-1). The first function (A) registers the evaluation maps to the Web Mercator coordinate system. The TIFF images were georeferenced (1), and auxiliary files (2) containing the transformation metadata were automatically created by ArcMap for each image. The georeferenced images were then integrated into a raster mosaic dataset (3) stored in an enterprise geodatabase (4). Additional supporting feature layers were also created and included in the enterprise geodatabase. This geodatabase is hosted on an MSSQL server on the University of Redlands server bank, and is accessed using ArcGIS for Desktop 10.2 installed on a Lenovo Thinkpad T440p.

The second function (B) makes these data available for use in a web-based application through the use of a number of Esri web services. The raster mosaic database was published as an image service (5), and the feature layers as feature services (5), to a GIS server running ArcGIS for Server 10.2 (6), also a part of the University of Redlands server bank. These services are then utilized in a JavaScript script developed using Esri's 
ArcGIS API for JavaScript and hosted on a web server (7) running Microsoft's ISS. This script is utilized by the end user as a web application (9) through any modern web browser (8), allowing them to access the images in their georeferenced form.

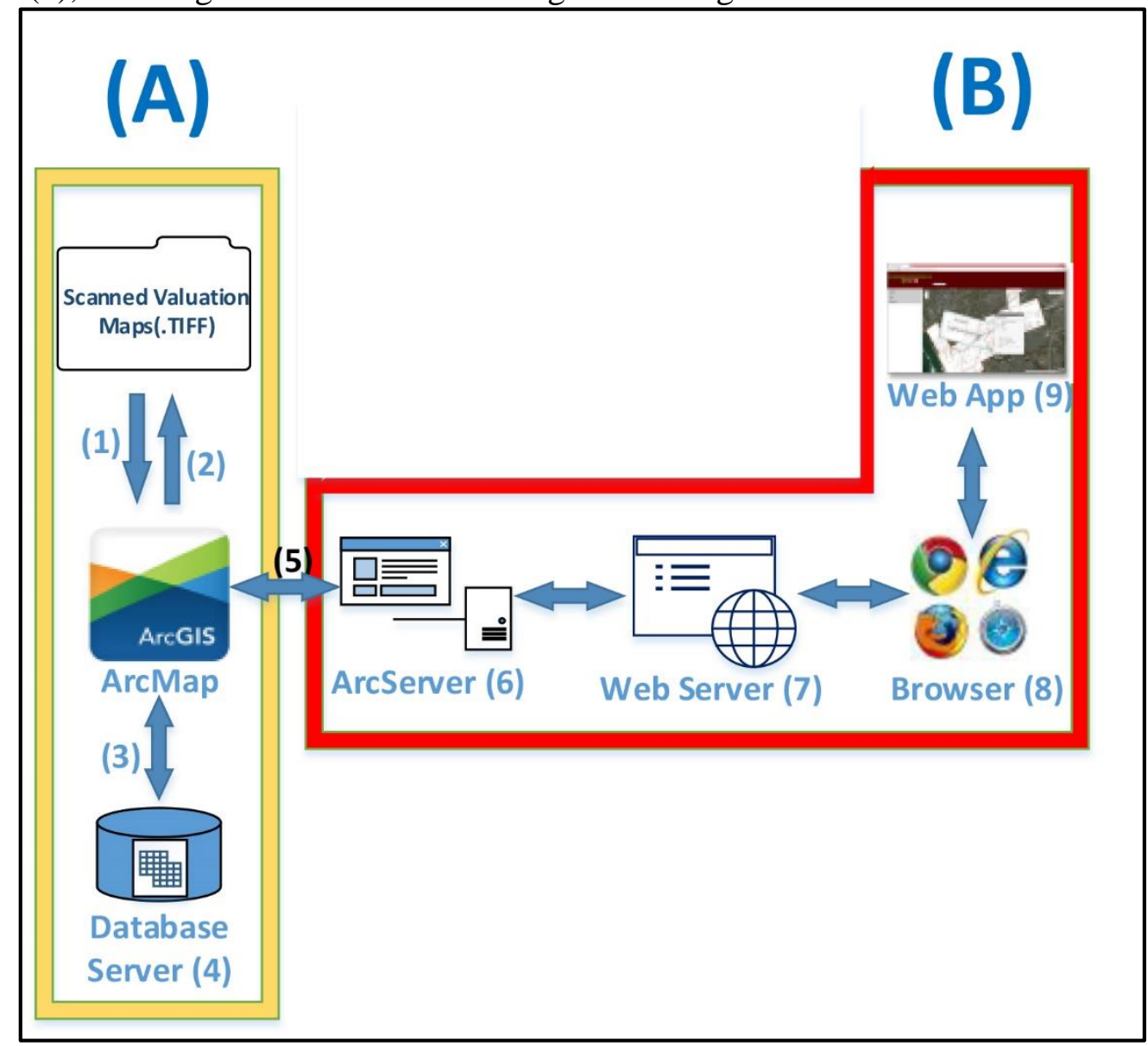

\section{Figure 3-1. System Design}

\subsection{Project Plan}

Given the loosely defined nature of the project at its outset, and overly confident estimates of the project team's abilities to develop the required skills, the final schedule for the project varied greatly from the original project plan. Table 3-3 illustrates the plan as it was when first initiated.

Table 3-3 Initial Project Plan

\begin{tabular}{|l|l|l|l|l|l|l|l|l|l|l|l|l|}
\hline Activity & Jan & Feb & Mar & Apr & May & Jun & Jul & Aug & Sep & Oct & Nov & Dec \\
\hline Planning & & & & & & & & & & & & \\
\hline
\end{tabular}




\begin{tabular}{|c|c|c|c|c|c|c|c|c|c|c|c|}
\hline $\begin{array}{l}\text { Primary Data } \\
\text { Collection }\end{array}$ & $x$ & $x$ & & & & & & & & & \\
\hline $\begin{array}{l}\text { Secondary Data } \\
\text { Collection }\end{array}$ & $x$ & $x$ & $x$ & $x$ & $x$ & $x$ & $x$ & & & & \\
\hline Database training & & & & $x$ & $x$ & & & & & & \\
\hline Web GIS training & & & & & $x$ & $x$ & $x$ & & & & \\
\hline Georeferencing & & & & & $x$ & $x$ & & & & & \\
\hline $\begin{array}{l}\text { Web App } \\
\text { Development }\end{array}$ & & & & & & & $x$ & $x$ & & & \\
\hline Testing & & & & & & & & $x$ & $x$ & & \\
\hline Documentation & & & & & $x$ & $x$ & $x$ & $x$ & $x$ & $x$ & \\
\hline $\begin{array}{l}\text { Public } \\
\text { Presentation }\end{array}$ & & & & & & & & & $x$ & $x$ & \\
\hline Poster & & & & & & & & & $x$ & $x$ & \\
\hline Defense & & & & & & & & & & & $x$ \\
\hline
\end{tabular}

The first major variance from the project plan was the planning stage. As the project team became more familiar with the data and developed the required skills, the scope of the project shifted a number of times. Certain elements were added or reprioritized through the course of the project, with a final design being established in June, 2014. The primary change was the rebalancing of the weights given to the georeferencing and geodatabase construction elements and the web component. When it was agreed that the final product would be a proof of concept, the number of valuation maps in the sample area was set to 15 and the georeferencing was relegated to the data processing phase as opposed to being the major aspect of the project. Additionally, the custom Python script for handling the georeferencing of the images that had been originally proposed was scrapped in favor of using the built-in georeferencing tools that are part of ArcMap 10.2. The second effect was that the web-based component of the Erie Lackawanna Historic Map Index was given a higher priority. Originally the plan had been to publish the georeferenced maps as a web service to ArcGIS Online and utilize the service in a simple map viewer using Esri's Web App Builder. This aspect of the project was given a higher priority and changed to include a custom scripted, ArcServer-based, web application for two reasons. First, the valuation maps, once georeferenced, were organized into a raster mosaic dataset and published as an image service. Image services cannot be published to ArcGIS Online and require hosting on an ArcServer. Second, it was decided that the skills of the project team had developed to a point that a custom script was a reasonable deliverable, and WebApp Builder did not offer the flexibility and customization required for the final design of web application.

The primary data collection of the valuation maps was completed on time with the hand-off of a copy of the full collection via DVD, but the secondary data collection of archival materials ran over schedule. This was largely due to that part of the project being de-prioritized due to time constraints. In the end, the client was able to provide some materials, and others were procured from the ELHS site and other internet sources. The available materials were placed as sample data with arbitrary spatial locations.

In May, 2014 other projects demanded the majority of the project team's time and most of the project work had to be put on hold. In August the project resumed, with the 
georeferencing of the selected valuation maps being completed, as well as organizing them into a raster mosaic dataset. Upon the completion of the web GIS class, however, it was determined that the skills in web development and working with Esri's ArcGIS API for JavaScript had not been fully developed during the class, and required further training. This was accomplished through Esri's training in August, as well as self-training in HTML, CSS, and JavaSript, making use of the resources available through W3Schools.com. At the beginning of September, the geodatabase of the valuation maps, including the manual digitization and attribution of outline polygons for each map, was completed. At this point the web application development commenced, though there were further delays as it was discovered that certain pieces of the technological architecture were not in place and required configuration.

\subsection{Summary}

By working with the client, the project team was able to devise a set of requirements that were then used to create a project plan, from a list of general desires. However, due to the initial vagueness of the project goals, overly ambitious time estimates, and unexpected conflicts, the project plan saw a number of changes by the time the Erie Lackawanna Historic Map Index was completed. 


\section{Chapter 4 -Database Design}

This chapter describes the conceptual and logical data models that were used in developing the geodatabase and web application for the Erie Lackawanna Historical Map Index (ELHMI), as well as detailing the process for integrating the historical valuation maps into the system. The conceptual model outlines key entities within the model, while the logical model goes into more detail about the organization of the data within the geodatabase.

Section 4.1 discusses the conceptual model and the relationships present in the data and Section 4.2 outlines the logical database structure. Section 4.3 lays out the sources of the data used in the project, and Section 4.5 goes into detail about how the data were organized and implemented in the system.

\subsection{Conceptual Data Model}

In 1913 The Interstate Commerce Commission (ICC) instated the Bureau of Valuation to oversee the complete valuation of all property and assets held by every railroad company in the United States. As a result of this, between 1915 and 1920 each railroad operator (Figure 4-1) commissioned their own sets of railroad valuation records, or valuation maps, which were used by the ICC in an attempt to regulate shipping tariffs for each company based on total holdings (Pfeiffer, 1997). These valuations were done individually for each state in which the company had property and were divided into valuations sections, which were further comprised of individual valuation maps. These sheets were produced at a set of scales, each covering from half a mile to two miles of track.

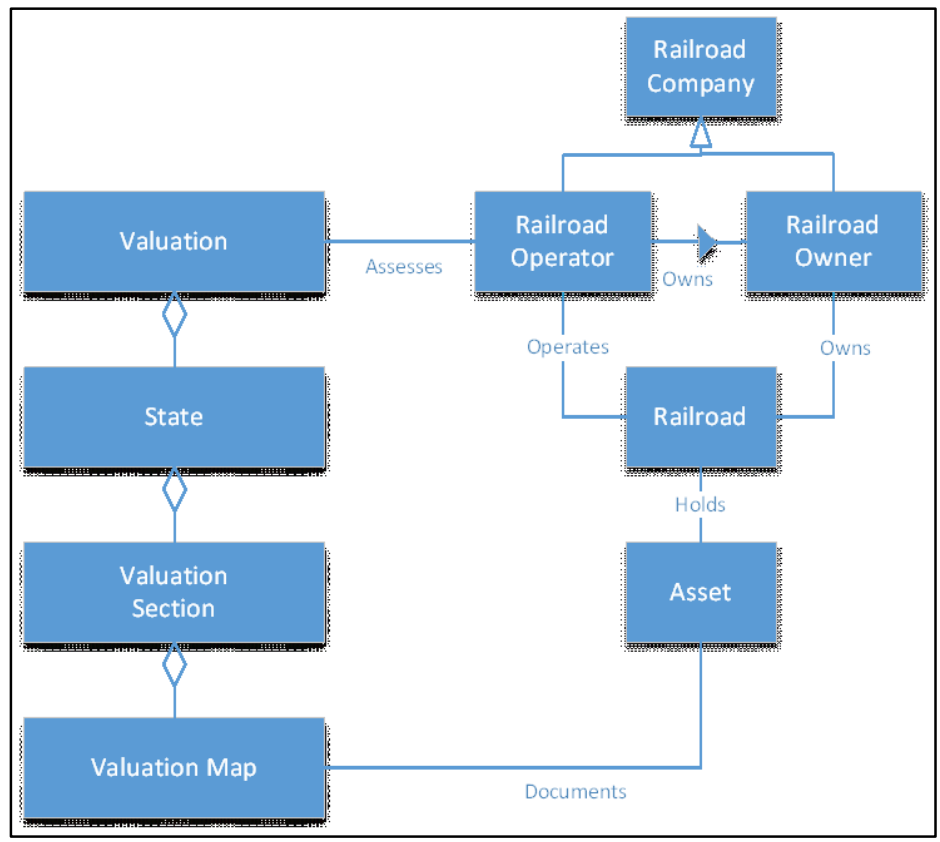

Figure 4-1. Conceptual Data Model 
Historically, the organization for the ownership of each railroad could vary, depending on size, complexity, or even what states it ran through, but for the purposes of the Erie Railroad and this project, the model can be illustrated simply as it appears in Figure 4-1. There was one railroad company that was the railroad operator and was comprised of other railroad companies that were, individually, railroad owners. The railroad owners were the direct owners of the physical assets and properties that comprised the railroad, while the railroad operator was the direct owner of all the railroad owners. As far as the ICC was concerned, the railroad valuation assessed the total assets owned by the railroad operator.

The valuation maps were drafted by professional surveyors and detailed all tracks, rights-of-way, structures, and property parcels (collectively, the assets) held by the railroad company. Along with the assets, the maps often included surrounding contextual features immediately adjacent to the properties such as waterways, streets, and tracks owned or operated by other railroad companies. In addition to the graphically represented data, the sheets also include textual records, such as deed ownership schedules, starting and ending survey stations, railroad owner and operator, division and branch information, valuation section and sheet number, and scale and notes about revisions. For the scope of this project, these textual records were the easiest to extract and were the key metadata included in the logical model as attributes of the valuation maps, held in the individual Outline polygons.

\subsection{Logical Data Model}

While the maps themselves contain a wide variety of information and features, the raster file format of the map scans meant that none of these data were natively accessible to use digitally. Each map scan is simply a collection of pixels, with values that only have meaning when interpreted by the human eye. This project focused on the georeferencing of the maps, extraction of key metadata, and the organization of the results into an index. These were the first steps in unlocking the information in these maps, and laid the groundwork for future projects.

The logical model included two separate geodatabases, as illustrated in Figure 4-2: one containing the ValMaps raster mosaic dataset, the other containing the feature services. The raster mosaic dataset organized all of the georeferenced valuation maps and allowed for publishing a unified image service to the ArcGIS Server. This raster mosaic dataset links to the individual raster files which are stored in a single Windows folder on the same server as the database. 


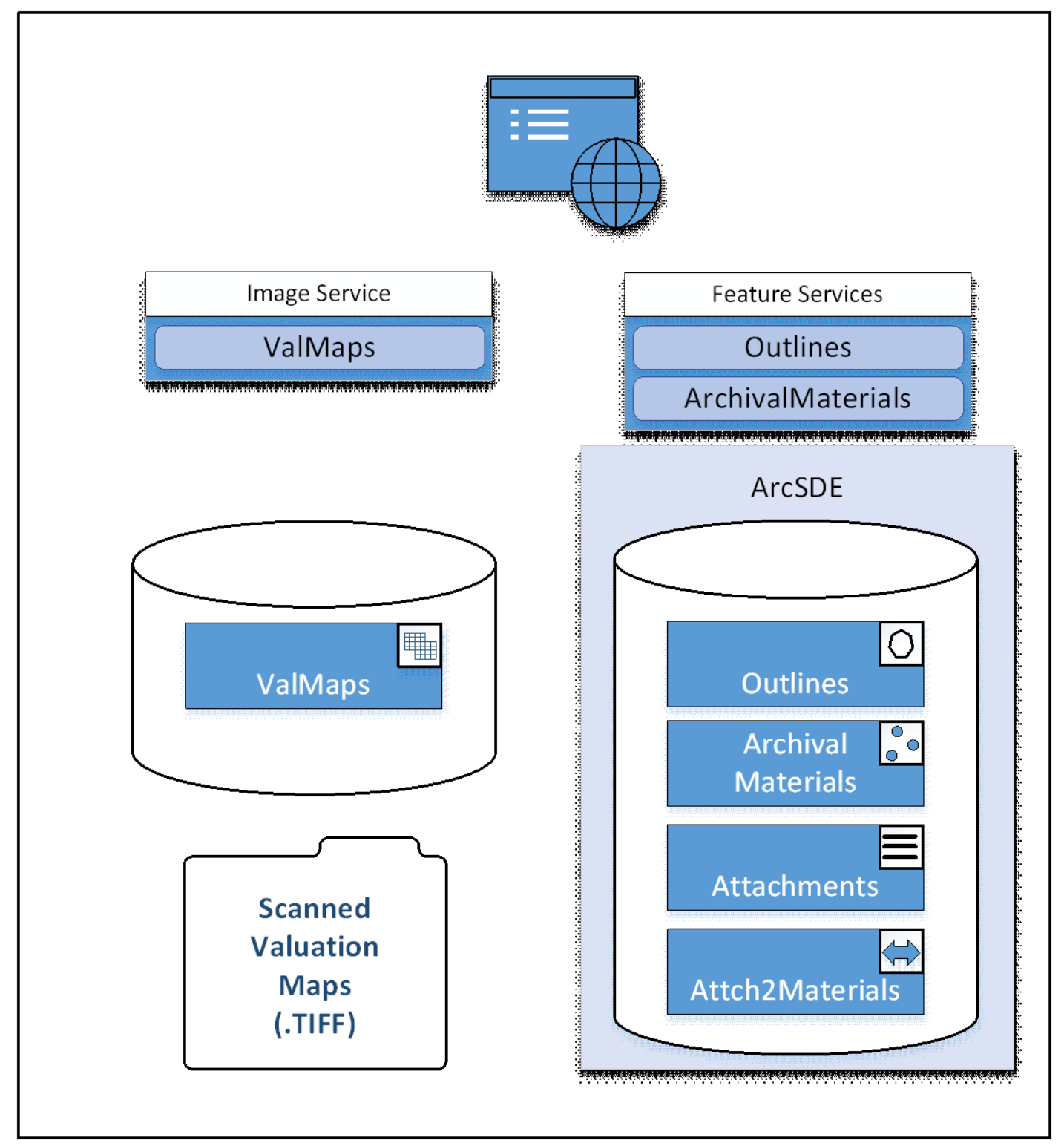

Figure 4-2. Logical Data Model

The Outlines polygon feature class stored in the second database, contains an outline polygon for each valuation map raster. These polygons were a design construct required for the system and served two purposes. First, they visually denote the actual footprint of each georeferenced valuation map, and act as the interactive layer in the web application. Secondly, each polygon carries the metadata that were manually extracted for each map as feature attributes, which could then be queried. Also stored in this same database was a point feature class for the Archival Materials. Each document was added as an attachment to a particular point feature. Included in the database are the Attachments table and the Attch2Materials relationship class. Both feature classes were published to 
an ArcGIS Server as feature services and accessed through the web application along with the image service.

\subsection{Data Sources}

In 1990 the Erie Lackawanna Historical Society (ELHS) acquired the original 1918 linen valuation sheets for the entire Erie Railroad, and in 2000 they completed digitally scanning this collection. While the individual maps cover specific extents, no spatial reference is included in the original maps, and therefore the scans do not either. The ELHS and their members also have collections of historic materials related to the railroad, such as photographs and documents. In addition to giving spatial context to the maps, the ELHS also wanted the ability to do the same for these materials and relate them to the maps.

The primary data for this project were the valuation map scans provided by the ELHS. They were delivered by Scott Randolph in the form of four CD-ROMS containing the full scanned valuation map collection as Tagged Image File Format (TIFF) files. In addition to the maps, the project also included archival materials in the form of photographs and documents. These materials were collected by the project team from web sources recommended by Scott Randolph, including Flickr and Railfan.net. Most of the materials did not have a clear spatial context. However, this was not a concern since, for the scope of this project, it was deemed appropriate to implement these materials as sample data.

\subsection{Data Scrubbing, Loading, and Creation}

\subsubsection{File Selection}

When the ELHS presented the valuation maps to the project team, they were in unrectified TIFF format and required rectification before they could be implemented. The first step was to sort out only the images that pertained to the study area. Included with the valuation map scans were reference maps that illustrated the layout of the individual maps as a series. Figure 4-3 shows a close-up reference map for the Buffalo, NY area, with each black rectangle, highlighted in red in the figure, representing an individual valuation map. 


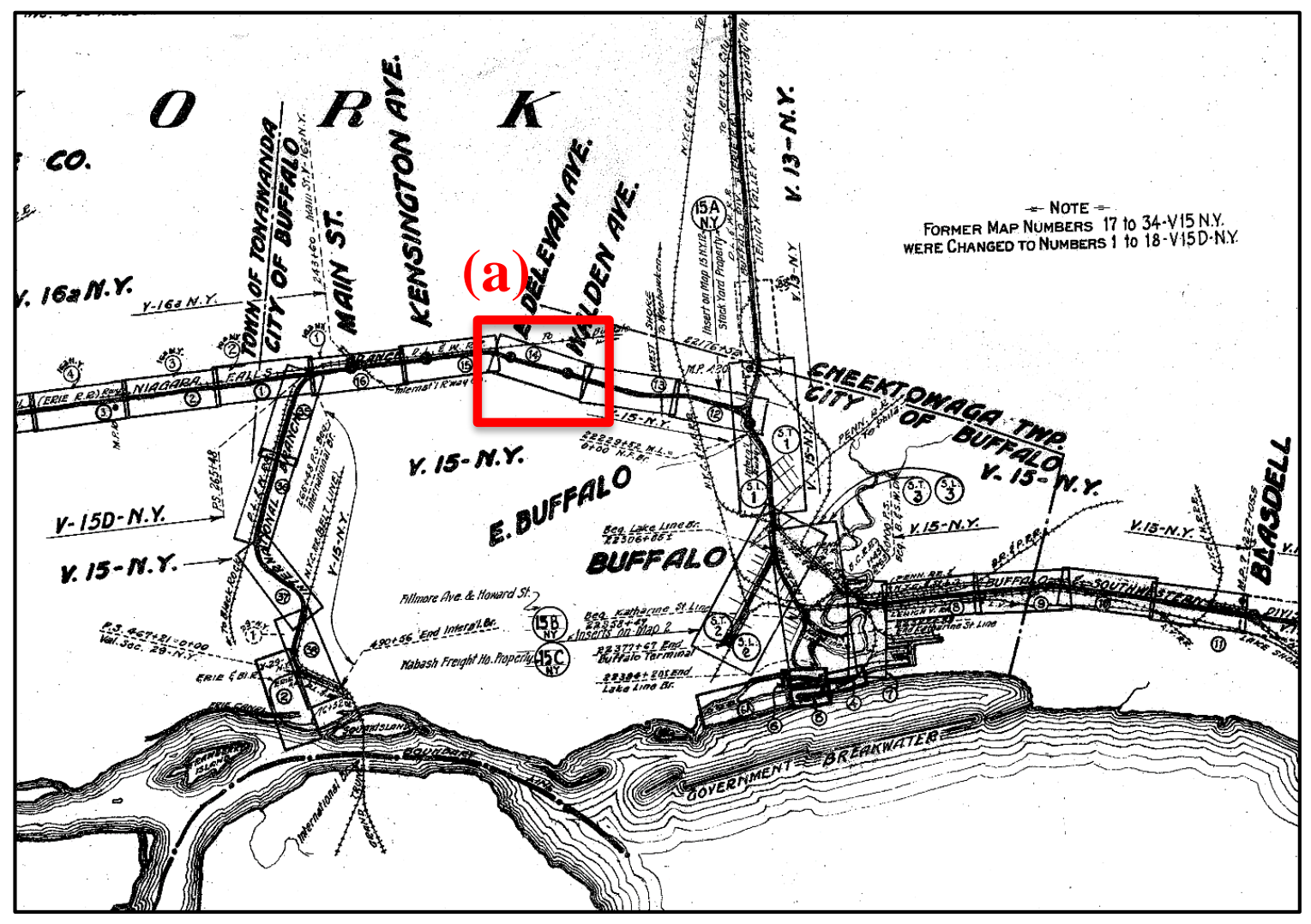

Figure 4-3. Close-up of Buffalo, NY area valuation section map

Finding the individual maps within the collection was relatively easy once the numbering system was explained; however, the system was not intuitive. Each file was labeled with the full valuation designation of the individual map it represented. Figure 4-4 shows an example of how each valuation section has its designation-in this case "V. 15- N.Y." meaning valuation section 15 in New York State - then each individual map is labeled with its page number, i.e. page 15. The labeling scheme for the TIFF files were based on this method. If one wanted to find the file for page 15 (Figure 44a) in Figure 4-2 it could be found under the file name "2.V.15.NY.15," the addition of the 2 at the beginning referring to the disc number the file could be found on. Once this labeling method had been figured out, it was only a matter of finding all the sheets covering the sample area and then copying the corresponding files to a separate folder. Once the appropriate files were separated from the collection, they then had to be loaded into Esri's ArcMap 10.2 and georeferenced. 


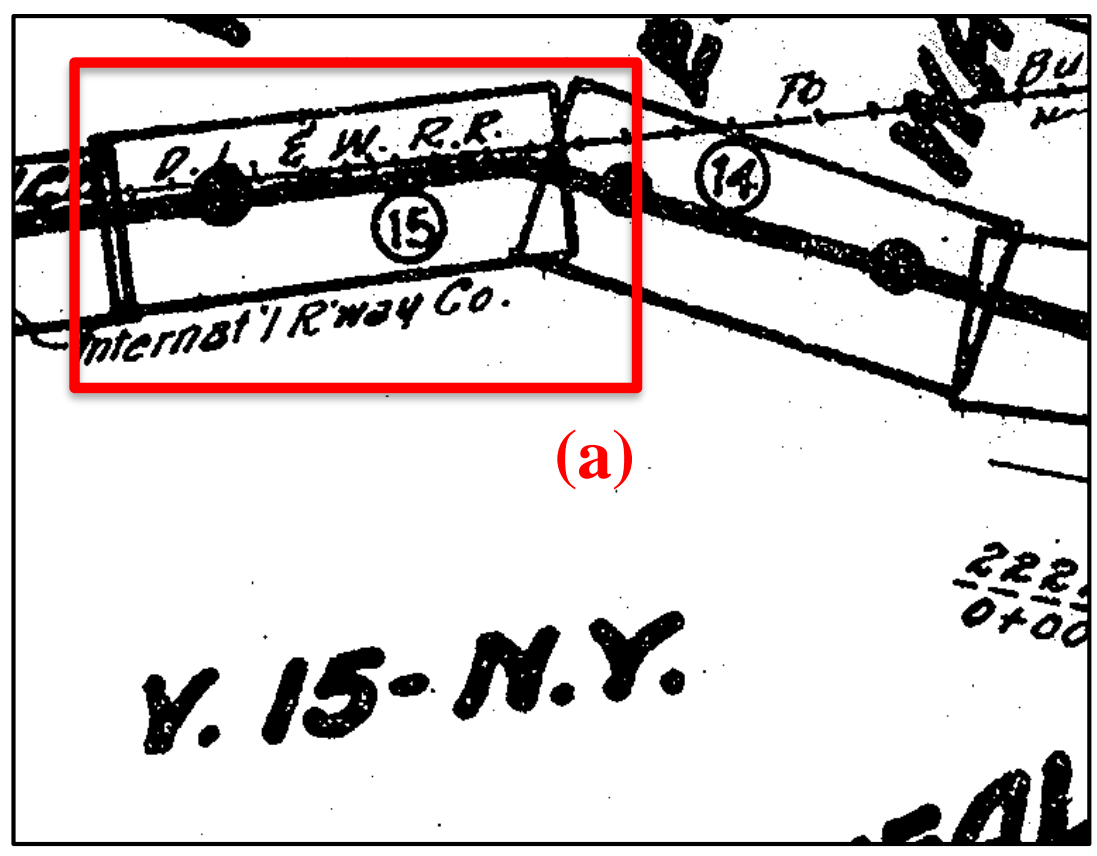

Figure 4-4. Close-up of individual valuation map 2.15.NY.15 as represented in valuation section map.

\subsubsection{Georeferencing}

Starting with a new map document with the coordinate system set to WGS 1984 Web Mercator (Auxiliary Sphere), Esri's World Imagery and World Streets Map basemaps were loaded as separate layers to be used as references for placing ground control points. Following this, each TIFF file was loaded as a layer. For each map, it was required to select a set of control point pairs, the first being placed in the non-georeferenced source - the valuation map - and the second being placed in the referenced map coordinate target layer - the base map. A minimum of three control points were required for each image in this project, and had to be placed on unique features that were present in both source and target images. For best results, the control points also needed be spaced as far apart as possible and away from a straight line.

The nature of the valuation maps and the lack of historic imagery posed a number of problems, the key problem being that the maps themselves were very sparse in identifiable features beyond the railroad tracks and in many of the maps contained only the tracks. This issue was exacerbated by the fact that the project team had to rely on modern imagery, meaning that there was nearly 100 years of change between when the maps were drafted and the imagery was captured. This required the project team to develop a number of creative methods for selecting reliable control points. Chapter 5 will go into more detail on the specific problems and describe the solutions that were developed. Once the maps were georeferenced, they were loaded into a single raster mosaic dataset using ESRI's ArcMap 10.2. 


\subsubsection{Outline Polygons}

Each of the maps was given an outline polygon. These polygons were manually digitized within a separate feature class using the Create Features tool in ArcMap 10.2. Once the polygon was created, the attributes were manually entered for each feature using the Edit Features tool. The attributes were taken from the reference notation included in each map (Figure 4-5), and were loaded as they are described in Table 4-1. The polygons served multiple purposes within the web application, such as serving as graphical indicators of the exact borders of each of the georeferenced map images. This was required because in many cases the maps overlapped. However, their primary role was functional in that they contained the attributes for each map and served as the functional layer that would be actively interacted with by the user.

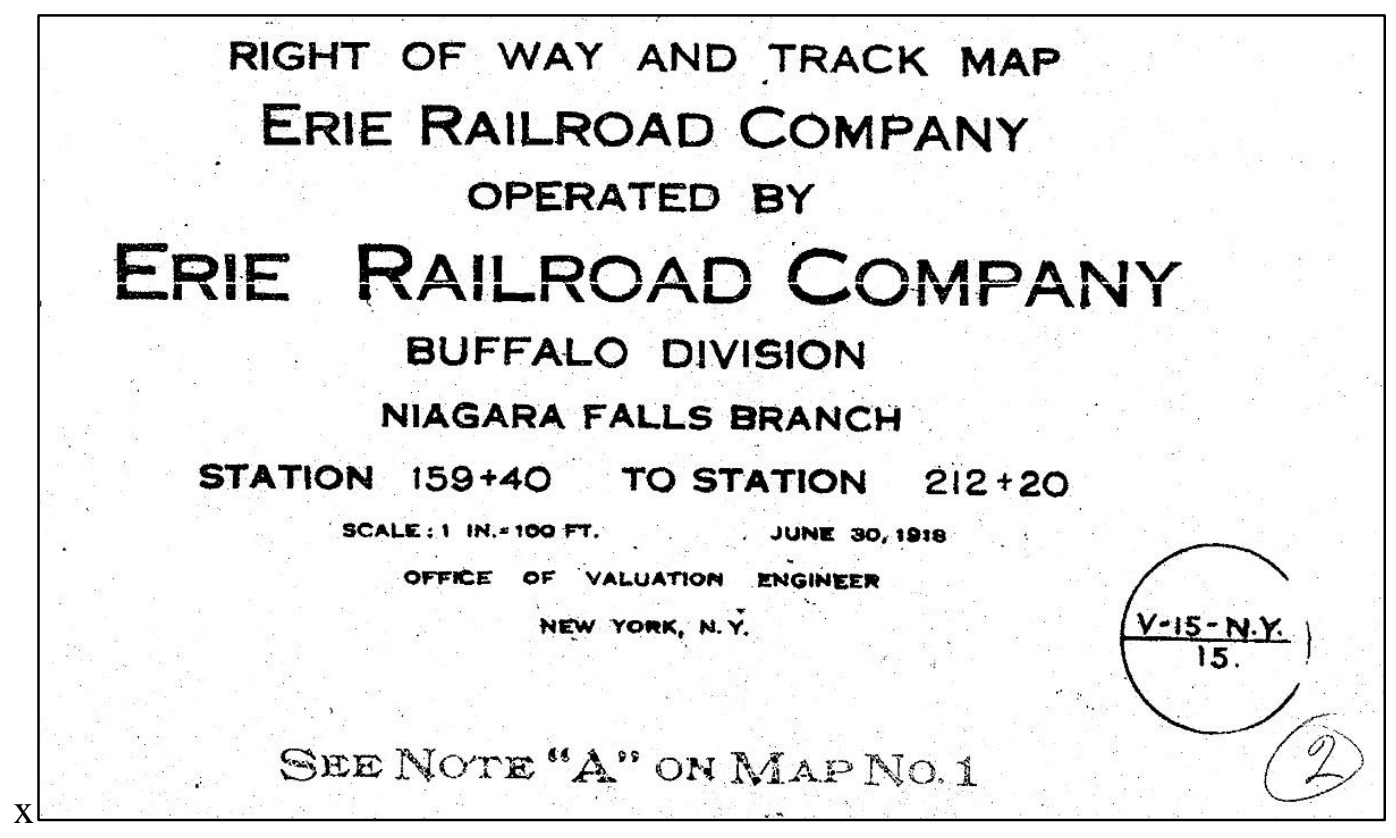

Figure 4-5. Close-up of valuation map reference notation 
Table 4-1. Outlines Feature layer attributes

\begin{tabular}{|l|l|l|}
\hline Field & Alias & Object ID \\
\hline OBJECTID & SHAPE & Geometry \\
\hline SHAPE & SHAPE.STArea() & Double \\
\hline SHAPE.STLength() & SHAPE.STLength() & Double \\
\hline Name & Name & text \\
\hline FileName & File Name & text \\
\hline Val_Year & Valuation Year & Short Integer \\
\hline url & URL & text \\
\hline Thumb & Thumb URL & text \\
\hline Stn_start & Start Station & text \\
\hline Stn_end & End Station & text \\
\hline Division & Division & text \\
\hline Branch & Branch & text \\
\hline RR & Railroad & text \\
\hline
\end{tabular}

\subsubsection{Archival Materials}

Once the collecting of archival materials was complete, they were loaded into a single feature class that could then be published as a feature service for use in the web application. These materials had no spatial reference included and had to be placed manually. This was done by creating and placing a point feature for each item, then relating the original file to the feature as an attachment. As mentioned in section 4.3, the materials did not contain any spatial references, and the majority did not have any documentation to suggest their locations. For those materials that did contain some reference, it was only as specific as a note about general location, or relation to a landmark. These materials were placed as closely as possible, such as placing it along the tracks that ran through the geographic area as described, or within close proximity to the 
noted landmark. Materials that contained no hint to original location were loaded in locations that were appropriate to the content. For example, images that contained structures such as stations or bridges were placed in relation to similar features present in the valuation maps. Each of the point features were given attributes that described the attached material (Table 4-2).

\section{Table 4-2. Materials attributes}

\begin{tabular}{|l|l|}
\hline Field & Type \\
\hline OBJECTID & Object ID \\
\hline SHAPE & Geometry \\
\hline Title & string \\
\hline submitter_Name & string \\
\hline submission_Date & date \\
\hline Email & string \\
\hline material_Date & Date \\
\hline isTestData & text \\
\hline
\end{tabular}

\subsection{Summary}

This chapter described the conceptual and logical models for the web application developed for the ELHS, as well as the sources for the data and the methods used to load them into the system. The methodology for deploying these models is described in more detail in Chapter 5, as are the challenges the team faced and the techniques developed to implement them. 



\section{Chapter 5 -Database Preparation}

This chapter looks at the steps that were taken in getting the 1918 Erie Railroad valuation maps into a coordinate system, as well as the development of supporting data. Section 5.1 looks at the decision process for selecting a transformation method for the georeferencing of the maps. Section 5.2 discusses the challenges the project team faced in the selection of ground control points and the solutions that were derived. Section 5.3 looks at the inclusion of additional supporting data and the processes for preparing these data for use in the final web application

\subsection{Transformation Selection}

Georeferencing is the process of aligning spatial data to a known coordinate system. When the spatial reference for the data in question is not known, it is necessary for the data to be manually georeferenced. In the Erie Lackawanna Historical Map Index (ELHMI) the historical railroad valuation maps did not have any spatial reference metadata and so had to be georeferenced before they could be used. Aligning the valuation maps to a known coordinate system was done with the use of ground control points (referred to hereafter as points), which were identifiable locations on the valuation maps that were also present in the reference maps with a known coordinate system. The points were then used to calculate the transformation that would align the valuation map into the coordinate system.

There are many transformation methods, each with its own benefits and constraints. The key constraint when choosing the appropriate transformation for the valuation maps was the availability of identifiable features present in the maps. The valuation maps varied greatly in the number of identifiable features around the tracks, limiting the potential number of points that could be measured. In the best of the valuation maps the streets, neighboring tracks, and structures in the surrounding area were recorded, but did not usually fill the full extent of the map (Figure 5-1).

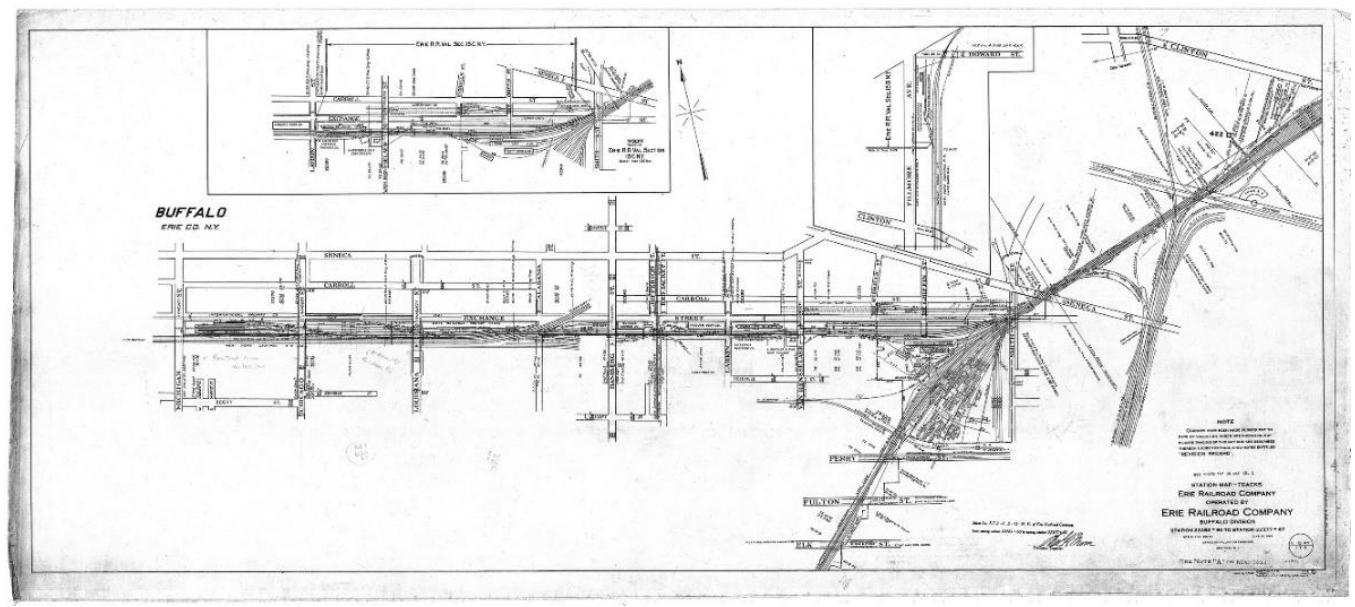

Figure 5-1. High feature-detail valuation map 
This last factor was important because, regardless of the number of points, they should be as well dispersed as possible. In the worst cases the valuation map depicted only the line of the track and the right-of-way with no other surrounding details (Figure $5-2)$.

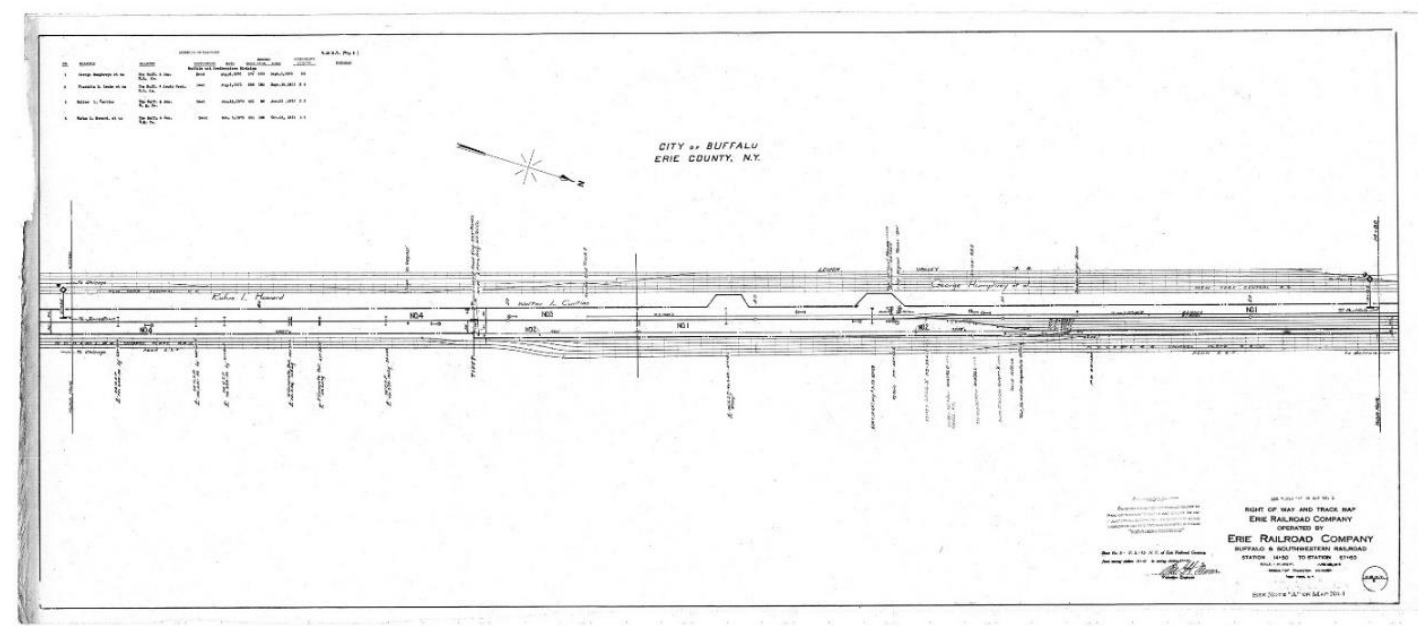

Figure 5-2. Low feature-detail valuation map

An additional challenge to point selection was that neither detailed historical maps nor historical aerial imagery for the study area were available and, therefore, modern imagery had to be used. Nearly 100 years separated the drafting of the valuation maps and the collection of the imagery used. In that time, many of the structures, and in some cases even the tracks, had been removed or changed in such a way that they were not recognizable in modern imagery. This meant that some of the prominent features present in the valuation maps did not have recognizable counterparts in the reference imagery.

Because of the limitations on point selection, a first order polynomial, or affine, transformation was decided upon. The affine transformation is one of the simplest and requires only a minimum of three point pairs. Even so, finding three points posed a challenge in some of the valuation maps. With an affine transformation, the image can be rotated, scaled, skewed, and translated as necessary to be fitted to the reference image. Figure 5-3 illustrates each of these processes. 


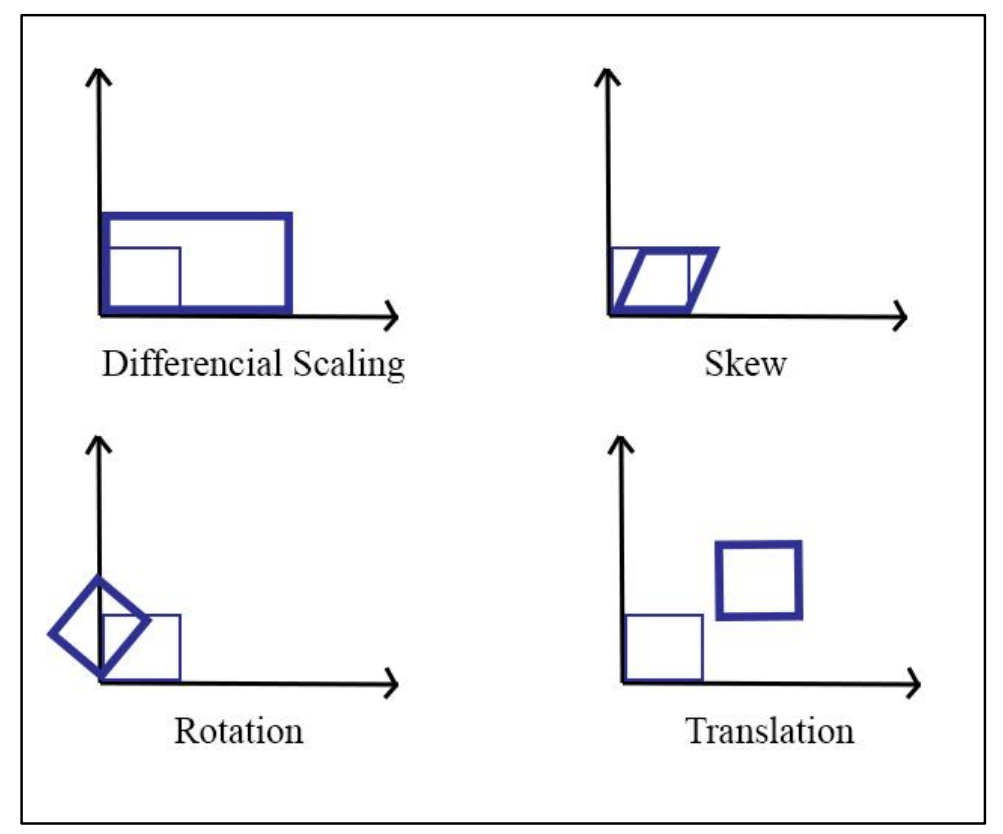

Figure 5-3. Affine transformation processes. Recreated from geodata.ethz.ch.

\subsection{Control Point Selection}

The primary method for selecting control points was to use street intersections whenever possible. During their visual inspection of the valuation maps, the project team found streets that appeared to have been renamed, expanded, narrowed, redirected, or had sections removed; however the majority of the street grid was close enough to how it was depicted in the maps to be confident in using them as a reliable source of control points. Additionally, because of the project team's familiarity with the history of Buffalo, New York, it was known that the subject area had gone into an economic depression in the mid- to late- $20^{\text {th }}$ century. This was relevant because it allowed the project team to assume that there had been a minimum of major infrastructure reconstruction.

Working with these assumptions, the first features that were considered when selecting control points were intersections of labeled streets as far to the edges of the maps as possible. These streets were then located in the referenced coordinate system layers, first in the labeled World Street Map layer, then the exact center of the intersection was confirmed using the imagery layer. Figure 5-4 illustrates this selection process. Figure 5-4(a) is the valuation map, which shows the intersection of Central Avenue and Williams Street. In the center (b) is the same intersection in the imagery, and on the right (c) is how it is shown in the World Street Map layer. The reason that both the street map and imagery were used for reference is that the street maps showed the street names, while the aerial imagery depicted the scale and geometry of the street as it was illustrated in the valuation map. This accuracy in width was important in determining a more accurate center of the intersection. 


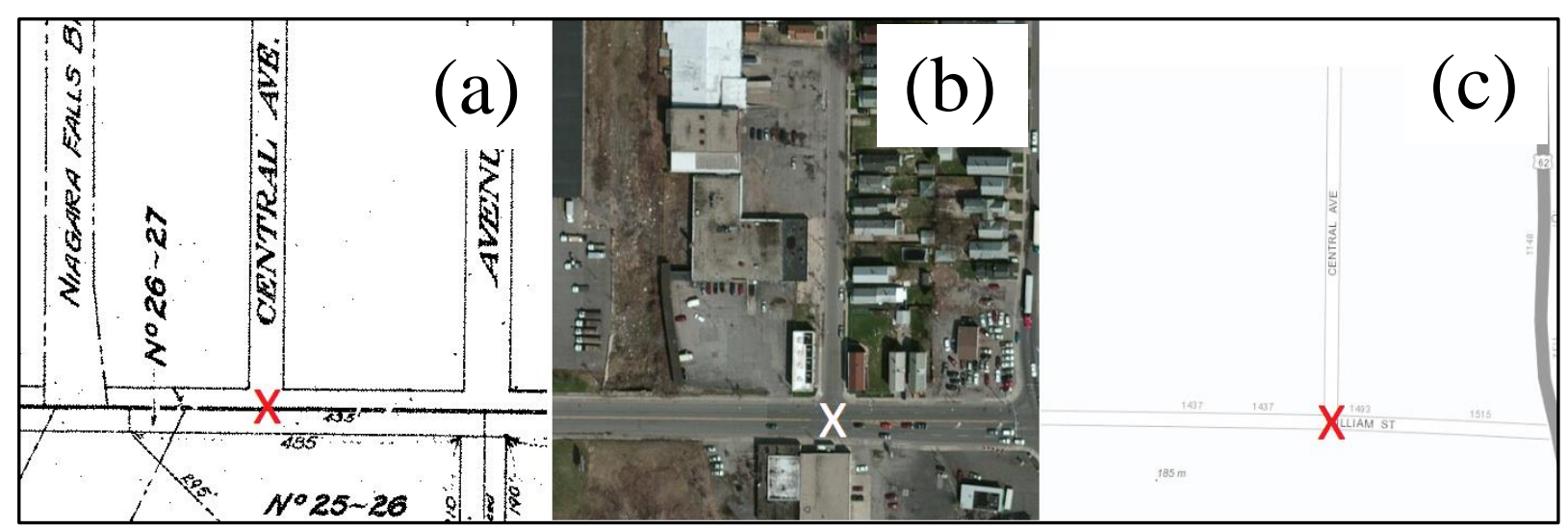

Figure 5-4. The same intersection as illustrated on the valuation map(a), imagery(b), and World Street Map(c)

In many of the maps other physical features were depicted, including rail beds, bridge crossings, and buildings. The rail beds could be treated in much the same way as street intersections. Even if the rails had been removed, the scars left on the terrain could still be easily recognized in the imagery. Figure 5-4(a) depicts another railroad company's Niagara Falls Branch, cropped to "Niagara Falls B" in the figure, to the left of Central Avenue. This was not recoded in as much detail as property owned by the Erie, who had commissioned the maps, however a very similar shape is recognizable in the abandoned rail bed where it meets Williams Street. If no better feature was available, this intersection could also be used as a control point.

When georeferencing modern aerial and satellite imagery, one of the more common features used to select control points is a corner of a recognizable building present in both the source and reference images. Although the valuation maps often had buildings and other structures recorded, in the time between the drafting of the maps and when the modern imagery was captured, most of these structures are no longer present. Even in the event that a building could be matched between the maps and the imagery, it was often too small or there had been significant changes to the footprint of the structure which reduced the confidence in an accurate match to any corner. Surprisingly, there were many of the larger structures, which had been demolished, that offered a better option. While the buildings were no longer present, the concrete foundations were. The nature of these foundations made them easy to spot for two reasons. First, the light color of the foundations made them stand out in contrast to the surrounding ground. Secondly, even if the area had surrounding overgrowth, the geometric shapes were easily discernible as manmade. For instance, major track facilities such as a roundhouse turntable leave distinct artifacts on the ground. A turntable is a large rotating platform that locomotives would pull on to and be redirected to one of bays of the roundhouse for storage and repairs. Figure 5-5 shows a turntable as represented on the valuation maps (a), and what is left of the turntable and its radiating tracks long after it had been removed (b). 


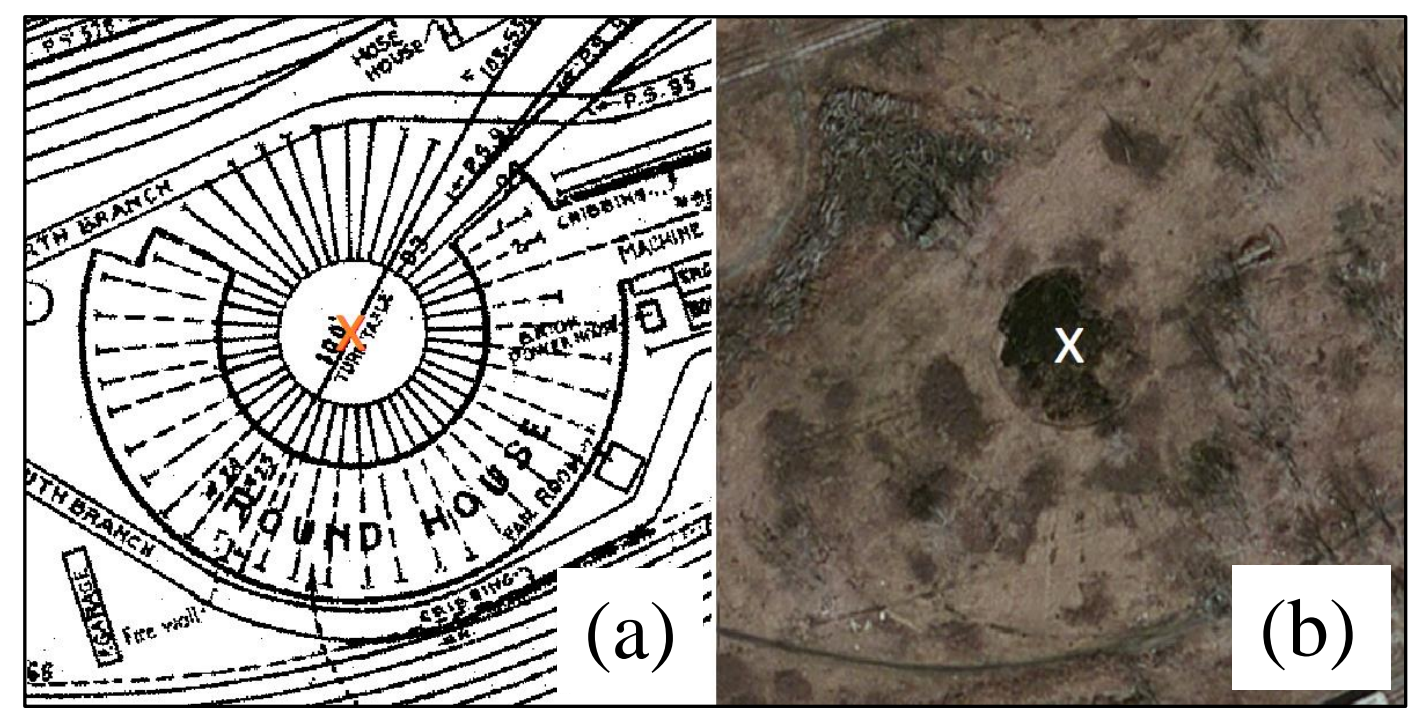

Figure 5-5. The left (a) is a roundhouse as it was depicted on the original 1918 Erie Railroad Valuation map, the right (b) is what remains of the same round house as it appears in modern imagery.

The last method employed in finding control points in difficult maps was to use the shared reference markings within a pair of maps: one georeferenced and one to be georeferenced. There were a number of notation marks used by the railroads when drafting these maps. For the purpose of this project the two important ones were the mileposts (Figure 5-6) and match marks (Figure 5-7). Match marks were corresponding sets of lines placed on consecutive maps that showed how they should line up with each other. These lines were not reliably of identical length, but often they would intersect surrounding features that were present in both maps. Because the match marks were perpendicular to the track they maintained the geometry between the match mark and intersected features on both maps. These intersections would then be used as control points. At best, it was possible to acquire two of the three required control points in this manner. A control point at the opposite end of the map could not be derived from previously georeferenced maps and, in most cases, there were not any distinct map features to tie to the imagery. 


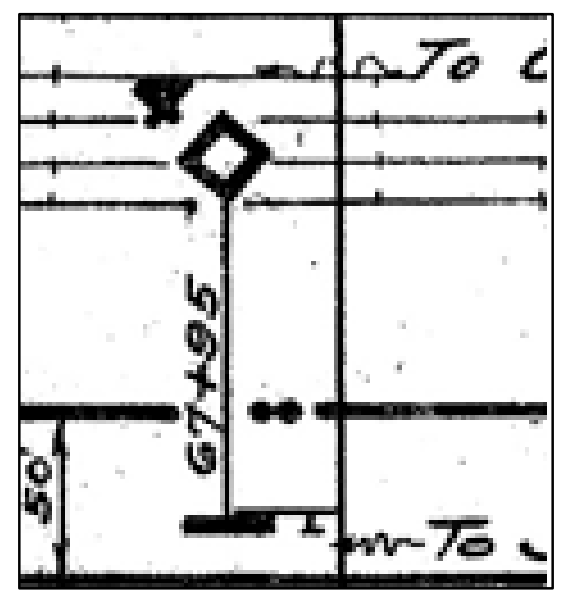

Figure 5-6. Example of a milepost symbol

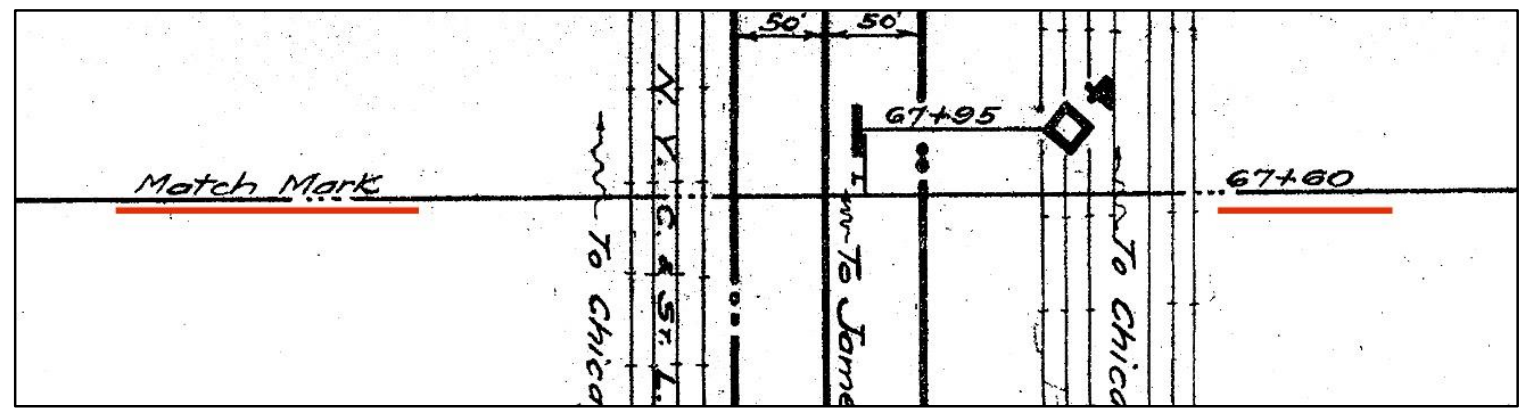

Figure 5-7. Close-up of a match mark from valuation map V15.NY.008

The second set of usable markings within the maps were the milepost symbols. Very often there was a matching milepost that existed in two consecutive maps. If one of the maps had been georeferenced, then that mile marker could be used as a control point for the second map. Starting from the mile marker in the georeferenced map, one mile was measured along the tracks present in the modern reference aerial imagery. It was then possible to place a set of control points using the second mile marker and the previously measured point. This method was used only when no other option was feasible because it relied on two factors that added a greater opportunity for error.

The first factor was the assumption was that the georeferencing of the valuation map being used as a reference had been accurate enough to place the mile marker in the correct place. If there was any error in the reference valuation map, it would likely be propagated in the next georeferencing, compounding the error for each consecutive valuation map.

The second factor was in the ability of the operator to correctly place the control point for the unrectified mile marker. The method worked best on straight sections of track. This approach was cumbersome, relying on multiple manual steps. The operator would first select the measurement tool, click on the first mile marker, and measure out to a mile. When using the measure tool in the ArcGIS interface, selecting any other tool, such as create feature or place control point, clears the measurement points. Because of 
this, the operator had to physically mark the point using a dry erase marker on the monitor, then select the edit features tool and add in the point feature, based on the physical mark. Once the point feature was added, the operator would return to the unrectified valuation map, add the first control point to the mile marker as drawn in the map, and then add the second control point to the point feature. Because of the likelihood of human error within these steps, there was a significant risk of inaccuracy. Within the scope of this project, this method was accurate enough. However, in an expansion of this project a more reliable method should be developed.

Once enough control points were collected for a map, the operator would do a visual inspection of the result to ensure the transformation resulted in a reasonable match between the valuation map and the features discernable on the imagery. This was accomplished by setting the transparency of the valuation map layer to 50\%, allowing the operator to see how the features within the valuation map aligned to their counterparts in the imagery layer (Figure 5-8). The operator would then use his judgment in determining whether the alignment was acceptable. Often, even if the transformation was not acceptable, the initial overlay revealed more suitable correlating features that might not have been obvious when comparing the maps and the imagery separately. If necessary, the operator would replace control points and repeat the process until an acceptable alignment was achieved.

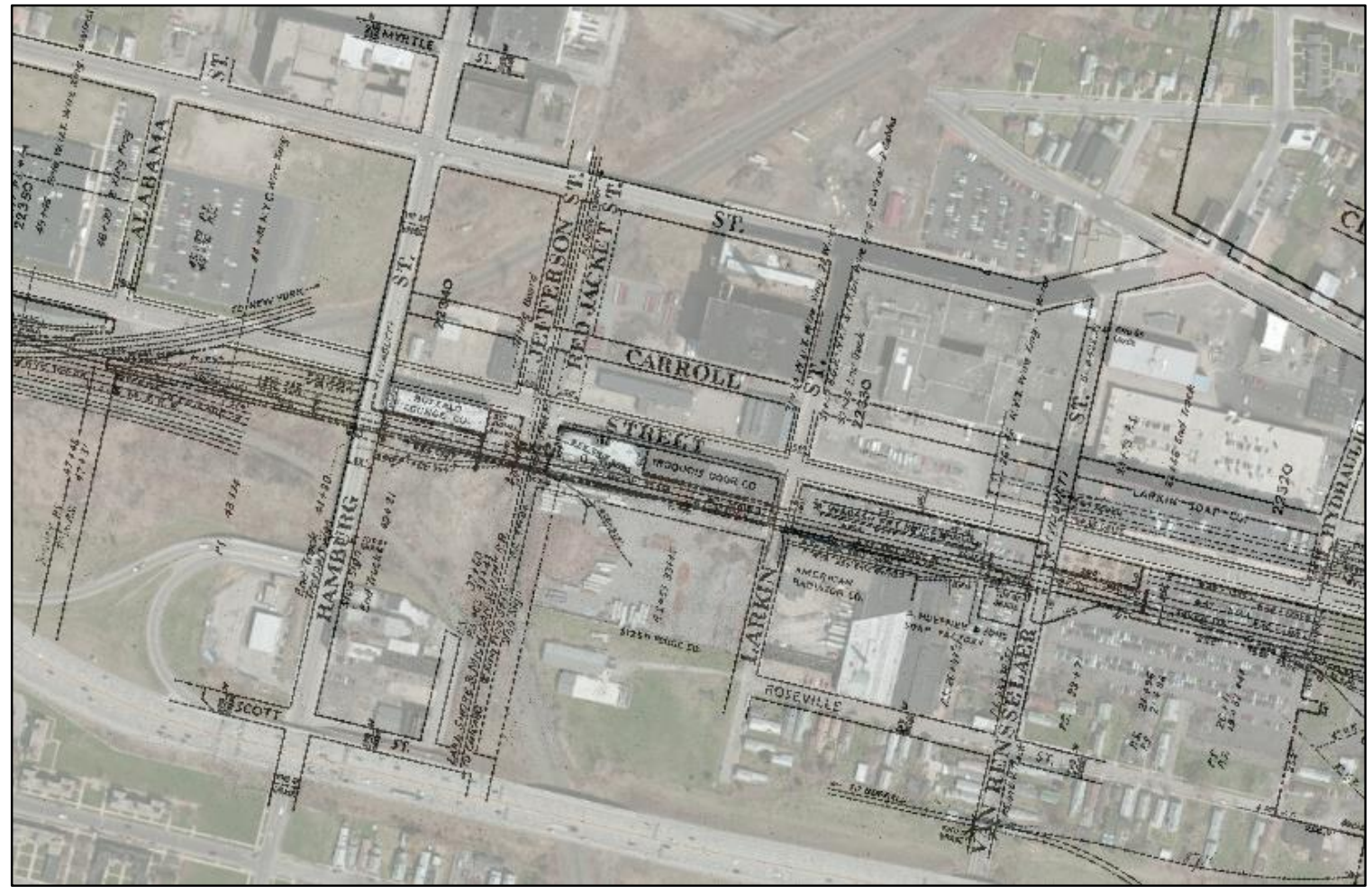

Figure 5-8. Illustration of transparent valuation map layer overlaying imagery. 


\subsection{Preparing Data for Sharing}

Once all of the valuation maps had been georeferenced, they had to be consolidated into a single dataset within the geodatabase. This was done through the Create Mosaic Dataset tool which is part of the Mosaic Dataset toolset (Figure 5-9). This required defining the target geodatabase (a), assigning it a name (b) and setting the coordinate system (c) to the one used for this project, namely WGS_1984_Web_Mercator_Auxillary_Sphere.

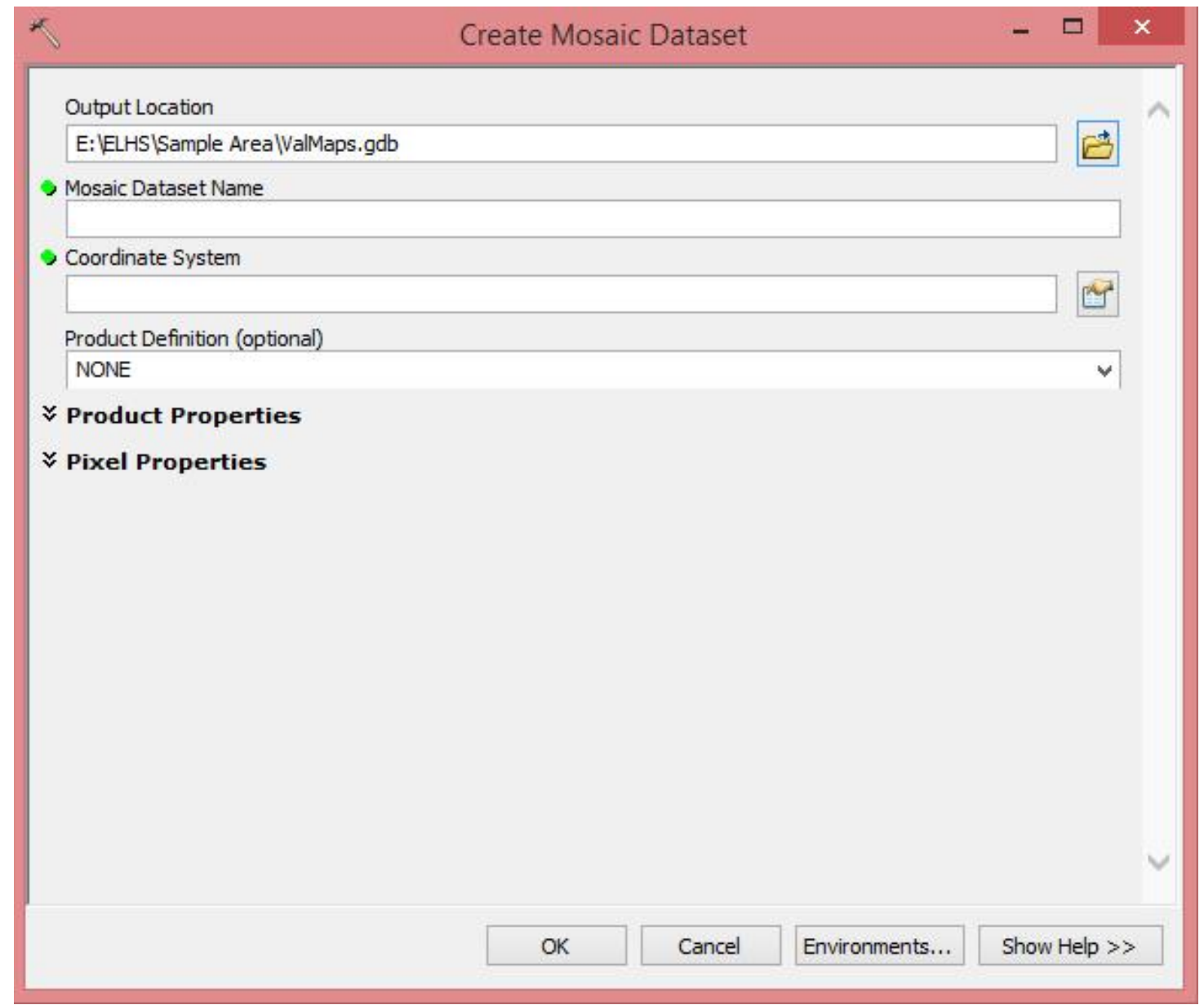

\section{Figure 5-9. Create Mosaic Dataset tool}

Once the mosaic dataset was created, it needed to be populated with the georeferenced valuation map rasters. This was done using the Add Rasters to Mosaic Dataset tool (Figure 5-10). The operator defines the target mosaic dataset (a), selects the raster type (b) and selects the individual valuation map rasters (c). 


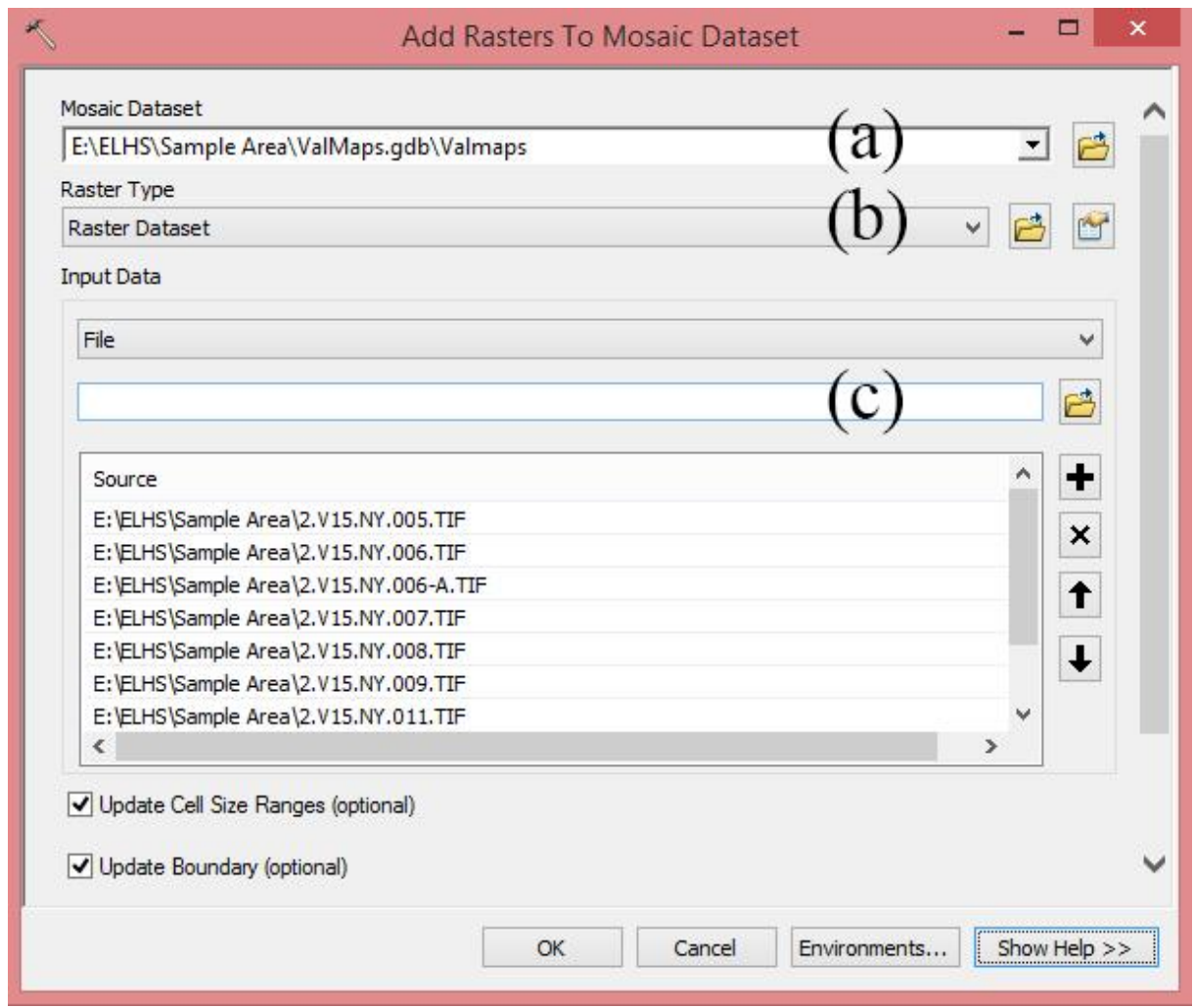

\section{Figure 5-10. Add Rasters to Mosaic Dataset tool}

Along with the mosaic image, the tool also creates a footprint polygon feature class representing the minimum bounding rectangles for each of the valuation map rasters (Figure 5-11) as well as a feature class with the bounding polygon for the entire raster mosaic. The footprint feature class holds metadata about the rasters, including the paths to each of the raster files included in the mosaic dataset. For the purposes of this project, it was preferred to have footprints for each valuation map that conformed to the actual outline of the image. The solution was to create a separate polygon feature class. A separate polygon for each valuation map raster was created (Figure 5-12) using the create features tool. 


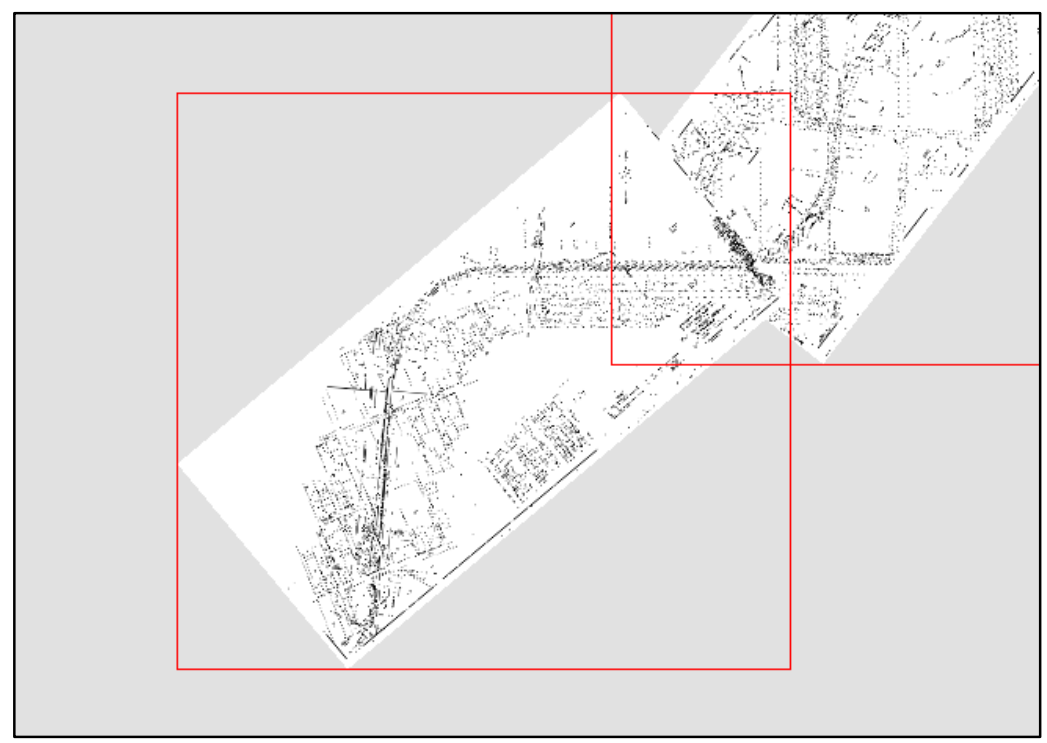

Figure 5-11. Minimum bounding box outlines in red

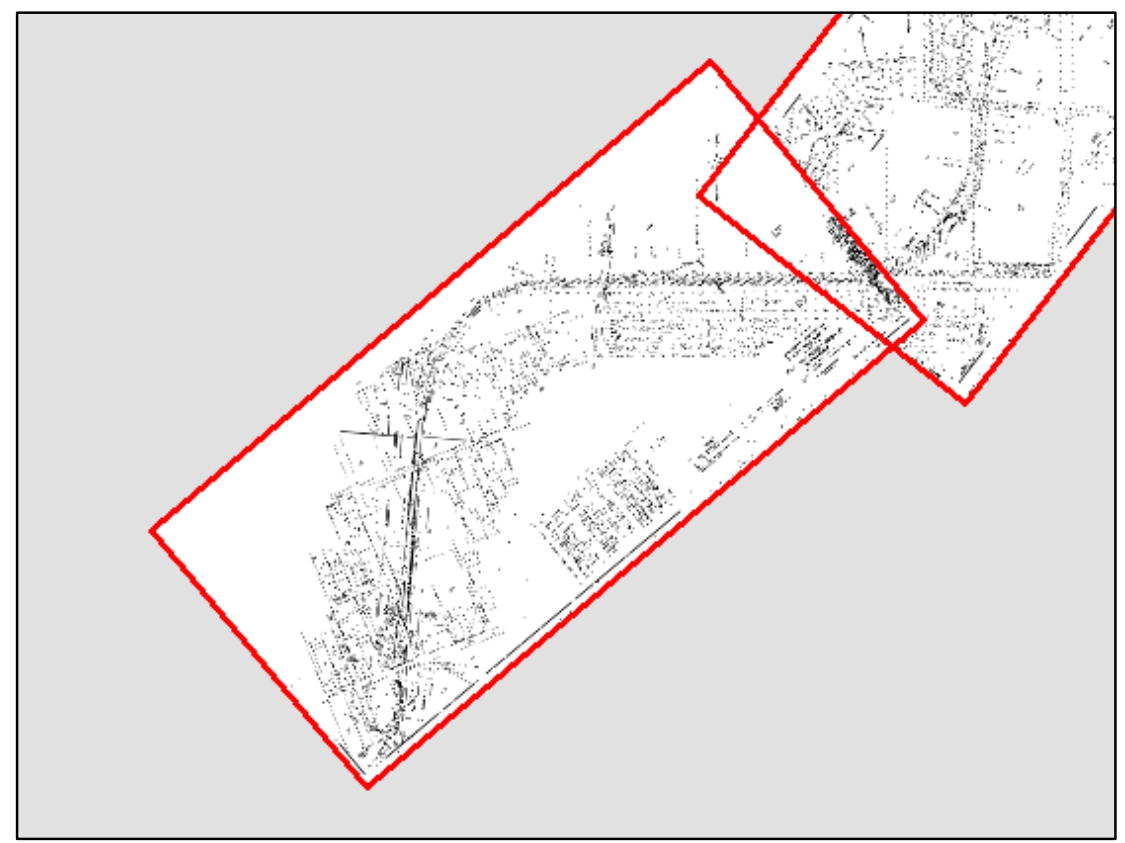

Figure 5-12. Manually digitized outline polygons

The primary function of the outline polygons was to visually delineate the geographic extent of each valuation map, especially in cases where there were multiple maps overlapping. The outline polygons also held the attributes of the individual valuation maps they outlined, which were taken from the reference notation of the valuation maps (Figure 5-13) and manually entered for each polygon. These metadata could then be queried and used within the web application. 


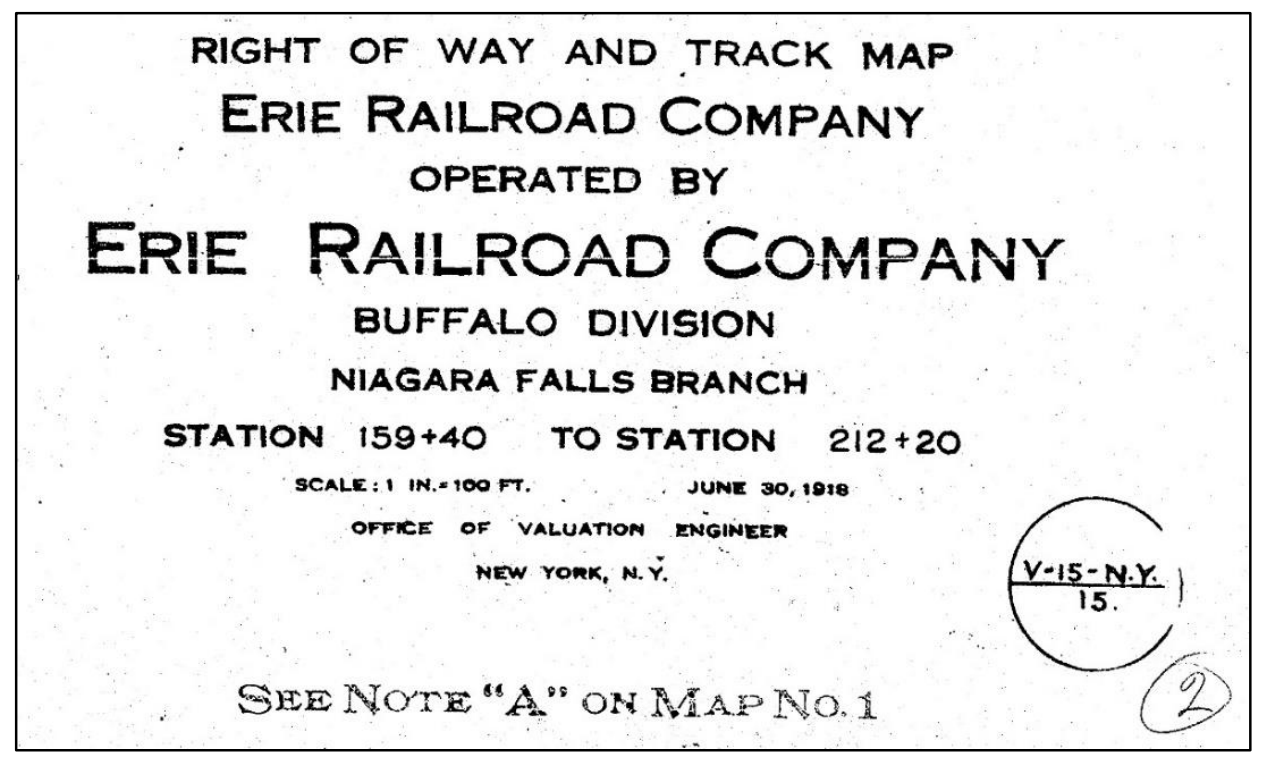

\section{Figure 5-13. Valuation Map reference notation}

The archival materials, in this case photographs, were the final features that needed to be loaded into to the geodatabase. This was handled by creating a new point feature class. In order to load the archival materials this point feature class had to have attachments enabled, which was done using the Enable Attachments tool in ArcGIS. By running this tool on the archival materials feature class, it enabled the functionality for adding attachments, as well as creating an attachments table, where each attachment was stored internally in a binary large object (BLOB) field. The tool also created a relationship class to relate the attachments table to the feature class. The relationship was one-to-many with the archival materials feature class as the origin feature class and the attachments table as the destination table. This allowed multiple archival materials to be associated with a single point feature. The configuration of the table and relationship class were handled automatically by ArcMap. Once the archival materials feature class had attachments enabled, it was a matter of placing point features and manually assigning attributes and attaching the appropriate file.

\subsection{Summary}

This chapter described the challenges the project team faced in georeferencing the 1918 Erie Railroad valuation maps, as well as the solutions that were employed. It also discussed the reasoning behind the selection of a transformation method. Finally, this chapter described the processes used for incorporating the valuation maps, outline polygons, and archival materials into the geodatabase. Chapter 6 will discuss how these elements were deployed for the Erie Lackawanna Historical Map Index web application, as well as the development of the web application's user interface. 



\section{Chapter 6 -Web Application Development}

This chapter describes the development process for the Erie Lackawanna Historical Map Index web application. Section 6.1 discusses the steps taken to publish services from ArcGIS for Desktop to be used in the web application. Section 6.2 goes into detail about the work flow and methods used to develop the web application.

\subsection{Service Publication}

The first step in making use of the mosaic dataset and feature classes as described in Chapter 5 was to move them to a database server. The project team did the georeferencing and feature creation locally in ArcGIS for Desktop. However for the feature classes to be accessible as feature services, they had to be hosted on an ArcServer running ArcSDE.

The original Tagged Image File Format (TIFF) files for the valuation maps were copied to a folder on an ArcServer, making sure to include all supplemental transformation files. In that same folder a geodatabase was created, to which the valuation map mosaic dataset was exported from ArcGIS for Desktop. The feature classes for the outline polygon features and the archival materials point features were exported to an SDE geodatabase also hosted on the ArcServer. The SDE and database were set up and configured by the University of Redlands system administrator. Once the data were migrated, the various services could be published.

The services were published from the ArcServer to the University of Redlands web server. The raster mosaic dataset was published as an image service and the two feature classes - the valuation map outline features and the archival material features - were published as feature services. The default service when publishing a feature class is as a map service. In order to change it to a feature service, the service must be registered with a SDE geodatabase and have "Feature Access" enabled under the Capabilities tab in the Services Editor.

An issue arose in the publishing of the image service. The individual rasters would disappear as the user zoomed out at different scales, with the smaller rasters being the first to disappear. The project team discovered that editing the maxPS field for each of the rasters in the mosaic dataset to a matching number resulted in a consistent visibility range. The maxPS field describes the maximum pixel size in meters present in a particular raster. Originally, each valuation map scan was roughly the same dimension in terms of pixel width and height; however, the original physical maps were in different scales. Once the scanned map images were georeferenced, the larger scale maps were scaled down so that the individual pixels of the image covered a smaller geographical area than the smaller scale map, resulting in greatly differing maxPS values. As the scale of the data frame became smaller, rasters with smaller maxPS values would no longer be displayed beyond certain thresholds. Each map had its maxPS set to 40, artificially inflating the data to a standard range of 0 minPS (minimum pixel size) to 40 maxPS to ensure that all rasters would be displayed at the same scale interval. 


\subsection{Web Application Development}

Once the services had been published, they could then be used by a client application. The script for the Erie Lackawanna Historical Map Index (ELHMI) web application made use of HTML, CSS, Dojo toolkits and ArcGIS API for Javascript. At the 2014 Esri Developers Conference, there were many panels that included comments and discussions of Esri as a company moving toward JavaScript as their primary web GIS scripting language. Additionally, in February of 2014, there was an official post to Esri's developer's blog that announced that Esri would be aggressively pushing developers towards JavaScript and that the Flex and Silverlight APIs would be receiving bug fixes only, with no foreseeable updates to functionality (Powell, 2014). Additionally, JavaScript is supported by the major web browsers, requiring no additional software or plug-ins, making it compatible on a wider variety of platforms. Because of these clear trends, and in the interest of making the web application as compatible as possible, JavaScript was chosen as the scripting language for handling the functionality and interactivity of the web application.

The ELHMI was designed as a single page application (SPA) developed using a combination of HTML, CSS, and Javascript. It made use of a number of resources such as the Esri ArcGIS API for JavaScript and the Dojo toolset. A SPA is a web application comprised of a single web page and allows users a variety of interactions without leaving that page. The interface of the application was comprised of two primary sections (Figure 6-1): the map viewer (a) and the side bar (b). The side bar contains the Layers menu, which contains layer visibility tools (1). Also in the side bar are two tabs (2), Maps and Materials, which display the results of the Search by Extent tool, which is accessed using the button locate within each tab.

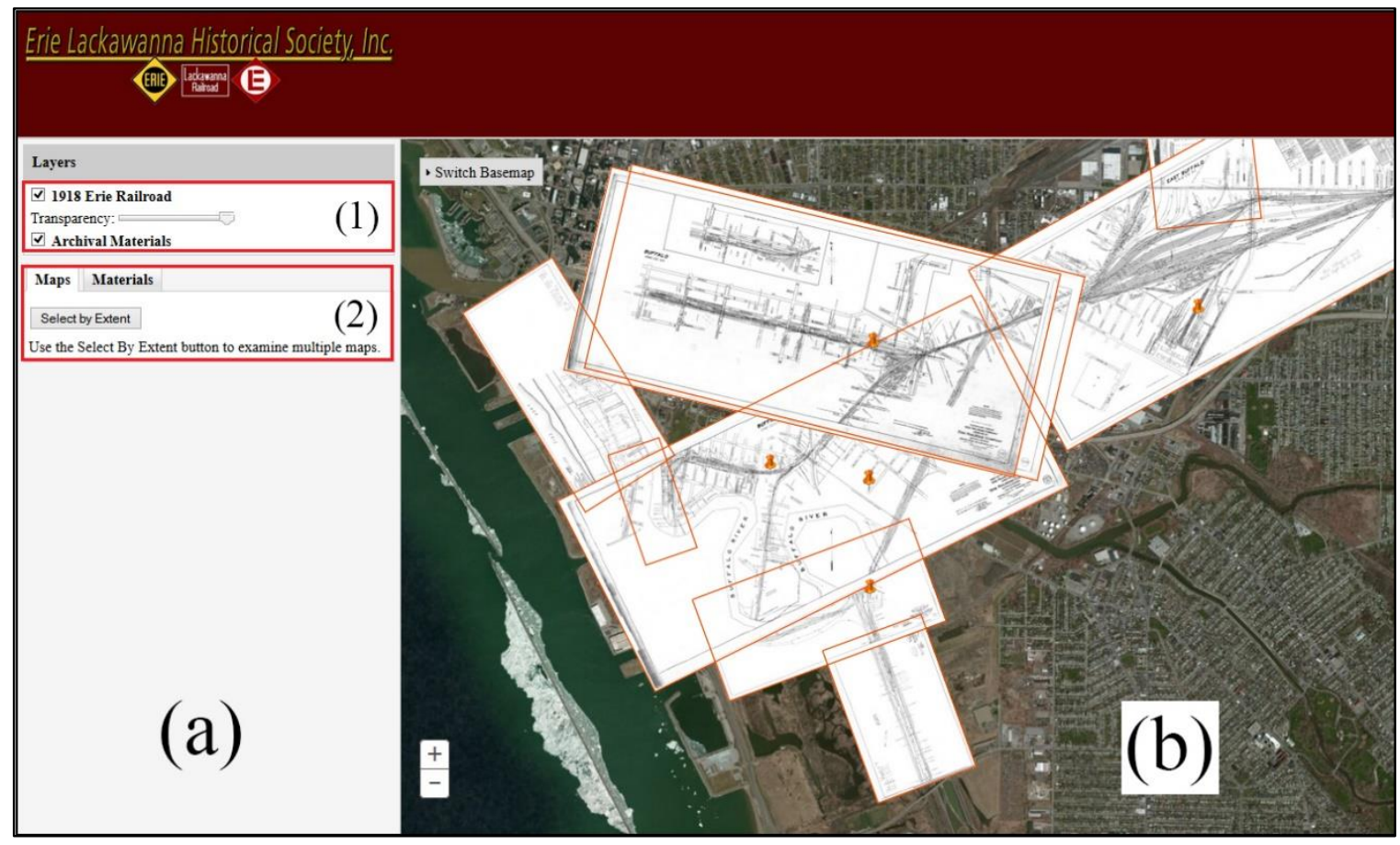

Figure 6-1. Overview of ELHMI web application 


\subsubsection{The Map Viewer and Layer Controls}

The primary element is the map viewer. The map viewer was constructed as a map widget using the Esri ArcGIS API for JavaScript. The constructor required defining which HTML container it would be held in, as well as defining a number of optional parameters. For this web application, the extent and center properties were configured so that the map would initially load with the frame filled by valuation maps, and the initial basemap attribute was set to "satellite," which brought in the standard Esri satellite basemap. Once the map widget had been configured, a scalebar widget was constructed and added to the map widget.

The next step was to construct the image and feature service layers, and add them to the map widget. The first layer was the image service for the valuation maps, constructed as a new ArcGISImageServiceLayer with the URL to the image service hosted on the University of Redlands web server as the source. All other parameters were left as default.

Two instances of the class of FeatureLayer were created. One for the map outlines feature class, which is the primary operational layer, and the second for the archival material point features. Both had their mode set as "MODE_ONDEMAND" which meant that the individual features would be retrieved and displayed as they were needed, depending on the extent of the map viewer. Both also had their outFields configured to include all their attribute fields, which would became important when they were queried by other functions in the application. The infoTemplate for each layer was defined with its own PopupTemplate, since the popups for each layer would display different information. In addition, the archival material's hasAttachments property was set to true, so that the popups for that layer would include a link to the attached materials such as photo or scanned document. Once the layers for the valuation maps, outlines, and archival materials were constructed, they were all added to the map widget using the addLayers() method. The Map Viewer was operational at this point.

Once the map viewer widget and layers are loaded, the addOpacityControl function is fired. This function creates a slider that allows a user to adjust the transparency of the valuation maps image layer. This was not a widget from the ArcGIS API of JavaScript, rather it was a functionality developed by Piotr Zalewa and Oskar Krawczyk, found at JSFiddle (2014). The function makes use of the HorizontalSlider Dojo input form and links it to the setOpacity method of the image layer. The minimum value for the slider is set to 0 and the maximum to 1 , corresponding to the possible range of the opacity property for the image layer. The event listener onChange fires when the slider is moved, and passes the current value of the slider form to the callback function, which in turn passes the value to the setOpacity method of the image layer. While the creators originally have the slider as a widget within the map container, the slider was moved to be included in the Layers tools.

The Layers tools also included functionality for toggling the different layers on and off, in the form of check boxes. Again, this was not an out-of-the-box widget included in the ArcGIS API, but was instead a custom scripted functionality developed by the project team, taking inspiration from Zalewa and Krawczyk's opacitySlider. The setVisible function makes use of the checkbox input form, and links the Boolean check property of the checkbox to the setVisibility method of the layers. Two check boxes were created, one for the valuation maps and outlines layers and another for the archival materials layer. An 
event listener was set up for each check box, and on "click" the setVisible function would fire, checking the value of each check box and assigning it to the visibility property of the corresponding layer(s). The decision to include the valuation maps and outlines as a single layer was based on the fact that the two layers operate functionally as a single entity.

In the map viewer, there is one more tool that allows users to adjust the appearance of the map widget; the BasemapGallery widget. This defines which map the gallery would be switching the basemap for, and specifies which HTML element the widget would be held in.

\subsubsection{Select by Extent Tool}

In addition to the Layers tools, the side bar also contains two tabs: Maps and Materials (Figure 6-2). At the top of each tab container is the Select by Extent tool (Figure 6-3), which allows a user to query multiple maps and archival materials based on a userdefined extent and have them displayed. Maps within the defined extent are displayed as a list within the Maps tab, and archival materials are displayed in the Materials tab.

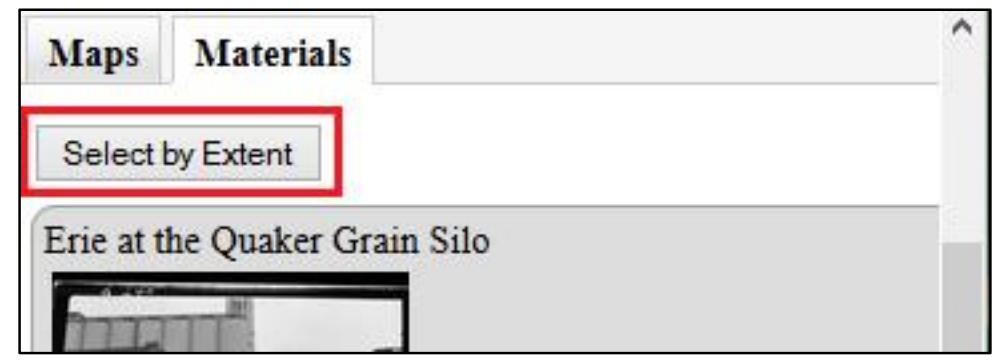

Figure 6-2. Select by Extent tool 


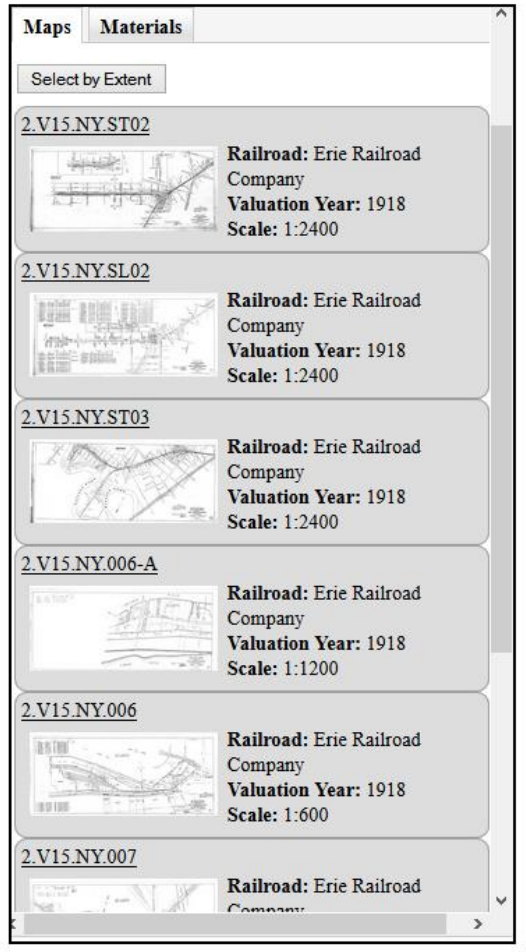

Maps List

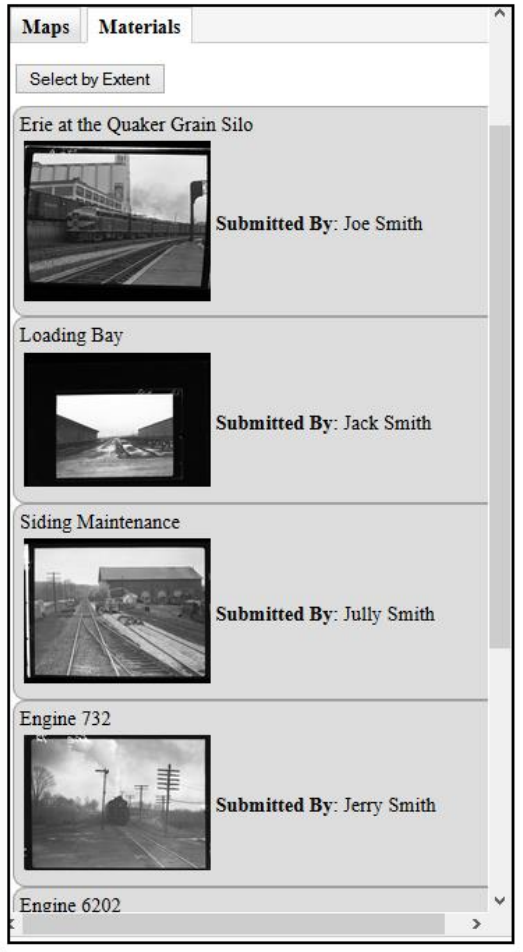

Materials List

\section{Figure 6-3. Maps and Materials lists}

Of all of the functions in the ELHMI, the Select by Extent tool required the most development and was made up of a number of interacting processes. The first process begins when the user clicks the Select Extent button. Upon clicking the button, an event listener fires the inExtent function which, in turn, constructs and actives a new Draw [Extent] toolbar. This toolbar disables the navigation functionality that allows the map to be panned by clicking and dragging within the map frame, and enables drawing, allowing the user to click-drag an extent rectangle to specify their area of interest. Once an extent rectangle is specified and the mouse button is released, the "draw-end" event listener fires the callback and passes the extent rectangle, as a geometry object, through to a nested query function. This function first creates a new query object, and then sets the geometry of the object to that of the extent rectangle object and the outfield to ["*"]. Setting the outfield to [“*”] captures all fields from the queried feature layer to the feature set created by a QueryTask using that query object. As mentioned in section 6.2.1, it is important to make sure that the outfield property on the feature layer that is to be queried is specified, as either specific fields or [“*”] for all field. This was an issue the project team ran into when first trying to query the valuation maps and archival materials feature layers.

Once the query had been configured, separate QueryTasks were constructed for valuation maps and archival materials feature layers, which required passing in the URL for the corresponding feature service, and then executing the QueryTask. The QueryTask required passing in the previously configured query object, which would create a feature 
set containing all features within the defined extent, as well as specifying the call back function to execute on that feature set. Each of the QueryTasks for the two layers used the same query; but had separate call back functions, getMaps for the valuation maps, and getMats for the archival materials. Each function first calls a previously built container that it will exist in, and saves it to the variable mapList or matList (collectively List). It then loops through each feature in the feature set and creates a new list item that will be appended to the List. It then parses key feature attributes to local variables set up within the loop. These variables were next concatenated into an HTML string that is assigned to the innerHTML of the new list item. Finally, it appends this list item to the List.

The purposes of both getMaps and getMats were functionally the same: retrieve a set of attributes and populate a list item. However, they each need to be programmed slightly differently. The major difference between the two functions was the method for handling the images related to each feature layer. In the case of the valuation maps, the map scan files were hosted in a folder structure, and each feature had two attribute fields, one holding the URL for the full sized image, and the other for the low resolution thumbnail image. For the archival material, the files were saved in a BLOB field within the attachments table related to the feature layer. This required the .queryAttachmentInfos method, which queried the attachments table based on the objectId attribute of a feature and returned the URL for the attachment. Each function has its output pointed to a different tab in the sidebar: getMaps to the Maps tab and getMats to the materials tab.

\subsection{Summary}

This chapter looked at the work flow of getting the feature and image services published from ArcGIS for Desktop and making them available for use on the web. Also discussed were the major functionalities and how they were developed, as well as some challenges the team had to work with. Chapter 7 will look at the application from the user's point of view and discuss use cases. 


\section{Chapter 7 - Results and Analysis}

This chapter looks at the results of the web application development. Section 7.1 explores two possible use cases for the application. Section 7.2 offers time estimates and recommendations for the expansion of the system to include the full collection of 3,600 1918 Erie Railroad valuation maps

\subsection{Use Cases}

\subsubsection{Historical Facilities}

In this scenario, an environmental justice team is looking for the locations of facilities which may have used any hazardous materials. They want to know if any of the facilities are still in existence, and if not, they want to know if anything has been built on the sites since.

Upon loading the website, the first thing the user does is zoom to the area she is interested in investigating (Figure 7-1). This is done by either using the zoom buttons (highlighted in a red box in the lower left of the map viewer) or by rotating the mouse scroll wheel. Once zoomed to a level at which the details are legible, the user can pan by depressing the left mouse button, and dragging within the map viewer.

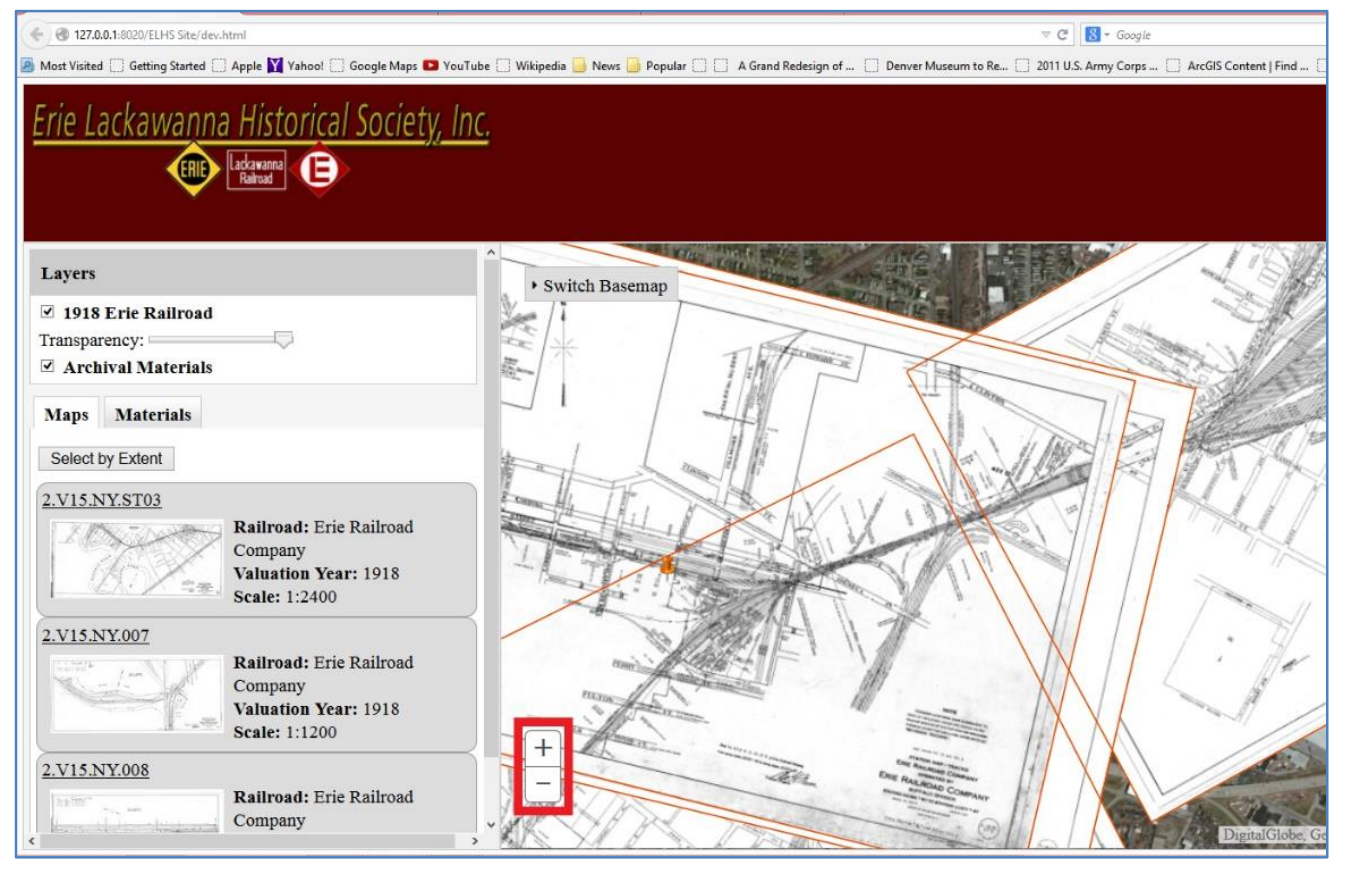

Figure 7-1. View zoomed by users

The first facility found is a roundhouse, where locomotives would be stored and repaired (Figure 7-2a). Maintenance on locomotives, such as painting, cleaning and lubrication, often included the use of hazardous chemicals, which could leach into the ground. The user is interested to see what the area the roundhouse sat on looks like in 
modern imagery, and has the option to toggle the valuation map layer on and off (Figure 7-3a) to do a visual comparison. However, if he wanted to get a better sense of how the roundhouse overlays the imagery (Figure 7-2b) he has the option of adjusting the transparency of the valuation map layer using the transparency slider (Figure 7-3b). In this case he finds that the round house has been removed, but find that there is some artifact of the turntable left in the center. The immediate area seems to be largely empty, surrounded by what appears to be industrial properties and some residences.

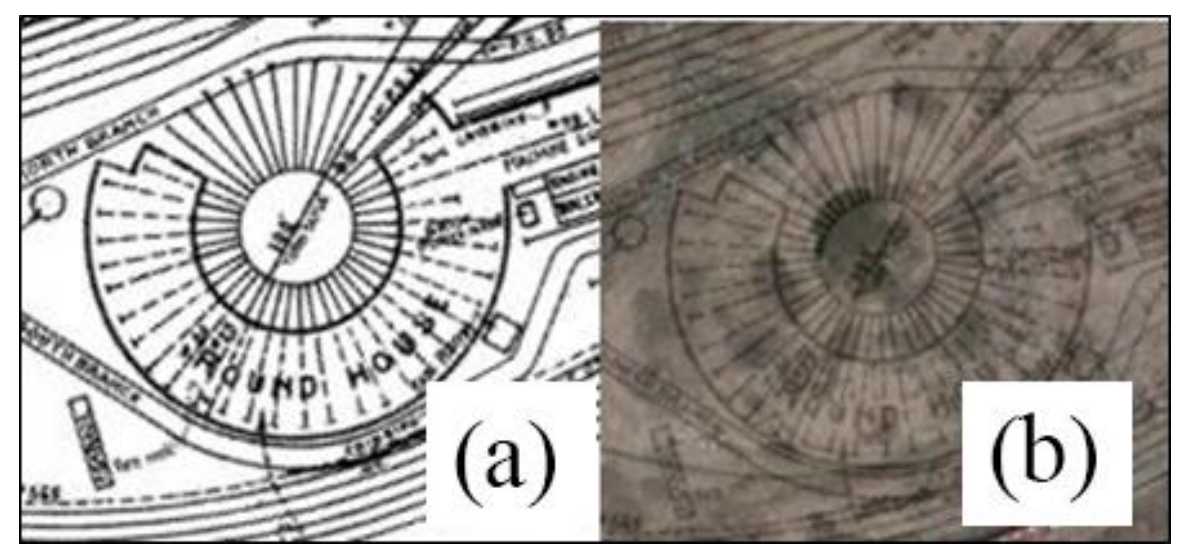

Figure 7-2. Close up of Roundhouse

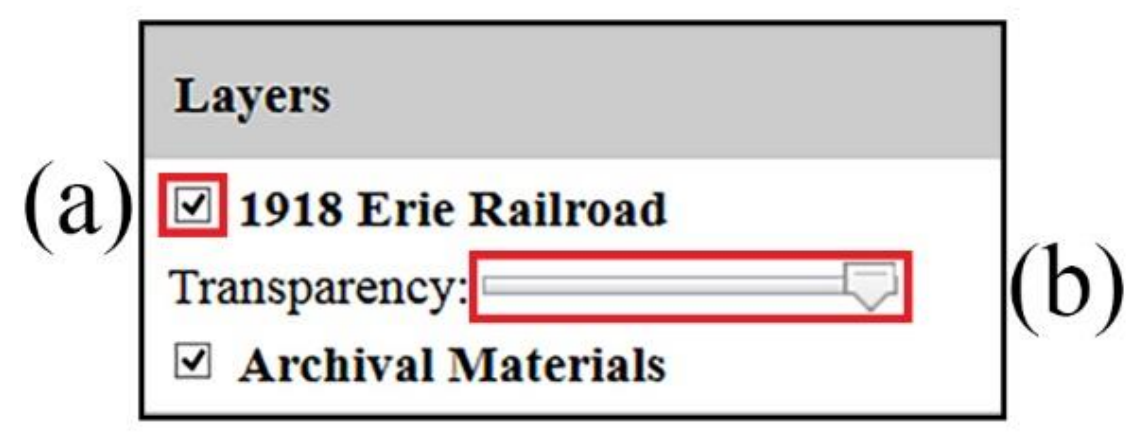

Figure 7-3. Layer visibility controls

The next facility the team finds is the American Agricultural Chemical Company (Figure 7-4a). Upon investigating the underlying imagery, the team finds that where the grounds of the company had once been, there is now a park with closely surrounding residences (Figure 7-4b). This appears to be a potentially high risk area, and the team decides that it warrants further investigation to determine what cleanup measures were taken during the redevelopment of the area. 


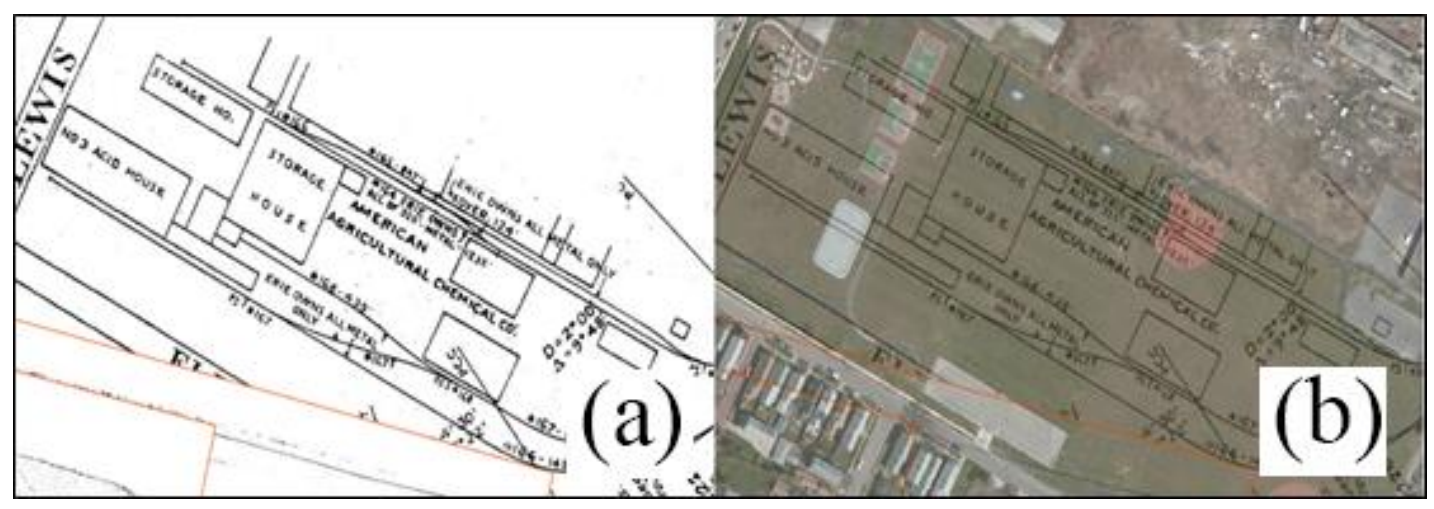

Figure 7-4. Close-up of American Agricultural Chemical Co.

\subsubsection{The Model Railroad}

In this scenario a model railroader wants to reproduce a stretch of track in the Buffalo area. He is looking for references to help create a realistic recreation of the tracks as they were in 1918, as well as the surrounding features. He comes to the Erie Lackawanna Historical Map Index to access the maps of the area of interest, as well as to find historic imagery that will help him get a sense of what the area looked like.

Upon loading the webpage, the first thing the user will do is pan and zoom to find the area he is interested in. If he clicks on an individual valuation map, he will be presented with a popup (Figure 7-5) that will include a thumbnail of the map in its original format, along with the title of the map and a list of information about the map including a reference date, station extent, and branch and division information. If he wants to access the full-size file for the scanned valuation map he can click on the thumbnail and the full-scale valuation map will load in a new window. 


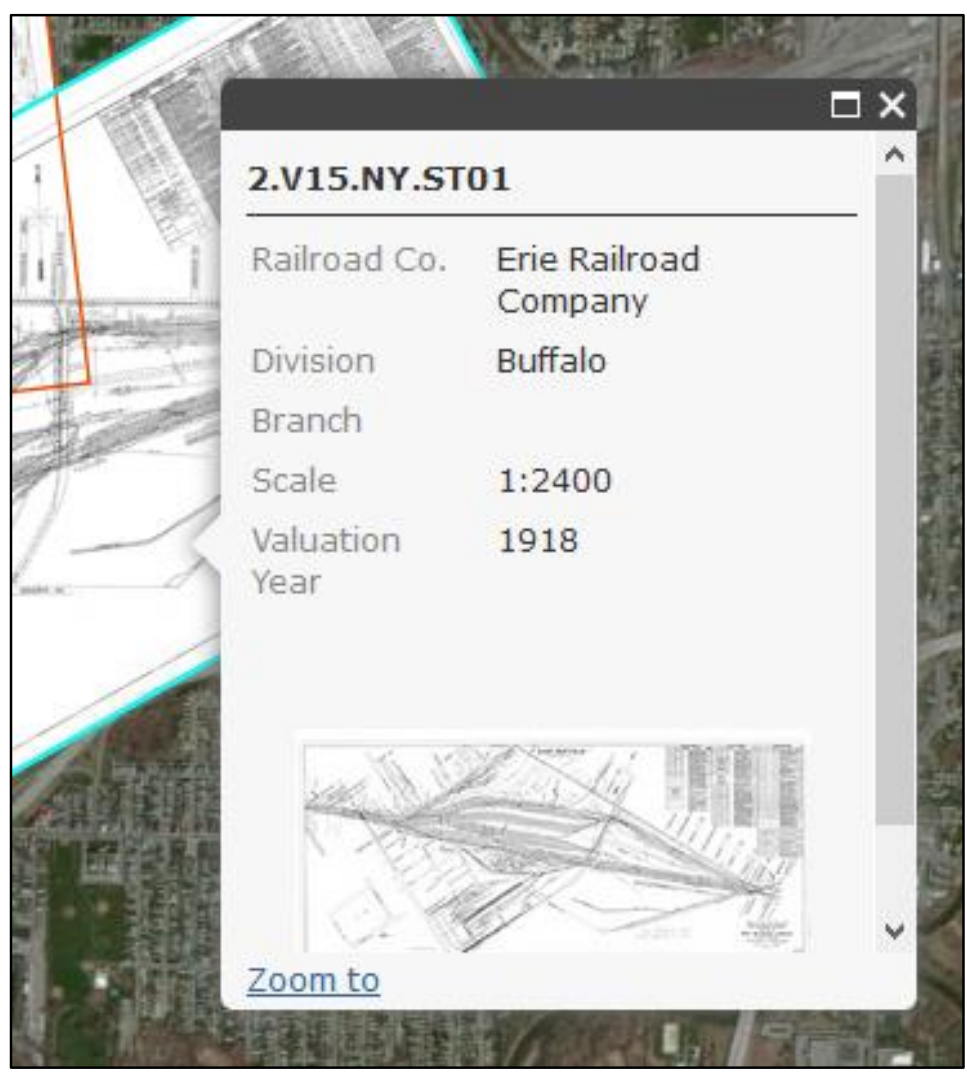

Figure 7-5. Close-up of map popup

To learn more about how the railroad and the surrounding area looked, the user can check out the archival materials represented as points on the map. Clicking the icon for an archival material attachment will present the user with a similar popup (Figure 7-6). However instead of a thumbnail there will be a link to the document and the information will contain different fields describing the document. If the user wants to access the attached document, he can click the link and be presented with the document in a new tab. 


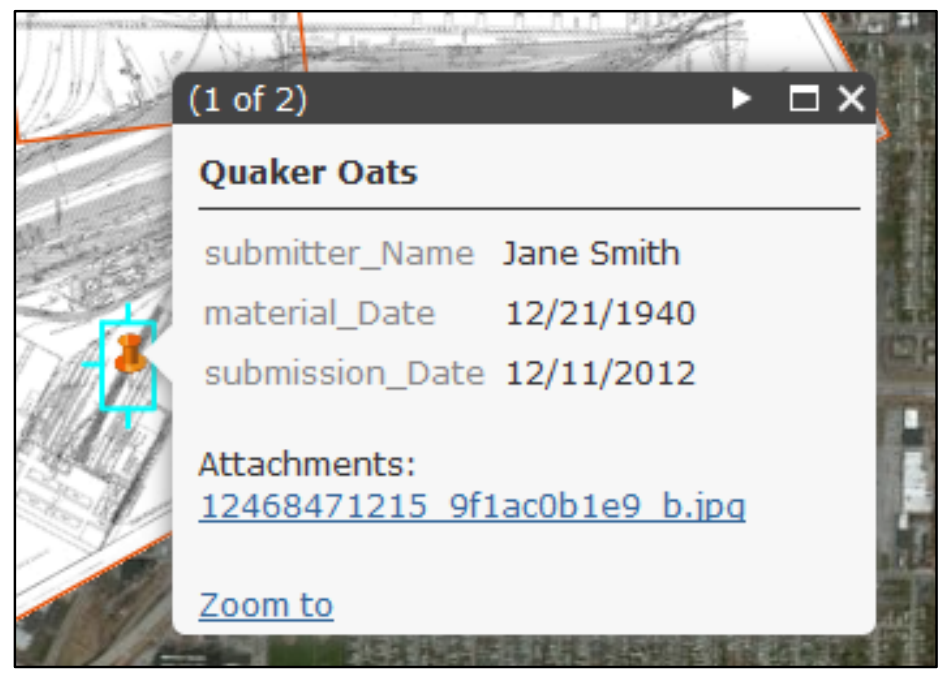

\section{Figure 7-6. Close up of archival materials popup}

If the user instead wanted to access all maps and archival materials for the area of interest, he can click the "Search by Extent" button, found under the "Maps" or "Materials" tabs (Figure 7-7), and drag an extent in the map viewer. Once he releases the mouse button, all maps and materials that intersect the extent will be listed in the "Maps" and "Materials" tabs in the left sidebar. This allows the user to quickly browse all relevant items. Each map and each item will have its own list item, with a similar format as the popups. When a user clicks on the thumbnail of either a map item or materials item he will be presented with the full-size image in a separate window. 


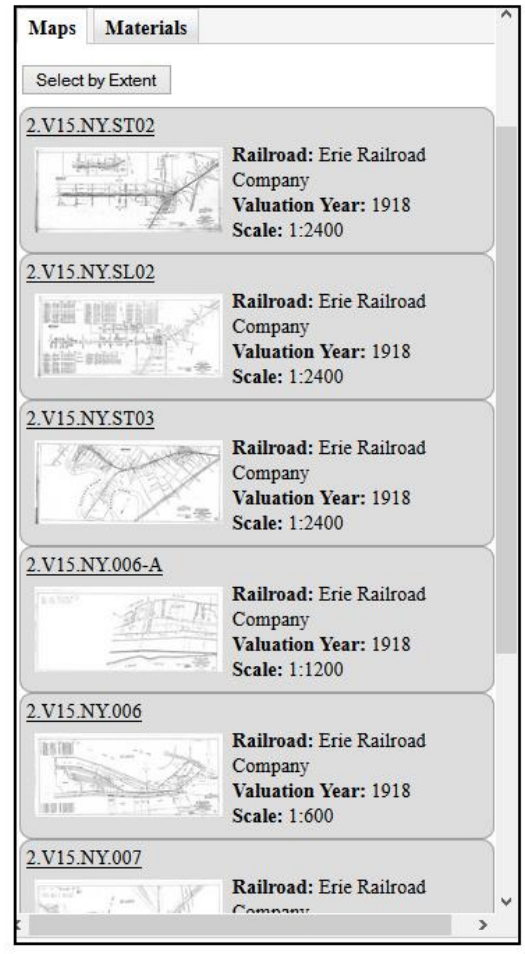

Maps List

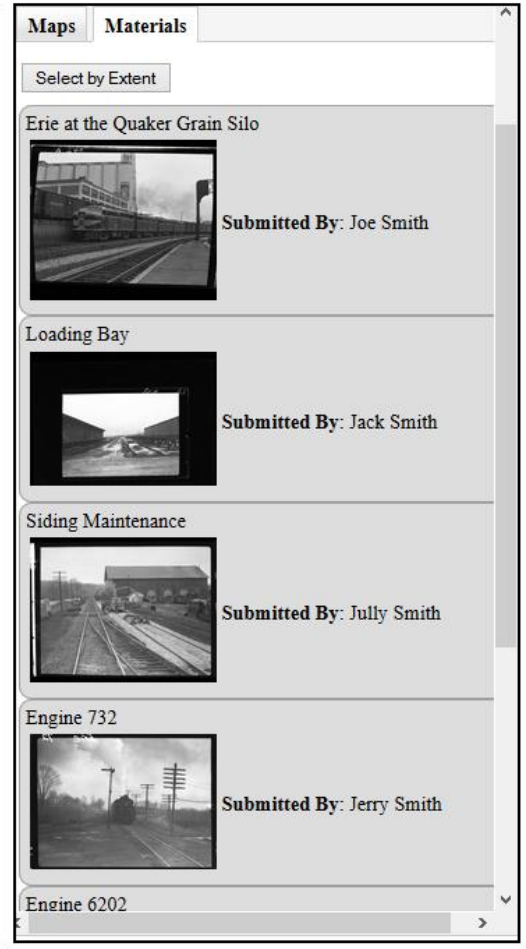

Materials List

Figure 7-7. Close up of "Select by Extent" and Map and Material lists

\subsection{System Expansion}

\subsubsection{Georeferencing of Maps}

The process of georeferencing took the project team an average of about 45 minutes per map. This included the selection of control points, gaining initial alignment, and then adjusting to refine the alignment. Timing varied depending on the difficulty of the particular map, with maps that had an even distribution of recognizable features requiring less time, and maps with few features or without an even distribution taking an hour or more.

After all fifteen maps were georeferenced, they were loaded all at once into a mosaic dataset. This took about 10 minutes per map, and included the time to set up the mosaic dataset. Adding more maps from the 1918 Erie Railroad Valuation collection, it will not require the creation of a new mosaic dataset, and it is recommended that additions to the mosaic be done in batch at the end of each georeferencing session.

In addition to adding the valuation maps to the mosaic dataset, each map had to have an outline polygon digitized and populated with the metadata. Each of these took approximately 10 minutes. The team attempted to do this after all the maps had been included in the mosaic dataset, however, since most of the maps overlapped, this made it difficult to identify some of the corners. Because of this each valuation map was reloaded 
into the data frame and handled one at a time. It is recommended to do this step after each map is georeferenced and before adding the map to the mosaic dataset.

Altogether, each map requires about one hour of work to be added to the Erie Lackawanna Historical Map Index. To include the full collection of the 1918 Erie Railroad valuation map collection would require an estimated 3,600 man hours to complete. If future projects can develop a means to automate any part of this process, it could result in a significant reduction in this time.

\subsubsection{Archival Materials}

For this project, the team used test data for the archival materials with the placement being arbitrary within certain guidelines. The time it would take to determine the true location of a document cannot be accurately estimated at this time, however, the process of creating a new point feature and populating it with information and attachments took a maximum of approximately five minutes per item. If the collection includes any materials that are geotagged, then the placement could be automated in future development, and it may be possible some of the metadata fields could be automatically parsed. One functionality that could be added is the ability for users to place materials directly through the web application, allowing them to add materials from their personal collections. It might also be possible to open the Erie Lackawanna Historical Society's (ELHS) collection of archival materials, once scanned into a digital format, to the user base, and have the users handle the placement of the materials. By crowdsourcing this work, it would take the time-cost off of the ELHS.

\subsection{Summary}

This chapter illustrated some of the possible uses of the Erie Lackawanna Historical Map Index. Additionally, it also offered some time estimates as to what would be required to expand the system to include the full collection of 1918 Erie Railroad valuation maps, and made recommendations for further development that could reduce that time. Chapter 8 will expand on this to include recommendations for future projects making use of the work done in the development of the Erie Lackawanna Historical Map Index. 



\section{Chapter 8 - Conclusions and Future Work}

The goal of this project was to develop a proof of concept demonstrating a methodology for making the Erie Lackawanna Historical Society's (EHLS) collection of 1918 Interstate Commerce Commission (ICC) railroad valuation maps accessible within a GIS, as well as exploring methods for disseminating these data. The project met these goals through the use of ArcGIS for Desktop for the georeferencing of the maps, creation of supporting layers, and the creation of the geodatabase, and the development of a custom web application using JavaScript, Dojo toolbox and the ArcGIS API for JavaScript, to make these data available to users online.

The work done in this project represents the first steps in extracting the information contained in ICC valuation maps. By georeferencing the maps, they can be used for visual comparison. However, if features such as rail centerlines, structures, and streets contained in the maps could be digitized, more advanced spatial analysis could be done. Future projects could look at developing a methodology for doing this digitization.

Using the work done for this project as a proof of concept, the client intends to pursue funding to expand the system to include the full collection of 3,600 valuation maps. Once work starts to make this a reality, it would greatly increase efficiency if some of the processes could be automated. One possibility could be to make use of the valuation section maps that depict how each map is oriented in the network. If the valuation section maps could be georeferenced, and each of the footprint rectangles digitized and cataloged, it might be possible to batch georeference the individual maps into an initial rough alignment that could then be adjusted for accuracy more quickly than handling each map individually.

The 1918 Erie Railroad valuation maps are not the only collection of their kind. The ELHS also has collections of revised valuation maps for the Erie Railroad from later dates, in physical form, and if they could be included in the system, it would allow historians to explore how the railroad changed over time. The ELHS also has maps for the Delaware, Lackawanna \& Western Railroad - many of which overlap geographically with the Erie Railroad - that could be included to offer a broader picture of the history of the railroad industry in the Northeastern United States. Other historical societies that have similar collections, and if a standardized methodology and naming schema were made available, these organizations could all publish web services that could be incorporated into a collaborative web application.

Similar projects could be done for other historical and archeological areas of study. One example would be to look at common iconography, such as fertility figures, from ancient cultures in the middle-east and Africa. By cataloging the locations of where the objects were found, as well as characteristics, it may be possible to map patterns of change and development not just through time but also geographic location, shedding light on how ideas migrated through a region. 



\section{Works Cited}

Ackerman, K. D. (2012, June 14). In 1968, a Wild Fraud to Dwarf Today's Political Sleaze. Retrieved November 15, 2014, from Bloombergview: http://www.bloombergview.com/articles/2012-06-14/in-1868-a-wild-fraud-todwarf-today-s-political-sleaze

American Railway Engineering Association. (1915). Conventional Signs. Chicago: American Railway Engineering Association.

Chauvin, D. (2008). A Digital Archive of Historical Railraod Property. Retrieved from digitalcommon.uconn.edu/uccgia_papers/5

Dempsey, P. S. (2012). The Rise and Fall of the Interstate Commerce Commission: The Tourtuous Path From Regulation to Deregulation of America's Infrastructure. Marquette Law Review, 95(4), 1151-1189.

Erie Railroad Historical Website. (2014). Erie History. Retrieved from ErieRailroad.org: http://www.erierailroad.org/erie-history/

Gregory, I. N., \& Ell, P. S. (2007). Historical GIS. New York, NY: Cambridge Univerity Press.

Knowles, A. K. (2002). Past Time, Past Place. Redlands: ESRI Press.

Locke, J. M. (2011). Visual Index to Historical Maps and Photographs in the Library (Masters thesis, University of Redlands).

McNamara, R. (2014). The Wall Street War to Control the Erie Railroad. Retrieved November 15, 2014, from About Education: http://history1800s.about.com/od/robber-barons/ss/Erie-Railroad-War.htm

Old Maps Online. (2014). Old Maps Online. Retrieved November 16, 2014, from Oldmapsonline.org: http://www.oldmapsonline.org/\#bbox=118.749032,33.773261,117.749276,34.173003\&q=\&datefrom $=1000 \&$ dateto $=2010$

Owens, J. B. (2007). What Historians Want. Retrieved from ESRI.com: http://www.esri.com/news/arcnews/summer07articles/what-historians-want.html

PBS. (2014). General Article: Interstate Commerce Act. Retrieved from PBS.org: http://www.pbs.org/wgbh/americanexperience/features/generalarticle/streamliners-commerce/

Pfeiffer, D. A. (1997). Riding the Rails Up Paper Mountain: Researching Railroad Records in the National Archives. Prologue Magazine, 29(1). 
Powell, J. (2014, February 21). Esri's Roadmap for Web Developers. Retrieved from Blogs.esri.com: http://blogs.esri.com/esri/arcgis/2014/02/21/esris-roadmap-forweb-developers/

Rumsey, D., \& Williams, M. (2002). Historical Maps in GIS. (A. K. Knowles, Ed.) Redlands, CA: ESRI.

Sakolski, A. M. (1915, March). Some Economic Problems of Railroad Valuation. The American Economic Review, 5(1), 12-26.

Titchenal, S. (2014). Research Prototype Material. NMRA 2014 Cleveland Convention Clinic. Cleveland.

University of Connecticut. (2011). New York, New Haven Hartford Railroad Valuation Map Index. Retrieved November 16, 2014, from UCON.edu: http://magic.lib.uconn.edu/mash_up/nynhhrr_index.html 


\section{Appendix A. Erie Lackawanna Historical Map Index Web Application Script}

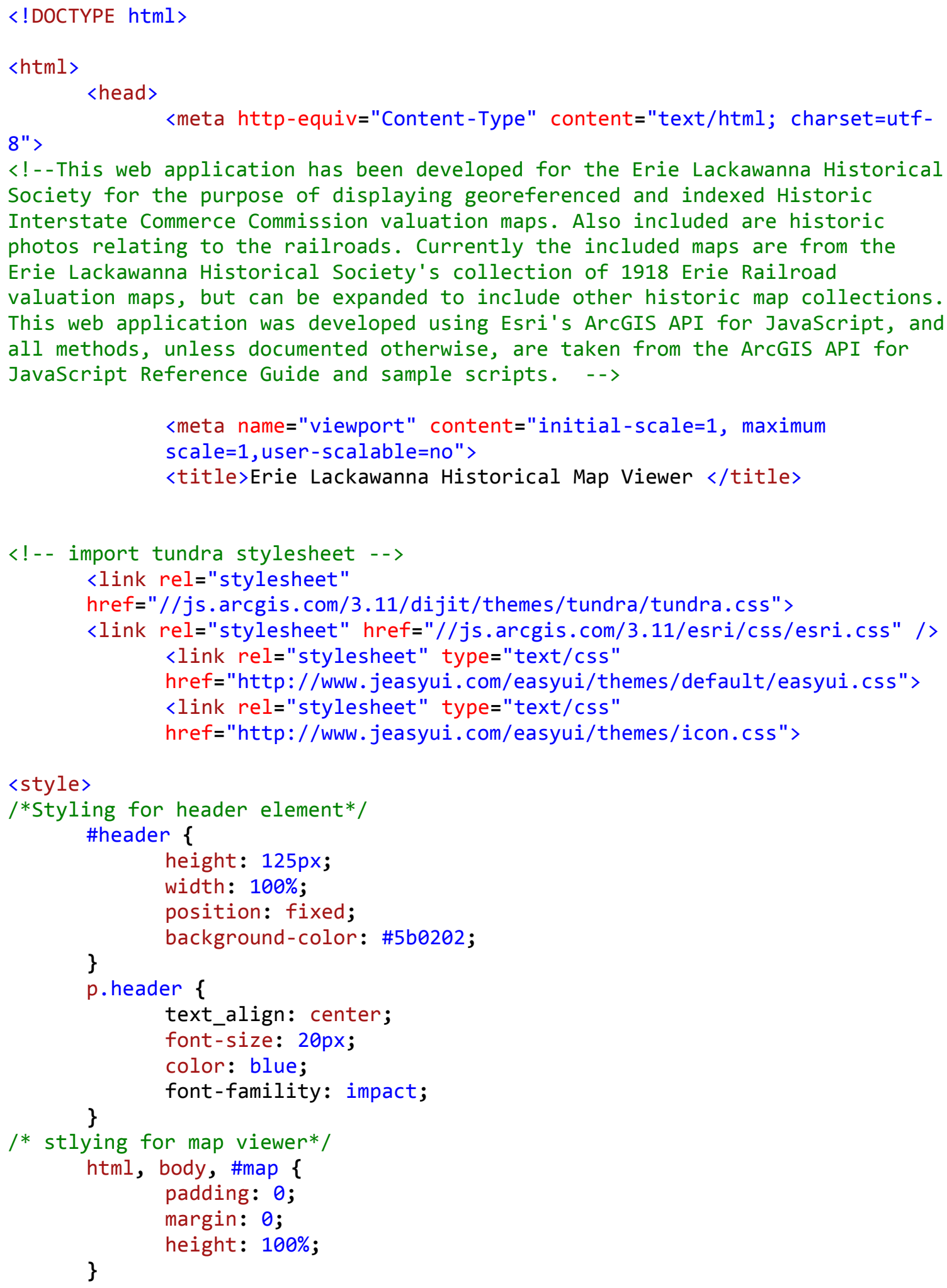




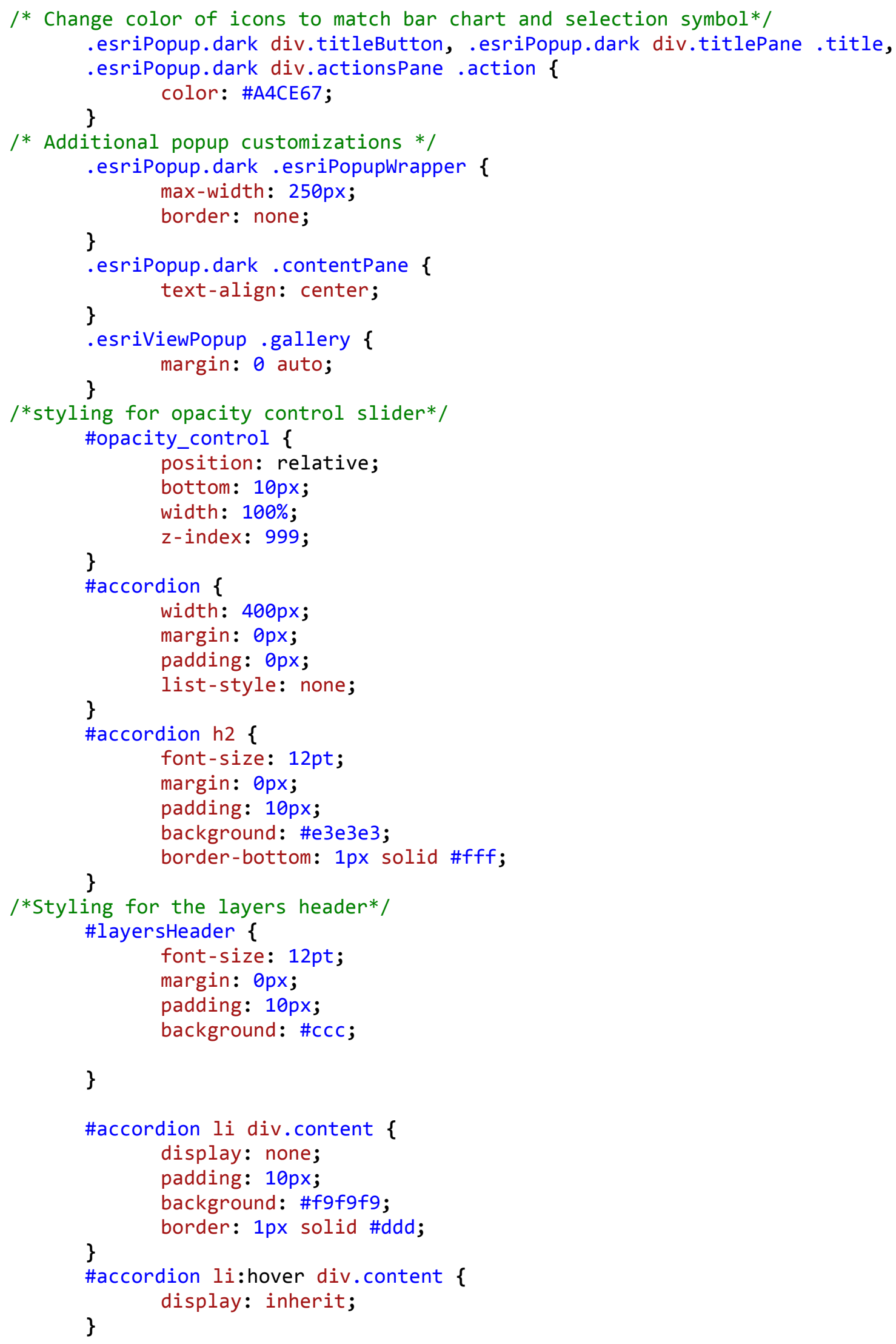




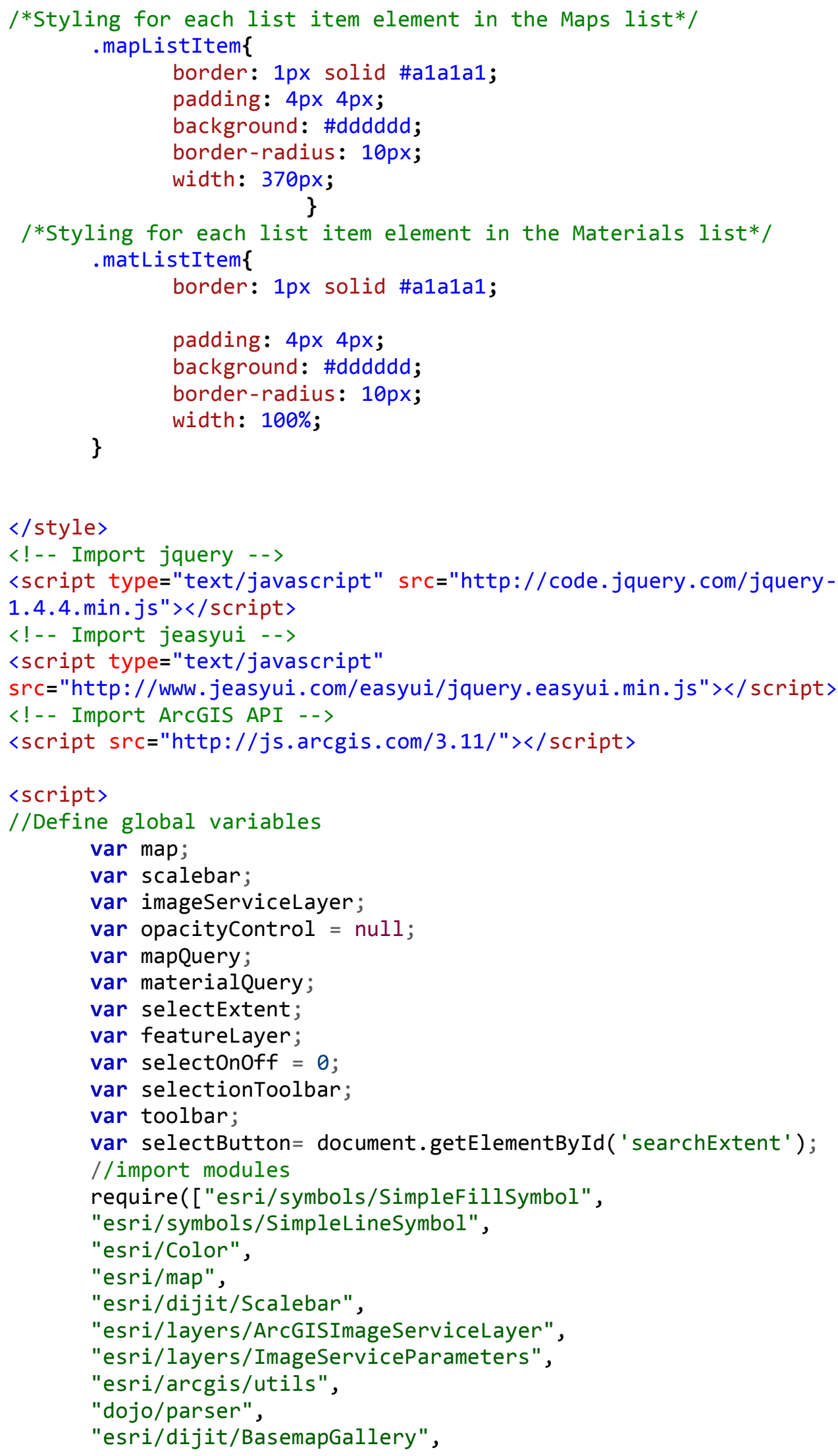




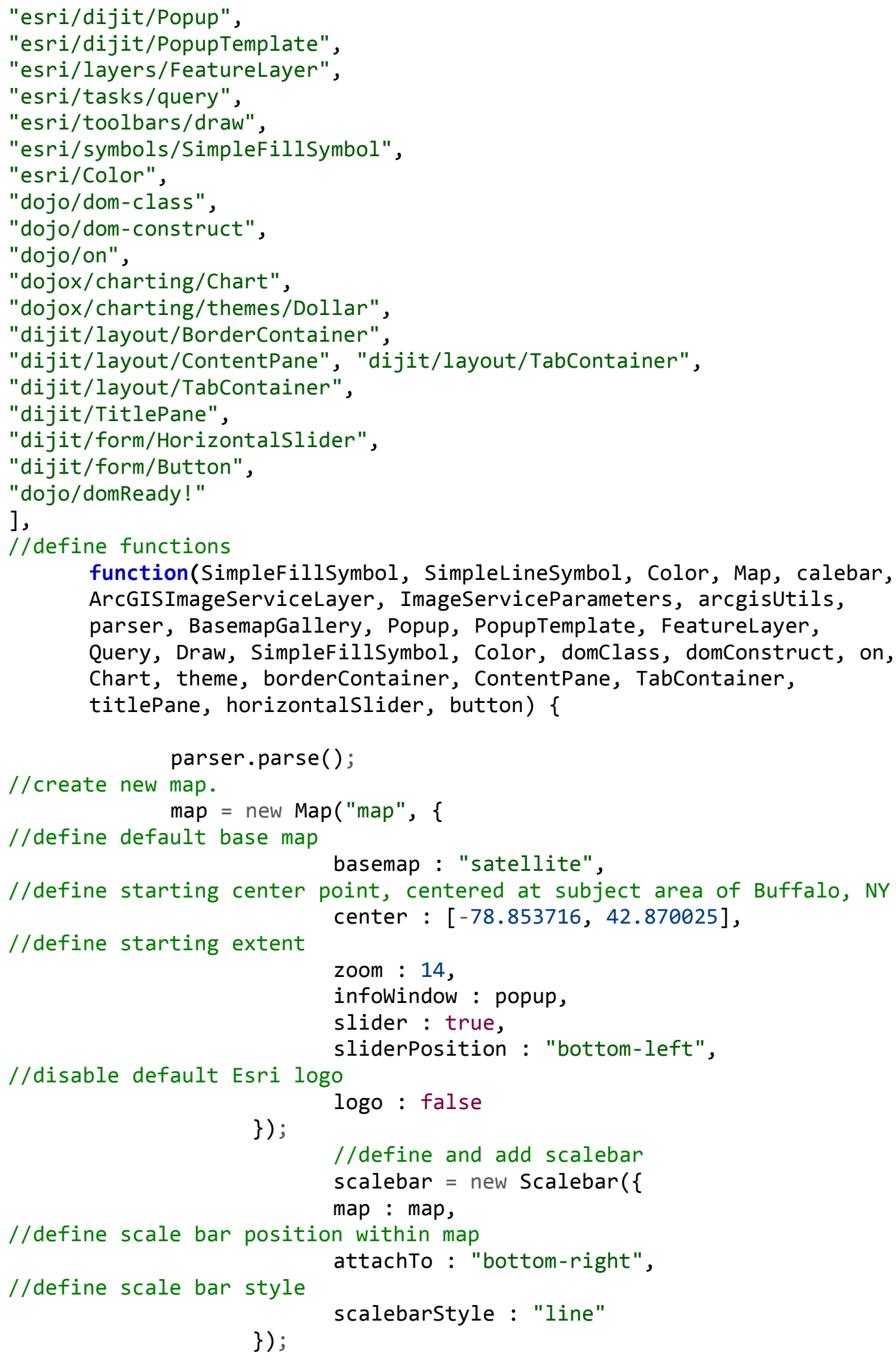




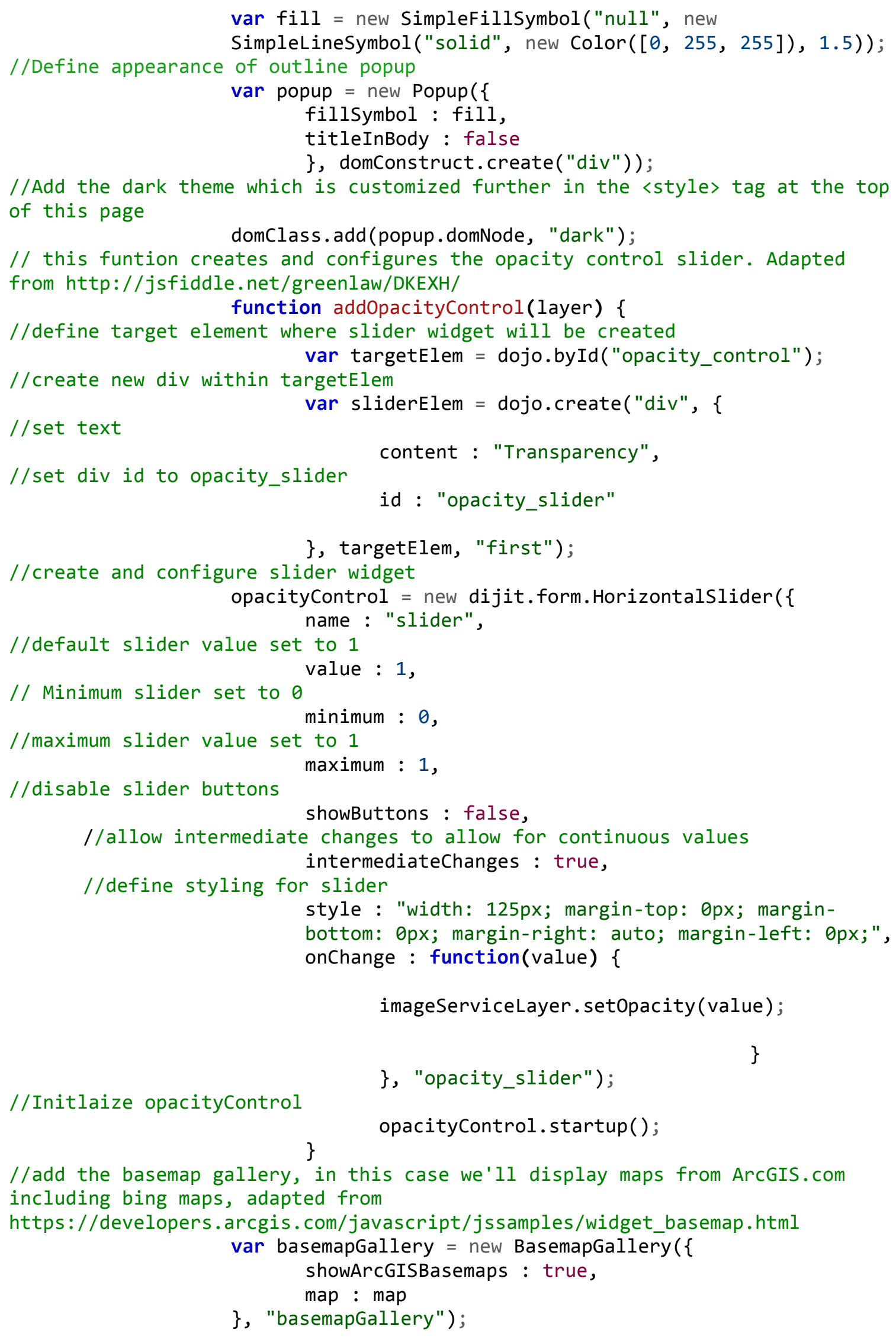




\section{basemapGallery.startup();}

basemapGallery.on("error", function(msg) \{ \});

console.log("basemap gallery error: ", msg);

//define popup template for valuation map info. Adapted from https://developers.arcgis.com/javascript/jshelp/intro_popuptemplate.html

var outlinePopup $=$ new PopupTemplate $(\{$

// Set title for map popup

title : " $\{$ Name $\}$ ",

description : " ",

//Configure text fields for map popup

fieldInfos : $[\{$

fieldName : "RR",

label : "Railroad Co.",

visible : true,

format : \{

places : 0

\}

\},\{

fieldName : "Division",

visible : true,

format : \{

places : 0

\}

\},\{

fieldName : "Branch",

visible : true,

format : \{

\}

places : 0

\},\{

fieldName : "scale",

label : "Scale",

visible : true,

format : \{

places : 0

\},\{

\}

fieldName : "Val_Year",

label : "Valuation Year",

visible : true,

format : \{

places : $\theta$,

\}

digitSeparator : false

\}],

//define images displayed in map popup

mediaInfos : $[\{$

caption : " ",

type : "image",

//URL for map thumbnail jpeg

value : \{ 
//Define the url for the image

"sourceURL" : "\{thumb $\} "$,

"linkURL" : "\{url\}"

\}

\}]

\});

//define popup template for archival materials layer info. adapted from

https://developers.arcgis.com/javascript/jshelp/into_popuptemplate.html var materialPopup $=$ new PopupTemplate $(\{$

//define materials popup title

title : "\{Title\}",

description : "",

//define text fields for materials popup

fieldInfos : [\{

fieldName : "submitter_Name",

visible : true,

format : \{

\}

places : 0

\},\{

fieldName : "material_Date",

visible : true,

format : \{

\}

dateFormat : "shortDate"

\},\{

fieldName : "submission_Date", visible : true,

format : \{

\}

dateFormat : "shortDate"

\}],

//Enable display of attachments

showAttachments : true

\});

//create new feature layer for map outline polygons, and specify REST URL for outlines feature service

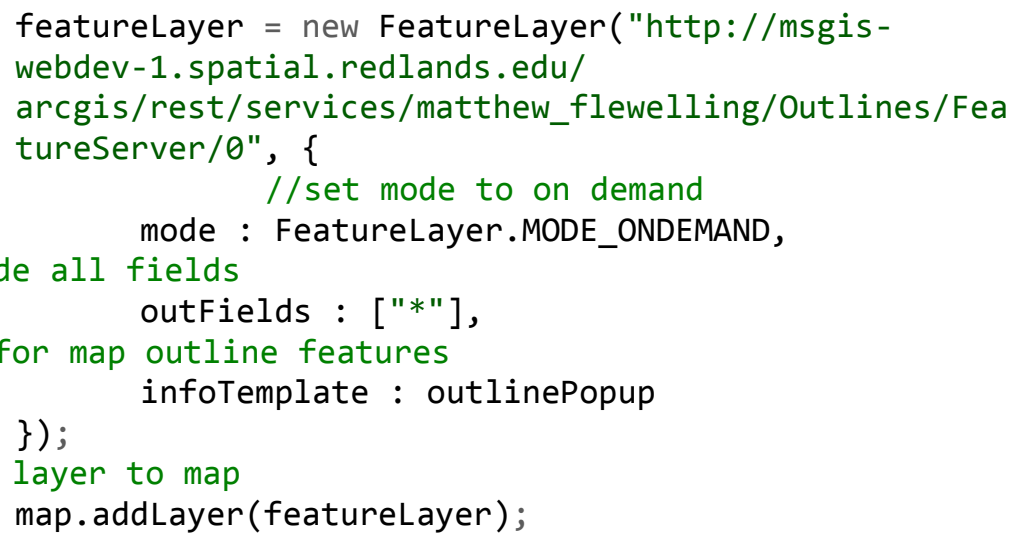


//create new feature layer for archival materials and define REST URL for materials feature service

materialFeatureLayer = new

FeatureLayer("http://msgis-webdev-

1. spatial.redlands.edu/arcgis/rest/services/matthew flewelling/ArchivalMaterialsFeatures/FeatureServer $/ \overline{0}$

//set more to on demand $",\{$

//set out fields to include all fields

mode : FeatureLayer.MODE_ONDEMAND, outFields : ["*"],

//specify popup template for materials features

//enable attachments

infoTemplate : materialPopup,

\});

hasAttachments : true

//add materials feature layer to map

map.addLayer (materialFeatureLayer);

//create new image service layer and specify REST URL for valuation maps image service

imageServiceLayer $=$ new

ArcGISImageServiceLayer("http://msgis-webdev-

1. spatial.redlands . edu/arcgis/rest/services/matthew flewelling/matthew_flewelling_MATTHEW_FLEWELLING_Va $\bar{l}$ Map/ImageServer");

//add valuation maps image service layer to map

map.addLayer (imageServiceLayer);

//call addOpacityControl to create new opacity slider for valuation maps image service layer

$$
\text { addOpacityControl(imageServiceLayer); }
$$

//this function sets the visibility of each of the layers, and is called by the event listeners assigned to the erieCheck and matCheck checkbox input fields. The current state of each check box's checked attribute field

(Boolean), is passed to the corresponding layers visibility attribute field. function setVisible() \{

//capture the current value of eriecheck.checked var erievisible = document.getElementById('erieCheck'). checked;

//capture the current value of matCheck.checked input element var matVisible $=$ document.getElementById('matCheck'). checked;

//assign the value from eriecheck.checked to the visibility attribute of both the map outlines feature layer and the valuation maps image service layer

$$
\text { featureLayer. setVisibility(erieVisible); }
$$

imageServiceLayer. setVisibility(erieVisible);

//assign the value from matCheck. checked to the visbility attribute of the materials feature layer

materialFeatureLayer . setVisibility (matVisible ); 
//this function creates a new Draw toolbar which enables the user to draw an extent polygon, which is then used to query the map outlines feature layer for all polygon features that intersect the extent polygon. In addition to using

the ArcGIS API reference, this function was also influenced by discussion with Nate Strout of the Center for Spatial Studies

function inExtent() \{

//create new draw toolbar

//activate drawing of type "Extent"

toolbar = new esri.toolbars.Draw (map);

toolbar.activate(Draw["EXTENT"]);

//upon draw-end pass extent geometry to anonyms function to perform query toolbar.on("draw-end", function(geom) \{

//deactivate drawing

$$
\text { toolbar.deactivate(); }
$$

//create a new Query object

var extentQuery = new Query ();

//set geometry of Query object to that of the extent polygon

extentQuery.geometry = geom.geometry;

//query all fields in the outline polygons

//set returnGeometry to false

extentQuery.outFields $=[" * "]$;

extentQuery. returnGeometry = false;

//create new queryTask to be performed on the map outlines feature service

var queryMaps = new

esri.tasks.QueryTask("http://msgis-webdev-

1.spatial.redlands.edu/arcgis/rest/services/matthew_ flewelling/Outlines/FeatureServer/0");

//execute queryMaps, passing in extentQuery, and then pass the resulting

featureset to the getMats callback function

queryMaps.execute(extentQuery, getImages);

//create new queryTask to be performed on the materials feature service

var queryMats $=$ new

esri.tasks.QueryTask("http://msgis-webdev-

1.spatial.redlands.edu/arcgis/rest/services/matthew_

flewelling/ArchivalMaterialsFeatures/FeatureServer $/ \bar{\theta}$ ");

//execute queryMats, passing in extentQuery, and then pass the resulting

featureset to the getMats callback function

queryMats. execute(extentQuery, getMats);

\}

$$
\text { \}); }
$$

//using the results of the queryMaps queryTask, this function loops though each of the features, creates a new list item element and builds an HTML string to display the image and attributes for that feature and appends the list item to the Maps list. This function was custom developed, making use of the ArcGIS API reference, and with help from Nate strout of the Center for Spatial Studies 
function getImages(featureset) \{

//define target HTML container

var mapList $=$ document.getElementById('maplist' $)$;

//clear any previous results

mapList.innerHTML = " ";

//loop thorough each feature in the featureset

//create new div element

for (var $i=0$; $i$ featureSet.features.length; $i++)\{$

var newMapListitem $=$ document. createElement ('div' $)$;

//capture all attributes of the current feature

var $a$ = featureset.features[i].attributes;

//set id of new div element to the value of the Name attribute of the current element

newMapListItem.id = a. Name;

// set class of new div element to 'mapListItem'

newMapListItem.className = "mapListItem";

// this sets the inner html of the new div element to a string that is

comprised of standardized snippets as text strings concatenated with variables

for each of the different attributes of the current feature. a. Name= name of

the current feature, a.url= the url for the full resolution jpeg for the

corresponding map, $a \cdot R R=$ railroad name, etc .

newMapListItem.innerHTML $=$ '〈ins $\rangle$ ' + a.Name +

' $\langle/$ ins $\rangle\langle$ table $\rangle\langle t r\rangle\langle$ td $\rangle\langle$ a target $=$ "_blank" href=' +

a.url + '><img style= "margin: 4px $4 \mathrm{px}$ "src=' +

a.thumb + ' width="150px" $/\rangle\langle/ a\rangle\langle/$ td $\rangle\langle t d\rangle\langle b\rangle$ Railroad:

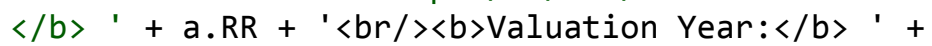

a.Val_Year + '<br/ $\rangle\langle$ b $\rangle$ Scale: $\langle/ b\rangle$ ' + a.scale +

' $\langle/$ td $\rangle\langle/$ tr $\rangle\langle/$ table $\rangle$;

//append newly populated div element to the mapList container.

\}

mapList.appendChild(newMapListItem);

\}

//using the results of the queryMats queryTask, this function loops though each of the features, creates a new list item element and builds an HTML string to display the image and attributes for that feature and appends the list item to the Materials list. This function was custom developed, making use of the ArcGIS API reference, and with help from Nate Strout of the Center for Spatial Studies and Dr. Ruijin Ma of the University of Redlands

function getMats (featureset) \{

\author{
var features $=$ featureset.features; \\ //define target HTML container \\ var matList $=$ document.getElementById('matlist'); \\ //clear any previous results \\ matList.innerHTML = ""; \\ //define feature and matName variables \\ var feature, matName; \\ //define objectId variable \\ var objectId; \\ // create empty array to store attributes for feature \\ var objTitle = []; \\ //loop through features in featureset \\ for (var $i=0 ; i<$ features.length; $i++)\{$
}




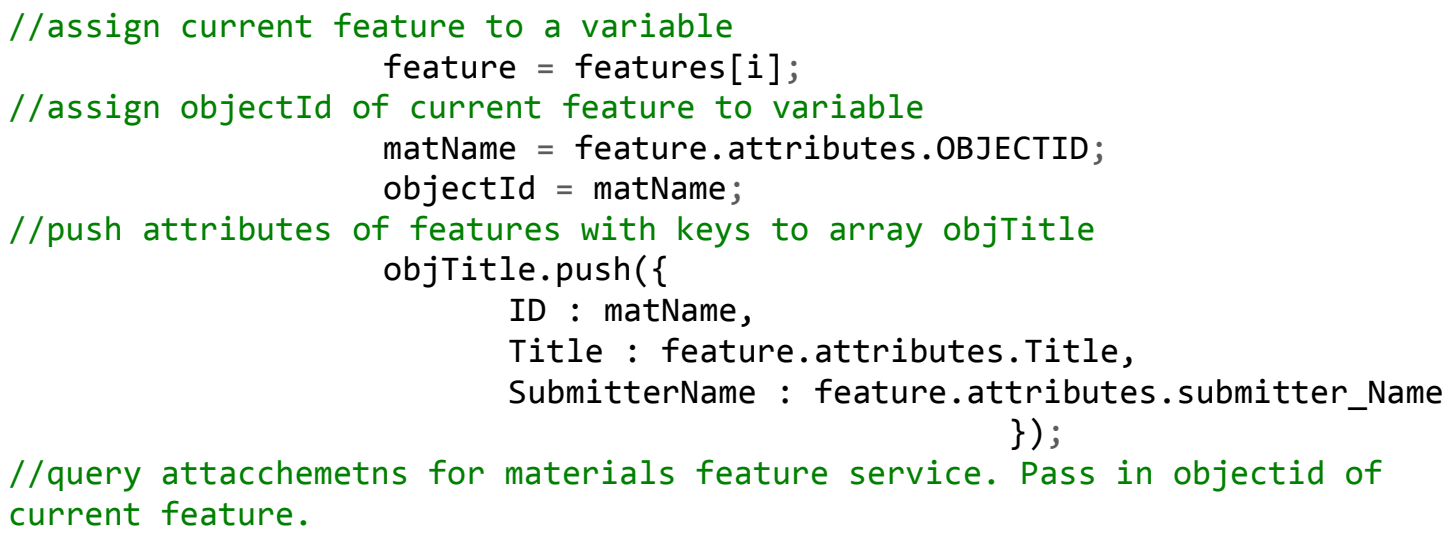

// this sets the inner html of the new div element to a string that is comprised of standardized snippets as text strings concatenated with variables for each of the different attributes of the current feature. newMatListItem.innerHTML = objTitle[j].Title + '〈table $\rangle\langle t r\rangle\langle t d\rangle$ ' + '<a target="_blank" href=' + infosm[0].ur $\bar{l}+$ '> $\langle$ img src=' + infosM[0].url + ' width="150" $\rangle\langle/ a\rangle '+$ ' $\langle/$ td $\rangle\langle t d\rangle\langle b\rangle$ Submitted By</b $\rangle$ : ' + ojTitle[j].SubmitterName + ' $\langle/$ td $\rangle\langle/$ tr $\rangle\langle/$ table $\rangle$;

//append new list item to the Materials list. 


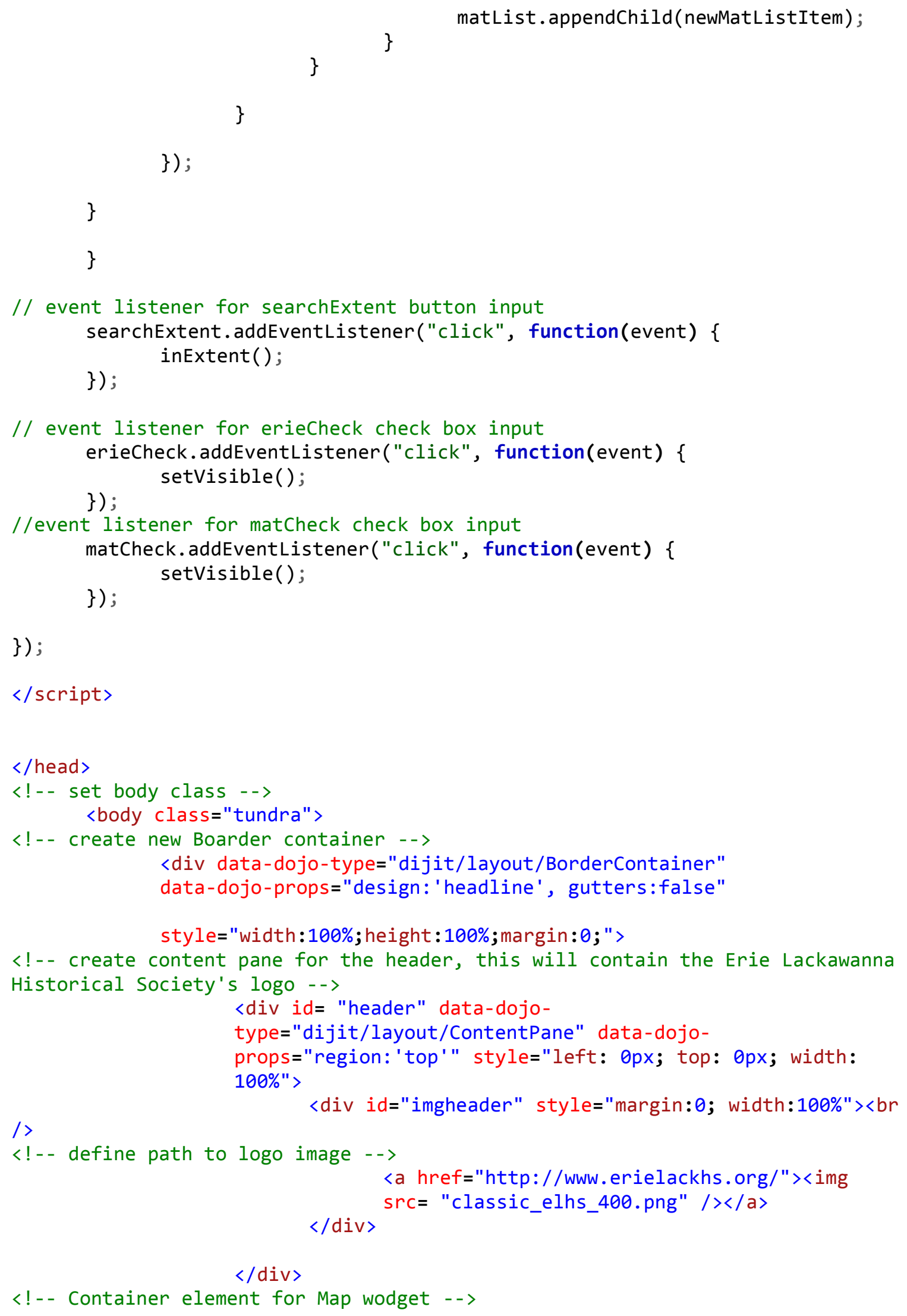




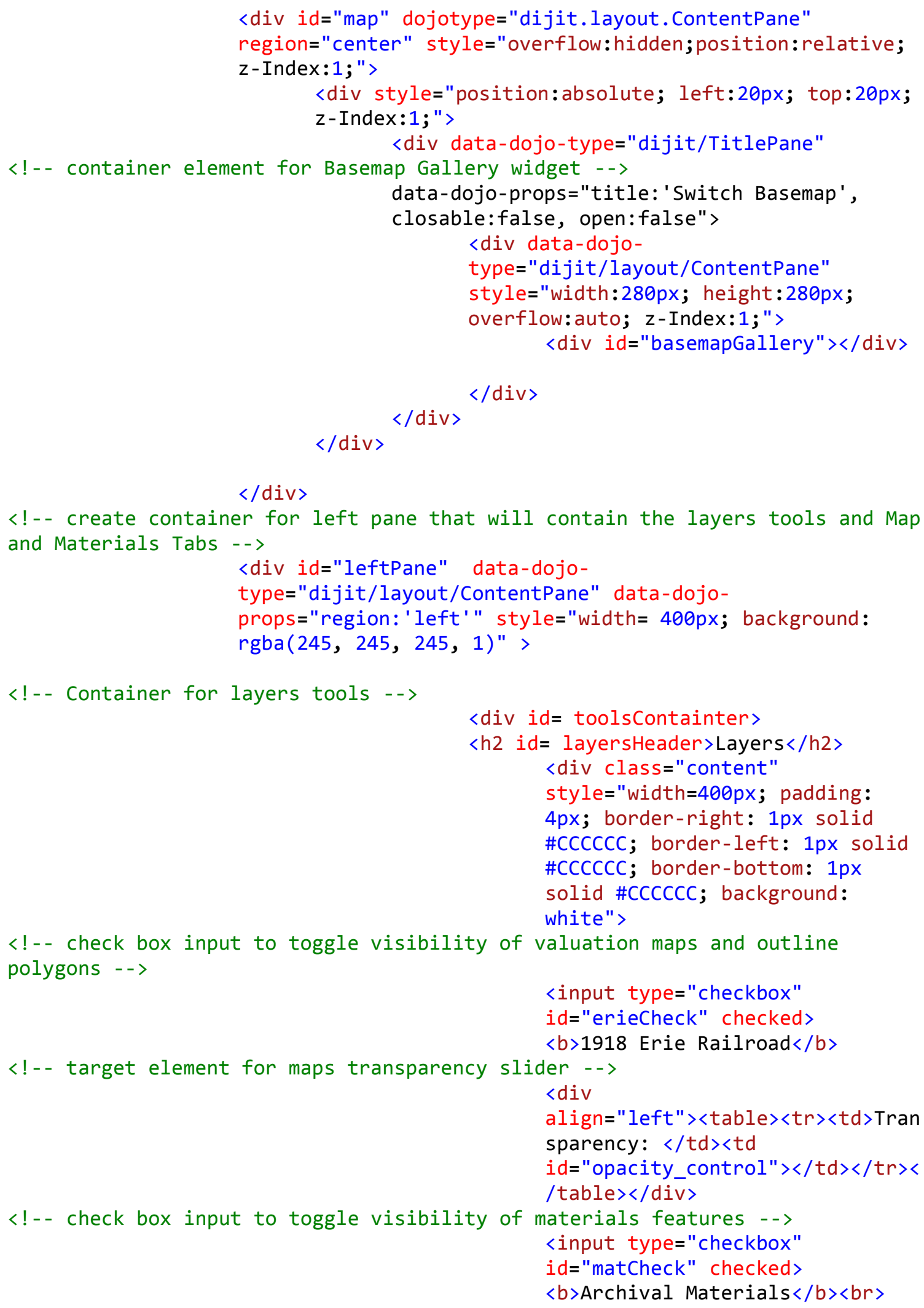


$\langle/$ div $\rangle$
$\langle/$ div $\rangle$

<div style="width: 400px; height: auto; margin-top: 10px">

<div style="width: 100\%; height:

$100 \% "\rangle$

$<$ !-- Create tab container -->

<!-- Create contentpane for Maps list tab -->

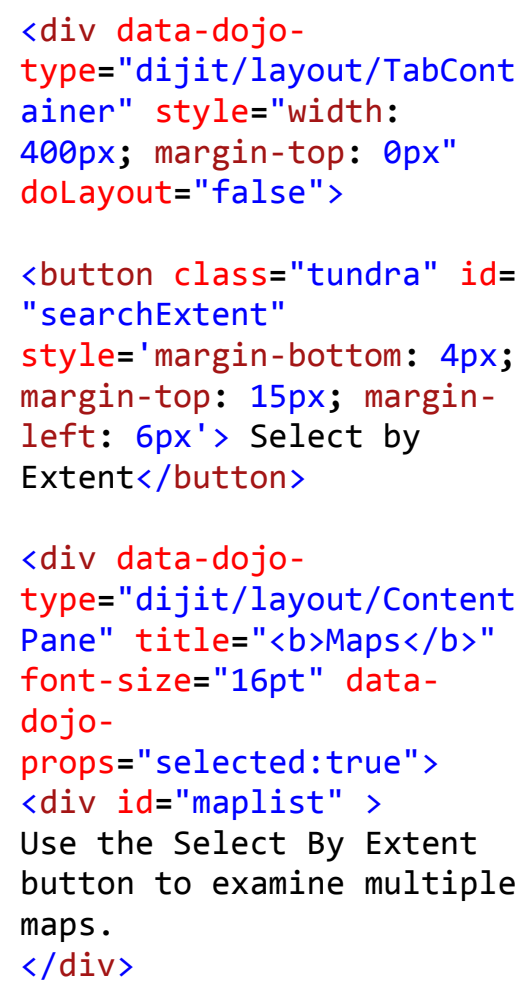


